$$
\begin{gathered}
\text { Universidade de São Paulo } \\
\text { Faculdade de Medicina de Ribeirão Preto - SP } \\
\text { Programa de Pós-Graduação em Gestão das } \\
\text { Organizações de Saúde }
\end{gathered}
$$
UNIVERSITÁRIO

Ribeirão Preto - SP 


\author{
Universidade de São Paulo \\ Faculdade de Medicina de Ribeirão Preto - SP \\ Programa de Pós-Graduação em Gestão das \\ Organizações de Saúde
}

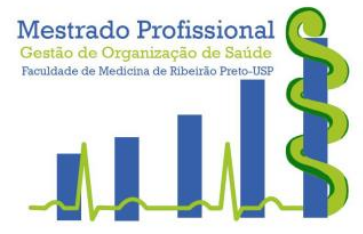

Frederica Montanari Lourençato

\title{
IMPLANTAÇÃO DE SERVIÇO DE CUIDADOS PALIATIVOS NO SERVIÇO HOSPITALAR DE EMERGÊNCIA DE UM HOSPITAL PÚBLICO UNIVERSITÁRIO
}

\begin{abstract}
Dissertação apresentada ao Programa de Pós-Graduação em Mestrado Profissionalizante em Gestão de Organizações de Saúde, da Faculdade de Medicina de Ribeirão Preto da Universidade de São Paulo, como um requisito para obtenção do título de Mestre em Gestão das Organizações de Saúde: Ciências.
\end{abstract}

Orientador (a): Prof. Dr. Antônio Pazin Filho

Ribeirão Preto - SP

2020 
AUTORIZO A REPRODUÇÃO E DIVULGAÇÃO TOTAL OU PARCIAL DESTE TRABALHO, POR QUALQUER MEIO CONVENCIONAL OU ELETRÔNICO, PARA FINS DE ESTUDO E PESQUISA DESDE QUE CITADA A FONTE.

\section{FICHA CATALOGRÁFICA}

Preparada pela Biblioteca Central do Campus Administrativo de Ribeirão Preto / USP

Lourençato, Frederica Montanari

IMPLANTAÇÃO DE SERVIÇO DE CUIDADOS PALIATIVOS NO SERVIÇO HOSPITALAR DE EMERGÊNCIA DE UM HOSPITAL PÚBLICO UNIVERSITÁRIO. Ribeirão Preto - SP, 2020.

115p.: il.; $30 \mathrm{~cm}$

Dissertação de Mestrado, apresentada à Faculdade de Medicina de Ribeirão Preto/USP. Área de concentração: Gestão.

Orientador: Pazin-Filho, Antônio.

1. Serviço Hospitalar de Emergência; 2. Sistema Único de Saúde;

3. Cuidados Paliativos4. Hospitais para doentes terminais 


\section{FOLHA DE APROVAÇÃO}

\section{Frederica Montanari Lourençato}

\section{IMPLANTAÇÃO DE SERVIÇO DE CUIDADOS PALIATIVOS NO SERVIÇO HOSPITALAR DE EMERGÊNCIADE UM HOSPITAL PÚBLICO UNIVERSITÁRIO}

Dissertação apresentado ao Programa de Pós-Graduação em Mestrado Profissionalizante em Gestão de Organizações de Saúde, da Faculdade de Medicina de Ribeirão Preto da Universidade de São Paulo, como requisito para obtenção do título de Mestre em Gestão das Organizações de Saúde.

Aprovado em:

Prof. Dr.

Instituição:

Assinatura:

Prof. Dr.

Instituição:

Assinatura:

Prof. Dr.

Instituição:

Assinatura:

Prof. Dr.

Instituição:

Assinatura: 
Saber Viver

Não sei se a vida é curta
ou longa para nós,
mas sei que nada do que
vivemos tem sentido,
se não tocarmos
o coração das pessoas.

Muitas vezes basta ser:

colo que acolhe,

braço que envolve,

palavra que conforta,

silêncio que respeita,

alegria que contagia,

lágrima que corre,

olhar que acaricia,

desejo que sacia,

amor que promove.

E isso não é coisa

de outro mundo,

é o que dá sentido à vida.

É o que faz com que ela

não seja nem curta,

nem longa demais,

mas que seja intensa,

verdadeira,

pura enquanto durar.

Feliz aquele que

transfere o que sabe

e aprende o que ensina.

(Cora Coralina) 


\section{DEDICATÓRIA}

"Dedico os frutos deste trabalho primeiramente a Deus, por ser TUDO em minha vida, meu porto seguro e me direcionar sempre para que o bem prevalecesse em todo o meu trabalho e minha missão."

"Dedico todo meu esforço empenhado, ao meu pai e minha mãe, que mesmo longe no espaço físico me acompanharam e me deram a força e direção necessária para que tudo isto fosse possivel"

"Dedico este trabalho a minha família, em especial meu marido e meu filho (extensivo a minha avó, meu irmão, cunhados, afilhados e sobrinhos), aqueles que comigo dividem a vida e meus ideais"

"Dedico este trabalho especialmente a todos os pacientes que de alguma forma ao dividirem um espaço nessa vida comigo, me ensinaram a ser melhor a cada dia e a rever todos os meus conceitos e valores de vida nesta jornada de aprendizado.

"Dedico enfim à Equipe de Internconsulta de Cuidados Paliativos da Unidade de Emergência do HCFMRP/USP pelo trabalho realizado! E ao Dr. André Filipe Junqueira dos Santos pela parceria e aprendizado. Sem equipe não se faz cuidados paliativos, então o mérito é nosso! E apoio nos momentos difíceis e pelo aprendizado conjunto que tivemos e construímos. " 


\section{AGRADECIMENTOS}

"Ao Prof. Antônio Pazin Filho, pelo direcionamento e tutoria em minha vida, por ter acreditado em mim, quando nem mesmo eu achava que fosse capaz. Por ter me oferecido a oportunidade de transformar a minha prática de trabalho em algo que pudesse transpor os muros do necessário para o ideal”.

“' A Coordenadoria da Unidade de Emergência na pessoa do Dr. José Paulo Pintyá, pelo apoio, aprendizado e por ter acreditado no trabalho de um grupo de profissionais que vislumbraram um horizonte diferente para seus pacientes. Que nos auxiliou desde o início e direcionou nosso trabalho para que pudéssemos obter o melhor de nós com humanização e técnicas necessárias." 


\section{ABREVIATURAS}
AVC
CAP
CP
CS
CTI
DCNT
DM
DRS XIII
ECOG
ECP
FMRP-USP
HAS
HCFMRP/USP
IBGE
INCA
NIR
OMS
ONU
PNH
PNHOSP
RAS
RRAS
RUE
SADT
SAMU
SHE
SIDA
SPCIT-BR
SRUE
SUS
U.E.-HCFMRP/USP
UCO
UPA
USP
Acidente Vascular Cerebral
Caixa de Aposentadorias e Pensões
Cuidados Paliativos
Cuidado à Saúde
Centro de Terapia Intensiva
Doenças Crônicas Não Transmissíveis
Diabetes Mellitus
Departamento Regional de Saúde de Ribeirão Preto
Performance Status do Eastern Cooperative Oncology Group
Equipe de Cuidados Paliativos
Faculdade de Medicina de Ribeirão Preto-USP
Hipertensão Arterial Sistêmica
Hospital das Clínicas da Faculdade de Medicina de Ribeirão Preto- USP Instituto Brasileiro de Geografia e Estatística
Instituto Nacional de Câncer José Alencar Gomes da Silva
Núcleo Interno de Regulação
Organização Mundial da Saúde
Organização das Nações Unidas
Política Nacional de Humanização
Política Nacional de Atenção Hospitalar
Rede de Atenção à Saúde
Redes Regionais de Atenção à Saúde
Rede de Urgência e Emergência
Serviço de Auxílio ao Diagnóstico e Terapêutica
Serviço de Atendimento Móvel de Urgências
Serviço Hospitalar de Emergência
Síndrome da ImunoDeficiência Adquirida
Supportive and Palliative Care Indicators Tool - (Brazilian version)
Sistema de Regulação de Urgência e Emergência
Sistema Único de Saúde
Unidade de Emergência do HCFMRP - USP
Unidade Coronariana
Unidades de Pronto-Atendimento
Universidade de São Paulo 
ABSTRACT

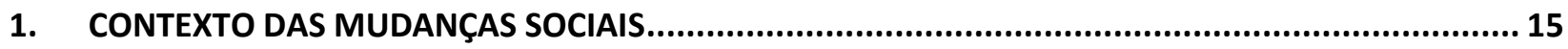

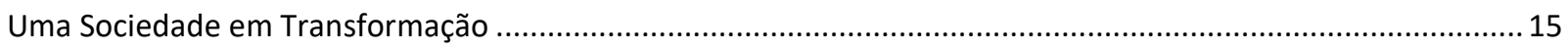

O Envelhecimento como Fenômeno Social e o Agravamento nas Questões de Saúde .........................................15

Aumento das doenças crônico-degenerativas e seu impacto nos Cuidados à Saúde............................................17

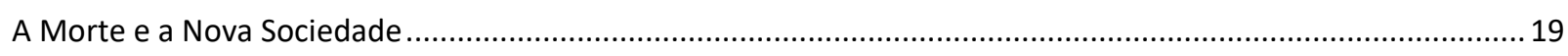

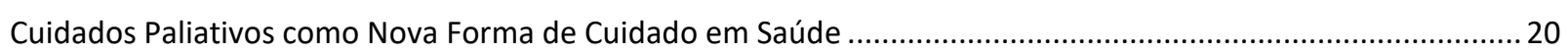

2. IMPACTO DAS MUDANÇAS SOCIAIS NOS SERVIÇOS HOSPITALARES DE EMERGÊNCIA................. 24

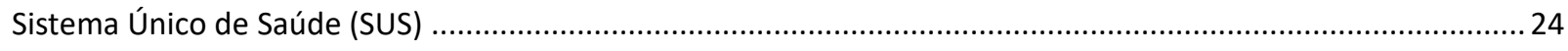

Características e Conceitos relativos aos Serviços Hospitalares de Emergência (SHE) ......................................25

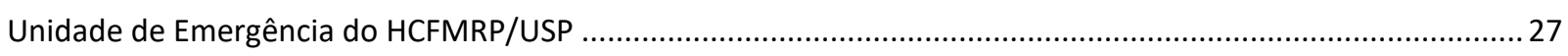

3. SOLUÇÕES PROPOSTAS PARA CONTORNAR A AGLOMERAÇÃO EM SHE ................................. 28

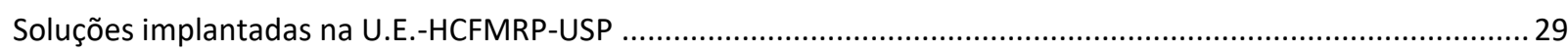

4. CUIDADOS PALIATIVOS NO SERVIÇO HOSPITALAR DE EMERGÊNCIA (SHE) ............................... 33

Processo de Formação da Equipe de Cuidados Paliativos (ECP) na U.E. - HCFMRP/USP ...................................36

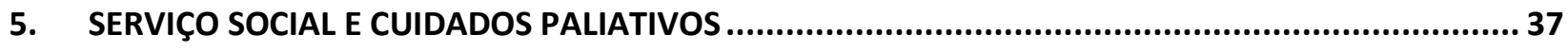

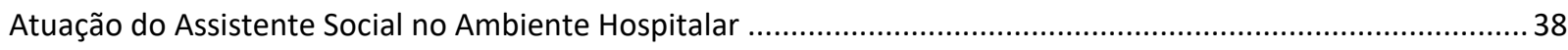



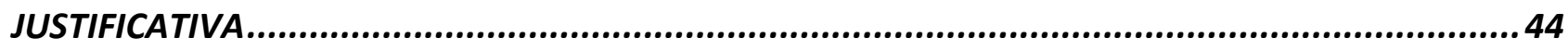

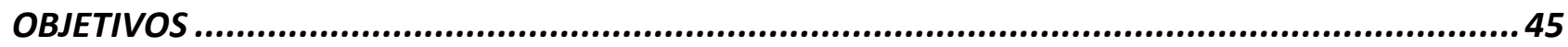

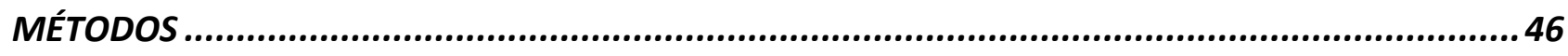

1. Implantação da Equipe de Cuidados Paliativos da U.E.-HCFMRP-USP....................................... 46

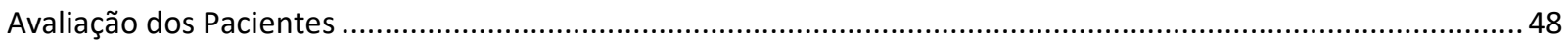

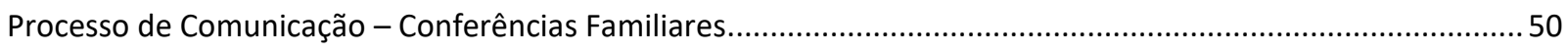

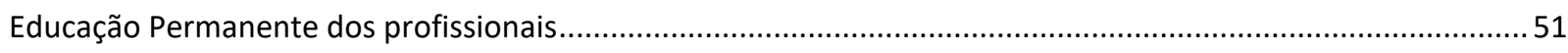

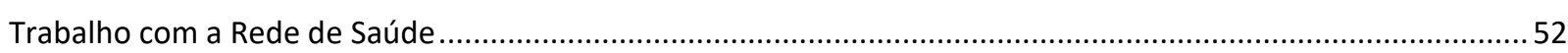

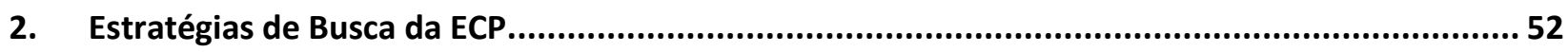

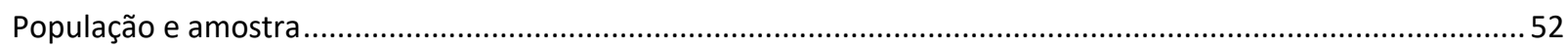


3. Coleta e Análise dos dados ................................................................................... 53

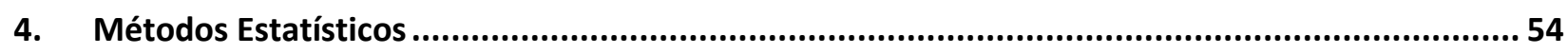

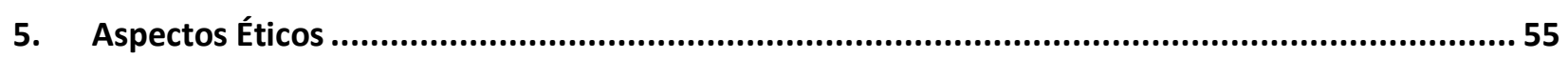

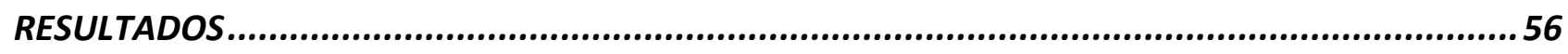

1. Implantação do serviço de cuidados paliativos na U.E.-HCFMRP/USP ...................................56

Cuidados Paliativos - Rede de Urgência e Emergência da DRS XIII ................................................................58

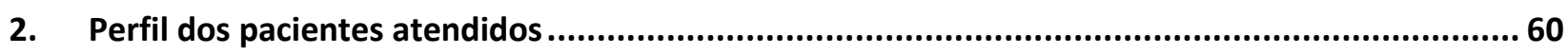

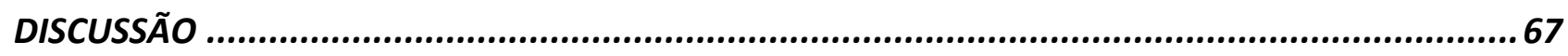

A implantação do Serviço de Cuidados Paliativos na U.E.-HCFMRP/USP ............................................................68

Perfil dos Pacientes Atendidos pela ECP de acordo com a Estratégia de Identificação dos Pacientes...................72

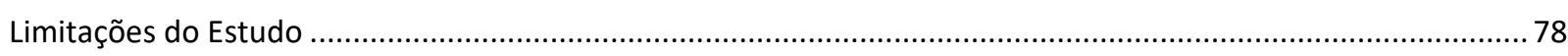

CONCLUSÃO

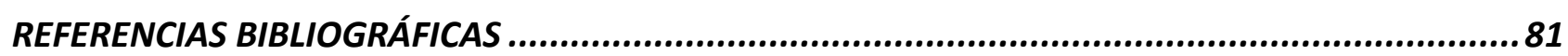



1. APÊNDICE 1 - LEVANTAMENTO DE PACIENTES POTENCIALMENTE PARA CUIDADOS PALIATIVOS 88

2. APÊNDICE 2 - PLANO DE CUIDADOS - UNIDADE DE EMERGÊNCIA (C. PALIATIVOS). ..................89

3. APÊNDICE 3 - PROPOSTA DE CAPACITAÇÃO PARA PROFISSIONAIS DA REDE DE URGÊNCIA E

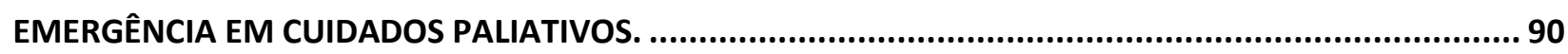

4. APÊNDICE 4 - PROTOCOLO DE SEDAÇÃO PALIATIVA. ........................................................ 103

5. APÊNDICE 5 - PROTOCOLO DE INFUSÃO DE MEDICAÇÕES E SOLUÇÕES POR HIPODERMÓCLISE.106

6. APÊNDICE 6 - FOLDER DE ORIENTAÇÃO - EQUIPE DE CUIDADOS PALIATIVOS......................... 109

7. APÊNDICE 7 - OFÍCIO CIRCULAR 02/2014 - IMPLANTAÇÃO DE INTERCONSULTA DA EQUIPE DE

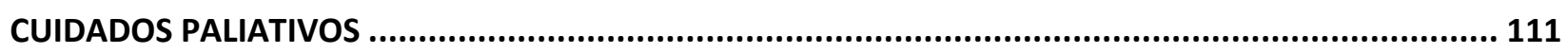

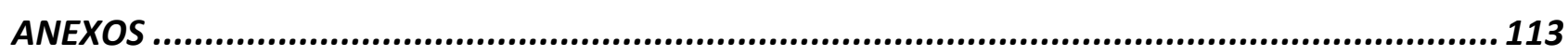

1. ANEXO 1 - APROVAÇÃO NO COMITÊ DE ÉTICA............................................................ 113 


\section{ÍNDICE DE TABELAS}

Tabela 1 - Histórico da Implantação do Serviço de Interconsulta da Equipe de Cuidados Paliativos da U.E. - HCFMRP-USP

Tabela 2 - Projetos da Capacitação da Rede de Urgência e Emergência em Cuidados Paliativos da Divisão Regional de Saúde - DRS XIII

Tabela 3 - Caracterização demográfica e clínica dos pacientes atendidos pela Equipe de Cuidados Paliativos da U.E.-HCFMRP/USP de acordo com a Estratégia de Identificação dos pacientes. ...... 60 Tabela 4 - Caracterização dos desfechos dos pacientes atendidos pela Equipe de Cuidados Paliativos da U.E.-HCFMRP/USP de acordo com a Estratégia de Identificação dos pacientes. 61

Tabela 5 - Caracterização dos indicadores da Equipe de Cuidados Paliativos da U.E.-HCFMRP/USP de acordo com a Estratégia de Identificação dos pacientes. 62

Tabela 6 - Associação entre a Demanda e o Desfecho 66 


\section{ÍNDICE DE FIGURAS}

Figura 1-Fluxograma da atuação da Equipe de Cuidados Paliativos da U.E.-HCFMRP-USP

Figura 2 - Fases do Cuidado Paliativo de acordo com o foco do cuidado - adaptado de Azevedo D, Tommaso ABG, Burlá C, Santos G, Dias LM, Py L, et al. Vamos falar de Cuidados Paliativos. SBGG; 2015. 24 p.3 48

Figura 3 - Fluxograma com foco no Controle de Sintomas da ECP - U.E.-HCFMRP-USP 49

Figura 4 - Fluxograma para Prognóstico e Terminalidade da ECP - U.E.-HCFMRP-USP. 50

Figura 5 - Box Plot dos Indicadores da ECP da U.E.-HCFMRP-USP de acordo com a Estratégia de Identificação dos pacientes.

Figura 6 - Curva de Sobrevida de Kaplan Meyer para os pacientes avaliados pela ECP da U.E.HCRMFP-USP de acordo com Estratégia de Identificação dos pacientes. A - Mortalidade intrahospitalar; B - Mortalidade após alta hospitalar. 64

Figura 7 - Hazzard Ratios e intervalo de confiança 95\% para os fatores de confusão incluídos na versão final do modelo de regressão de Cox para ajustar o impacto da Estratégia de Identificação dos pacientes. 


\section{RESUMO}

\section{LOURENÇATO, F. M. Implantação de serviço de cuidados paliativos no Serviço Hospitalar de}

Emergênciade um hospital público universitário. 2020. 115 f. Dissertação de Mestrado Faculdade de Medicina de Ribeirão Preto, Universidade de São Paulo, Ribeirão Preto, 2020.

Objetivos: Descrever o processo de implantação do serviço de cuidados paliativos na U.E.HCFMRP/USP e comparar a estratégia de intervenção de busca ativa em enfermarias com a estratégia no Serviços Hospitalar de Emergência (Sala de Urgência) Métodos: O estudo descreveu o desenvolvimento dos processos e do desenho do plano de trabalho da implantação do Serviço de Cuidados Paliativos da U.E.-HCFMRP/USP e a documentação sistematizada de dados demográficos, clínicos, das intervenções da ECP e dos desfechos para dois períodos distintos, a estratégias de busca ativa de pacientes nas enfermarias comuns e especializadas (Estratégia I) ou no Serviço Hospitalar de Emergência (Estratégia II). Resultados: A implantação do serviço de cuidados paliativos foi incorporada na prática institucional e os profissionais capacitados. Ferramentas foram construídas com processos de trabalho específicos e protocolos de atendimentos e foi realizada capacitação com os profissionais da RUE da DRS XIII. O estudo contou com 1203 pacientes, Estratégia I (587; 48,8\%) e Estratégia II $(616 ; 51,2 \%)$. Nas duas Estratégias foram prevalentes pacientes do sexo masculino e idosos. A maioria estava na clínica médica I (39,3\%) e II (57,9\%). As condições clínicas gerais foram mais prevalentes nas duas estratégias com mais de 40\%, após ficando a Oncologia na I $(27,7 \%)$ e II $(32,4 \%)$. Houve redução dos pacientes que estavam no CTI/UCO da I (20,9\%) para II (9,2\%) $\mathrm{p}<0.01$, queda na enfermaria da I $(60,8 \%)$ para a II $(42,5 \%)$ - $\mathrm{p}<0.01$ - e aumento significativo da I $(18,2 \%)$ para a II $(48,2 \%)$ na sala de urgência - $\mathrm{p}<0.01$. A percepção reduziu de 10,9 dias para 9,1 dias, o seguimento se manteve em 12 dias e a duração da internação teve queda de 24,3 para 20,7 dias - p<0.01. A maior demanda foi a definição de prognóstico (56,7\%). Acima de 70\% de todos os pacientes tinham PPS 10 e acima de $85 \%$ ECOG 4. A condição oncológica é a que apresenta maior risco para o óbito e o PPS tem efeito inverso, apresentando menor impacto (Razão de Chances; IC95\%). Conclusão: O serviço de cuidados paliativos no SHE foi estruturado pela ECP e incorporado à prática e cultura institucional e a Estratégia II foi a mais efetiva pois diminuiu a o tempo de reconhecimento dos pacientes no SHE e consequentemente a duração da internação.

Unitermos: Serviço Hospitalar de Emergência; 2. Sistema Único de Saúde; 3. Cuidados Paliativos; 4. Hospitais para doentes terminais. 


\section{ABSTRACT}

\section{LOURENÇATO, F. M. Implementation of a palliative care service in the Emergency Hospital}

Service of a public university hospital. 2020. 1159f. Master's Dissertation - Faculdade de Medicina de Ribeirão Preto, Universidade de São Paulo, Ribeirão Preto, 2020.

Objectives: To describe the process of implementing the palliative care service in the Emergency Unity (UE-HCFMRP / USP) and to compare the intervention strategy of active search in wards with the strategy in the Emergency Hospital Services (Emergency Room). Methods: The study described the development of processes and the design of the work plan for the implementation of the Palliative Care Service in the UE-HCFMRP / USP and the systematized documentation of demographic and clinical data, ECP interventions and outcomes for two different periods, active patient search strategies in common and specialized wards (Strategy I) or in the Emergency Hospital Service (Strategy II). Results: The implementation of the Palliative Care service was incorporated into the institutional practice and the professionals were trained. Tools were built with specific work processes and service protocols and the professionals of RUE of DRS XIII were also trained. The study included 1203 patients, Strategy I (587; 48.8\%) and Strategy II (616; 51.2\%). In both Strategies, male and elderly patients were prevalent. Most were in medical clinic I (39.3\%) and II (57.9\%). General clinical conditions were more prevalent in the two strategies, with more than $40 \%$, after were Oncology remained in I (27.7\%) and II (32.4\%). There was a reduction in patients who were in the ICU / CCU from I $(20.9 \%)$ to II $(9.2 \%)$ - $p<0.01$, reduction in the ward from I $(60.8 \%)$ to II $(42.5 \%)-p<0.01-$ and significant increase from I (18.2\%) to II (48.2\%) in the emergency room - $p<0.01$. The perception decreased from 10.9 days to 9.1 days, the follow-up continued for 12 days and the duration of hospitalization dropped from 24.3 to 20.7 days - $\mathrm{p}<0.01$. The major demand was the definition of prognosis (56.7\%). Over $70 \%$ of all patients had PPS 10 and ECOG 4 above $85 \%$. The oncological condition is the one with the highest risk of death and the PPS has the opposite effect, representing less impact (Chance Ratio; 95\% CI). Conclusion: The Palliative Care service in the SHE was structured by the ECP and incorporated into the institutional practice and culture and Strategy II was the most effective because it reduced the time of recognition of patients in the SHE and consequently the duration of hospitalization.

Keywords: Department Emergency, Palliative, Hospice, Unified Health System 


\section{INTRODUÇÃO}

\section{CONTEXTO DAS MUDANÇAS SOCIAIS}

\section{Uma Sociedade em Transformação}

As transformações sociais ocorridas nas últimas décadas são marcantes, com reflexos importantes no Cuidado à Saúde (CS). Muita investigação e reflexão ainda serão necessárias para compreender em profundidade o que se define como transformações e a influência de cada uma delas, mas algumas já são conhecidas e devem ser destacadas para proposição de novas estratégias, como, por exemplo, a implantação de uma Equipe de Cuidados Paliativos (ECP) no Serviço Hospitalar de Emergência (SHE).

Em primeiro lugar, deve-se destacar as mudanças demográficas e epidemiológicas. O crescimento populacional é inconteste, sendo que nunca a espécie humana atingiu densidade populacional acima de sete bilhões de habitantes. As melhorias das condições sanitárias e de alimentação, bem como as revoluções na Medicina são citadas como fatores associados a este crescimento, pelo entendimento de que ele não é apenas resultante de elevação da taxa de natalidade, mas sim de redução da mortalidade e aumento da expectativa de vida(1).

De acordo com projeções da Organização das Nações Unidas (ONU) a estimativa da população mundial do ano 2000 era cerca de 6 bilhões de habitantes e ficará entre 8,5 e 8,6 bilhões em 2030, entre 9,4 e 10,1 bilhões em 2050, e entre 9,4 e 12,7 bilhões em 2100. Já a população do Brasil que era de 169,8 milhões passará para 220 milhões em 2020 e 272,7 milhões em 2100(2).

A ONU confirma que o aumento do envelhecimento é devido ao aumento da expectativa de vida e até 2050, uma em cada seis pessoas no mundo terá mais de 65 anos e há a previsão de que o número de pessoas com 80 anos ou mais triplicará, de 143 milhões em 2019 para 426 milhões em 2050(2).

Considerando o reflexo do envelhecimento populacional no Brasil, as estimativas do Banco Mundial apontam que nos próximos 40 anos a população idosa brasileira crescerá a uma taxa de 3,2\% ao ano e atingirá 64 milhões de habitantes em 2050, com previsão de que a população de 65 anos ou mais será $13 \%$ maior que a população de até 19 anos(3).

\section{O Envelhecimento como Fenômeno Social e o Agravamento nas Questões de}

\section{Saúde}


O aumento populacional às custas de parcela significativa acima dos 60 anos tem dramáticas implicações para a promoção da Saúde. Esta população tem maior incidência e prevalência de condições crônico-degenerativas que impõem maiores limitações, tornando-se dependentes de cuidadores e postulando novos paradigmas para os profissionais de Saúde.

O envelhecimento é um fenômeno desafiador e complexo que envolve fatores fisiológicos, psicológicos e sociais que tem influências políticas, culturais e ideológicas. Além das características biológicas, os valores culturais e sociais têm repercussão direta neste processo. Em específico no Brasil, fatores como o panorama de pobreza, desigualdade social e instituições não totalmente consolidadas, tornam a questão social de maior relevância, repercutindo no aumento da demanda para as políticas de seguridade social.(4).

O envelhecimento encontra-se, na perspectiva de sociedades capitalistas, diretamente vinculado à vulnerabilidade da classe trabalhadora, considerando que o idoso se torna improdutivo. A partir desta consideração vemos que a velhice promove efeitos diferentes de acordo com a classe social a qual está inserida e na classe trabalhadora, que tem seu valor medido por sua capacidade produtiva, vemos como reflexos deste fenômeno o isolamento, a exclusão das relações sociais, do espaço público, do mundo produtivo e político(5).

Temos como destaque a aposentadoria que muitas vezes acontece como uma descontinuidade, uma ruptura com a vida anterior, que lhe traz certas vantagens, como o descanso, lazer, mas também graves desvantagens como desvalorização e desqualificação(6).

A caracterização dos idosos no Brasil é destacada pela proporção de maior crescimento de pessoas com 75 anos ou mais, a feminização com 55\% da população idosa, a urbanização e heterogeneidade do envelhecimento populacional(7). Considerando estas características é importante ressaltar que a feminização traz um agravamento, pois, apesar de viverem mais, as idosas não apresentam uma boa qualidade de vida, sendo na maioria das vezes viúvas ou solteiras e vivendo sozinhas, com baixo nível de instrução e renda, bem como com maiores queixas de saúde(8).

Considerando a dependência cada vez maior dos idosos de necessidade de cuidados, seja pela fragilidade de sua própria condição ou de adoecimento, um aspecto de fundamental importância a ser discutido é a possibilidade da família atual em assumir estes cuidados. De acordo com os dados do Instituto Brasileiro de Geografia e Estatística (IBGE) em 2013 aproximadamente 1 em cada 4 idosos vivia em família composta por casal sem filhos ou outros familiares e pessoas idosas que viviam com filhos de 25 anos ou mais de idade(9).

Sendo assim, vemos cada vez mais famílias onde somente vivem idosos, impossibilitando o cuidado efetivo destes ou famílias onde os idosos residem com os filhos em idade produtiva, que não tem condições de parar de trabalhar para assumir os cuidados destes, destacando a perda do poder 
aquisitivo da população em geral, mas que se torna mais pronunciado nesta parcela da população que apresenta maior gasto com suas necessidades de saúde.

\section{Aumento das doenças crônico-degenerativas e seu impacto nos Cuidados à Saúde}

As significativas conquistas da Medicina promoveram uma atitude positivista observada no final do século XX com ênfase na cura das doenças. Mesmo que a cura não pudesse ser obtida, avanços marcantes como a introdução do coquetel para pacientes com Síndrome da ImunoDeficiência Adquirida (SIDA) com a impressionante transformação de uma doença praticamente letal em uma doença crônico-degenerativa reforçaram essa atitude(10).

As doenças crônico-degenerativas estão associadas a diversos desafios que ainda não estão completamente equacionados, além do fato de que as soluções existentes não estarem totalmente implantadas. Como exemplo, embora existam medicamentos eficazes para o tratamento de condições como a Hipertensão Arterial Sistêmica (HAS) ou Diabetes mellitus (DM), um dos maiores desafios é a adesão a estes medicamentos. Estratégias consagradas, como dose supervisionada em casos de Tuberculose, ou inovadoras, como a utilização de tecnologias de informação na forma de aplicativos em dispositivos eletrônicos são utilizadas com maior ou menor sucesso(11).

No entanto, esta atitude positivista se mostrou ilusória em alguns aspectos. A inclusão tecnológica e o desenvolvimento de novos medicamentos trouxeram também um elevado custo social em diversas esferas. Houve aumento de eventos adversos relacionados, da futilidade da realização de procedimentos e da dificuldade em se aceitar a morte(12). Como exemplo, o envelhecimento associado com o aumento de doenças crônicas modificou o perfil dos óbitos no país nas últimas décadas - correspondendo a cerca de $70 \%$ de todas as mortes atualmente(13). Segundo estimativa do Instituto Nacional de Câncer José Alencar Gomes da Silva (INCA), o Brasil deve registrar no biênio 2018-2019, a ocorrência de 600 mil novos casos de câncer, para cada ano. Excetuando-se o câncer de pele não melanoma (cerca de 170 mil casos novos), ocorrerão 420 mil casos novos de câncer só neste ano, a estimativa é que surjam 582 mil novos casos - 300 mil em homens e 282 mil em mulheres(14). A incidência do câncer aumenta com o envelhecimento, considerando que $60 \%$ dos casos de câncer e 70\% das mortes relacionadas ao câncer ocorrem em pacientes com 65 anos ou mais(15) e nos Estados Unidos a expectativa para o ano de 2030 é de que $70 \%$ de todas as neoplasias ocorram na população idosa(16).

Esta tendência começou a ser modificada na virada do milênio com a publicação "To Err is Human" que iniciou um doloroso e longo processo de retomada do Cuidar na Saúde(17). O surgimento de movimentos de capacitação profissional, trabalho em equipe multiprofissional, 
Segurança do Paciente e acreditação hospitalar são apenas algumas das diversas transformações decorrentes desse movimento(18). A gênese e ênfase na promoção dos Cuidados Paliativos (CP) foram, sem dúvida, influenciadas por este movimento.

Os avanços e efeitos inesperados associados que foram ilustrados anteriormente também se refletiram na organização dos profissionais de Saúde. Em particular, a Medicina tem enfrentado diversos desafios que estão motivando adaptações. Para se adequar às dificuldades impostas pela enorme inclusão de tecnologia, a atuação do médico exige a criação de especialidades dentro de especialidades. A concentração de tecnologia exige o crescimento das instituições hospitalares, que se tornam cada vez mais complexas e onerosas e só podem ser mantidas em grandes centros, propiciando que o exercício da profissão exclusivamente nestas instituições seja realidade, como a recente figura do Hospitalista(19,20). A organização em especialidades baseadas em sistemas orgânicos, como cardiologia ou urologia, já não se adequa totalmente às necessidades de um Sistema que necessita atuação multiprofissional e que propicia o acesso hierarquizado e em Linhas de Cuidado.

De modo similar esses efeitos também são sentidos por outros profissionais de saúde, tanto tradicionais como a Enfermagem, como no crescente número de profissionais anteriormente raros. Fisioterapeutas, Fonoaudiólogos, Nutricionistas, Farmacêuticos, Assistentes Sociais, Terapeutas Ocupacionais e Psicólogos são mais prevalentes e estão sujeitos a estas mesmas pressões, ao mesmo tempo em que devem consolidar o espaço multiprofissional. Para todos a atuação multiprofissional é um desafio, pois não são preparados para esta modalidade em cursos de graduação e o estabelecimento do que deve ser o papel de cada profissional nestas equipes tem sido buscado por entidades representativas de classe que podem estar reforçando a atuação individualizada. Sem qualquer juízo de valores, discussões como o "Ato Médico" exemplificam este debate.

Finalmente deve-se destacar o quanto estas mudanças demográficas, epidemiológicas e associadas às profissões de saúde estão impactando a estrutura dos Serviços de Saúde, tanto público como complementar, muito embora para fins deste trabalho o interesse esteja voltado para o primeiro.

A implantação do Sistema Único de Saúde (SUS) ainda não está completa e, provavelmente, estará em constante evolução. A estruturação do SUS implica em Redes de Assistência de acordo com níveis de complexidade embasados na epidemiologia, sendo desenhado para que o acesso ocorra por duas "portas de entrada" principais: eletivo e emergência. Esta estruturação às vezes é conflitante com a especialização excessiva dos profissionais de saúde anteriormente comentada. Não sendo possível a permanência de diversos especialistas em regime de plantão nos prontos-socorros, a Medicina de Urgência está em desenvolvimento acelerado no país(21).

O aumento populacional também impacta o SUS de forma significativa. O aumento da demanda para uma oferta desproporcional de capacidade causa longas filas de espera. Mesmo com a 
implantação de novas estratégias de gerenciamento de fluxo, tanto no nível macro (Regulação Médica)(22) quanto no micro (Núcleo Interno de Regulação)(23), a demanda ainda persiste maior que a capacidade e ocorrem desvios, como o direcionamento de casos eletivos para a emergência. $\mathrm{O}$ fenômeno da "urgencialização" é multifatorial e sua discussão em profundidade não é escopo deste trabalho, bastando para seus objetivos documentar sua existência e levantar a possibilidade que ele possa ser combatido ao menos parcialmente pela implantação de uma ECP no SHE.

\section{A Morte e a Nova Sociedade}

Embora tenha sido postergada, a Morte persiste inevitável. Cerca de $1 \%$ da população morre a cada ano. Embora algumas mortes sejam inesperadas, a maioria pode ser prevista. Para fins didáticos e de estruturação dos serviços de saúde a serem prestados, pode-se dividir este processo em diversas dimensões. Para cada uma destas dimensões, o serviço de saúde deverá estar municiado de instrumentos que propiciem o atendimento adequado do paciente e de seus familiares. O CS não termina com a Morte, se estende aos familiares e progride até que haja um destino apropriado para o paciente que faleceu e para as demandas sociais e legais decorrentes.

Na dimensão biológica, a Morte pode ser um processo súbito ou de evolução rápida, decorrente de eventos inesperados, como por exemplo, um trauma automobilístico, ou um processo evolutivo de duração variável, como por exemplo, a evolução de um câncer terminal.

Na situação em que foi súbito ou de evolução rápida, o processo de atendimento inclui suporte na obtenção de atestado de óbito de acordo com as peculiaridades legais de cada caso (morte natural, acidental, intencional, etc) e identificação e suporte social para os familiares envolvidos. O suporte aos familiares pode ser de várias naturezas, incluindo acolhimento dos familiares e fornecimento de informações sobre a situação que levou ao óbito, contato com a rede social do paciente na localização de familiares não-presentes, apoio ao luto, auxílio na decisão de doação de órgãos, apoio aos aspectos legais necessários, dentre outras providencias como atendimento psicológico aos familiares.

Embora estes processos sejam aparentemente simples, na verdade ainda são extremamente complexos na Sociedade atual. A inexistência de suporte adequado nos momentos inesperados e não rotineiros em que o óbito ocorre, muitas vezes leva o transporte de pacientes para o SHE. Nestas situações, embora não tenha atendido o paciente antes do óbito, o SHE presta o auxílio que poderia ser ofertado em outras instâncias se houvesse preparo adequado. Esta demanda ainda carece de dados mais acurados para se estimar sua real dimensão, mas pode ocasionar sobrecarga para o SHE que já enfrenta enormes dificuldades. 
Na situação evolutiva de duração variável, além dos aspectos descritos anteriormente, surgem outras oportunidades de se desenvolver auxílio para mitigar (paliar) o processo de morte, sendo inúmeros os desafios. Nas situações em que Curar já não é possível, o Cuidar precisa ser aprimorado. Situações como mitigação da dor e outras necessidades são manejadas muitas vezes de modo inadequado. Familiares e cuidadores se sentem despreparados para esta e outras demandas. Estes aspectos acabam direcionando os pacientes para os serviços de saúde com maior frequência do que seria necessário, com aumento na realização de exames e procedimentos fúteis. As dificuldades em atender às demandas dos pacientes em nível domiciliar, já dificultadas pelos problemas sociais anteriormente descritos, são acentuadas por estes fatores e acabam implicando em internações prolongadas com grande sofrimento para pacientes, familiares, profissionais e para o sistema de saúde, que acaba tendo sua limitada capacidade de atendimento reduzida.

\section{Cuidados Paliativos como Nova Forma de Cuidado em Saúde}

O termo Cuidado Paliativo se confunde historicamente com o termo "Hospice", que são hospedarias que se caracterizavam por serem locais para receber e cuidar de peregrinos e viajantes, cujo relato mais antigo remonta ao século V. Já a palavra "paliativo" é originada do latim pallium que significa manto, proteção(24).

O Movimento "Hospice" Moderno foi introduzido por Dame Cicely Saunders em 1947, assistente social que estava em formação como enfermeira. Segundo ela, o ponto de partida para o compromisso com uma nova forma de cuidar surgiu quando ela conheceu um paciente David Tasma, visitando-o até sua morte, o que deu embasamento para um pensamento inicial sobre abordagem em cuidados paliativos, fundando em 1967 “St. Christopher's Hospice”, com objetivo de assistência aos doentes e desenvolvimento de ensino e pesquisa. O movimento "Hospice" cresceu ainda mais na década de 1970, quando houve o encontro de Cicely Saunders com Elisabeth Klüber-Ross nos Estados Unidos e, em 1982, o Comitê de Câncer da Organização Mundial da Saúde (OMS) criou um grupo de trabalho para definir políticas para o alívio da dor e cuidados do tipo "Hospice" para pacientes com câncer, e que fossem recomendados em todos os países(24).

De acordo com a OMS, o conceito de cuidados paliativos redefinido em 2012 é uma "abordagem que aprimora a qualidade de vida, dos pacientes e famílias que enfrentam problemas associados com doenças, através da prevenção e alívio do sofrimento, por meio de identificação precoce, avaliação correta e tratamento da dor, e outros problemas de ordem física, psicossocial e espiritual'.(24). Embora concebido para atender pacientes portadores de câncer avançado, o conceito 
de Cuidados Paliativos (CP) foi estendido a todo paciente portador de alguma doença fora de possibilidades terapêuticas de cura(25).

Estudos mostram que intervenções de cuidados paliativos comparados com cuidados habituais, na abordagem de sintomas e na utilização de cuidados específicos, melhoram a qualidade de vida e satisfação familiar considerando um amplo espectro de populações, incluindo pacientes com câncer em estágio avançado, doença neurológica, doença pulmonar e idosos com múltiplas comorbidades e fragilidade, expandindo consideravelmente o seu benefício a estas populações específicas e a pacientes gravemente doentes $(26,27)$.

Por definição, cuidados paliativos são cuidados interdisciplinares (Medicina, Enfermagem, Serviço Social, Capelania e outras especialidades quando apropriado) que se concentram em melhorar a qualidade de vida de pessoas, em qualquer idade, que apresentem alguma doença grave, com foco tanto na pessoa quanto em seus familiares. O objetivo é o tratamento da dor e outros sintomas físicos, além do sofrimento psíquico e espiritual, utilizando habilidades de comunicação para estabelecer metas de atendimento, fornecendo desta maneira apoio aos pacientes, seus entes queridos e equipes de assistência(28).

Idealmente, os cuidados paliativos devem ser iniciados no momento do diagnóstico de uma doença grave e sem possibilidade de cura e intensificado em proporção direta à evolução da doença (26).

Os cuidados paliativos atuam com bases científicas e são fundamentados na Bioética, devendo ser aplicados em conjunto com o tratamento curativo desde o diagnóstico inicial de uma doença potencialmente fatal, sendo que no curso de evolução desta doença, progressivamente tende a se tornar o único tratamento em sua fase avançada. Segundo a OMS, os Cuidados Paliativos são uma forma de melhorar a qualidade de vida dos pacientes e seus familiares na prevenção e no alívio do sofrimento. $\mathrm{O}$ atendimento é baseado em habilidades de comunicação: através da escuta ativa e participativa com os objetivos de alinhamento de expectativas e definição de metas de atendimento para elaboração do plano de cuidados que seja mais adequado ao paciente; prognosticação: definição do perfil do paciente com base no espectro de evolução das doenças e história clínica; controle de sintomas físicos, psicológicos, sociais e espirituais e atenção à terminalidade, tendo em vista a melhoria da qualidade de vida dos pacientes e de seus familiares (28).

Estudos comprovam que oferecimento de cuidados paliativos em geral melhoram a qualidade de vida e a carga de sintomas de pacientes gravemente doentes, sendo que estes foram associados com melhor planejamento de cuidados, maior satisfação do paciente e do cuidador com o cuidado e menor utilização de cuidados de recursos de saúde(27). 
Países como os Estados Unidos tem investido nesta evidência, sendo que na última década os programas de cuidados paliativos têm crescido em mais de $150 \%$, de modo que quase $90 \%$ dos hospitais com 300 leitos ou mais e dois terços dos hospitais com 50 leitos ou mais agora têm programas de cuidados paliativos e em 2011, foi estabelecido Acordo Avançado de Certificação para Programas de Cuidados Paliativos, o que demonstram a preocupação com estes serviços e sua importância(26). Uma intervenção interessante é a iniciativa de plano de saúde dos EUA para reembolsar conversas nas quais sejam abordadas discussões sobre o fim de vida com pacientes e familiares para estimular médicos a encontrarem tempo para este tipo de abordagem(29).

No Brasil, Cuidados Paliativos teve seu início na década de 80 e os serviços foram surgindo de forma isolada, sem vínculos entre si e sem a elaboração de protocolos ou manuais para sua prática efetiva. O primeiro estado brasileiro a ter Serviço de Cuidados Paliativos foi o Rio Grande do Sul, em 1983, quando anexou um Serviço de Cuidados Paliativos ao "Serviço de Dor" do Hospital das Clínicas da Universidade Federal do Rio Grande do Sul. Três anos após teve início o Serviço de Dor e Cuidados Paliativos da Santa Casa de Misericórdia de São Paulo, surgindo ainda iniciativas em Florianópolis (1989) e no Rio de Janeiro (1989) (30).

A área de atuação em cuidados paliativos foi recentemente reconhecida pela Associação Médica Brasileira em 2017, e hoje já é possível obter o título de especialista em cuidados paliativos.

No entanto, o documento da Academia Nacional de Cuidados Paliativo de outubro de 2018, intitulado "Panorama dos Cuidados Paliativos no Brasil" identificou através do "Global Atlas of Palliative Care at the End of Life", publicado em 2014 (31), que o Brasil recebeu classificação que caracteriza países onde a provisão de cuidados paliativos é oferecida de forma isolada, sendo o seu desenvolvimento irregular e não bem apoiado, com fontes de financiamento fortemente dependente de doações, disponibilidade limitada de morfina e um pequeno número de serviços de cuidados paliativos comparado ao tamanho da população, estando o sistema de saúde brasileiro muito atrasado na integração e apoio a estas equipes, apresentando mesmo nível de desenvolvimento, segundo a OMS, que Angola, Bangladesh, Congo, Moçambique e Irã(32).

O Ministério da Saúde publicou no final do ano de 2018, resolução que normatiza a oferta de cuidados paliativos como parte dos cuidados continuados integrados no âmbito do Sistema Único de Saúde (SUS)(33),e dispõe sobre as diretrizes para a organização à luz dos cuidados continuados integrados ofertados no âmbito das Rede Regionais de Atenção à Saúde (RRAS), incluindo a integração dos cuidados paliativos na rede de atenção à saúde com os objetivos principais de promover a melhoria da qualidade de vida dos pacientes, incentivar o trabalho em equipe multidisciplinar, fomentar a instituição de disciplinas e de cuidados paliativos no ensino de graduação e especialização, ofertar educação permanente em cuidados paliativos para os trabalhadores da saúde no SUS, promover a disseminação de informação sobre os cuidados paliativos na sociedade, ofertar 
medicamentos que promovam o controle dos sintomas dos pacientes em cuidados paliativos e pugnar pelo desenvolvimento de uma atenção à saúde humanizada, baseada em evidências, com acesso equitativo e custo efetivo, abrangendo toda a linha de cuidado e todos os níveis de atenção, com ênfase na atenção básica, domiciliar e integração com os serviços especializados.

A resolução baseia-se na ideia de que que os cuidados paliativos devem ser oferecidos em qualquer ponto da rede de atenção à saúde. As prerrogativas são dadas de acordo com cada ponto desta rede. A Atenção Básica deverá ser ordenadora e coordenadora do cuidado acompanhando os pacientes no seu território e funcionará como retaguarda dos demais pontos da rede de atenção sempre que necessária; a Atenção Domiciliar, observará o plano terapêutico singular do paciente e a intensidade do cuidado, contribuindo para a organização domiciliar com o objetivo de que este esteja preparado, sempre que possível, para o período de terminalidade e para pacientes em situação de restrição ao leito ou ao domicílio.

A Atenção Ambulatorial deverá atender as demandas em cuidados paliativos proveniente de outros pontos de atenção da rede e a Urgência e Emergência prestará cuidados no alívio dos sintomas agudizados, focados no conforto e na dignidade da pessoa, ficando a Atenção Hospitalar voltada somente para o controle de sintomas que não sejam passíveis de controle em outro nível de assistência.

Uma inovação muito importante e moderna desta resolução é que ela define que os especialistas em cuidados paliativos atuantes na Rede de Atenção à Saúde (RAS) poderão ser referência e potenciais matriciadores dos demais serviços da rede, podendo isso ser feito in loco ou por tecnologias de comunicação à distância.

Traz ainda a discussão do acesso aos medicamentos para tratamentos dos sintomas relacionados aos cuidados paliativos, notadamente opióides, que deverá seguir as normas sanitárias vigentes e observar as pactuações entre as instâncias de gestão do SUS.

E inclui o financiamento para a organização dos cuidados paliativos deverá ser objeto de pactuação tripartite, observado o planejamento e a organização dos cuidados continuados integrados na RAS.

Esta resolução bastante completa acaba por ser um avanço e um marco histórico para o nosso país, reconhecendo a necessidade desta forma de cuidado como direito das pessoas que são assistidas no SUS, no entanto, ainda há um longo caminho a ser estudado e percorrido para a eficácia de sua implementação e efetivação, e para que esta política se concretize considerando a sua inserção dentro das políticas de saúde já existentes. 


\section{IMPACTO DAS MUDANÇAS SOCIAIS NOS SERVIÇOS HOSPITALARES DE EMERGÊNCIA}

\section{Sistema Único de Saúde (SUS)}

A origem do Sistema Único de Saúde (SUS) se deve à evolução dos direitos sociais e consequentemente do direito à assistência à saúde no Brasil. Inicialmente o acesso à saúde não era considerado um direito social, e seu acesso era prejudicado, pois, as ações terapêuticas eram desenvolvidas pela iniciativa privada. Somente em 1923, quando através da Lei Eloy Chaves se criam as Caixas de Aposentadorias e Pensões (CAP), é que se tem início a Seguridade Social no Brasil. Todo esse processo culminou com a promulgação da Constituição da República Federativa do Brasil de 1988, estabelecendo o direito à saúde e ao acesso universal e igualitário às ações e serviços de saúde prestados pelo poder público(34).

Criado em 1990 pelas leis 8080/1990 e 8142/1990, o Sistema Único de Saúde (SUS) ainda está em constante evolução. A análise pormenorizada desta evolução foge ao escopo desta dissertação e pode ser analisada em outras fontes. Descreve-se a seguir a estruturação atual como base para a análise da intervenção proposta neste trabalho.

O Sistema Único de Saúde está organizado por Redes Regionais de Atenção à Saúde (RRAS), e estas são definidas como arranjos organizativos de ações e serviços de saúde, de diferentes densidades tecnológicas, que integradas por meio de sistemas de apoio técnico, logístico e de gestão, buscam garantir a integralidade do cuidado (35). Os atributos da RRAS são: atenção básica estruturada como primeiro ponto de atenção e principal porta de entrada do sistema, constituída de equipe multidisciplinar que cobre toda a população, integrando, coordenando o cuidado e suas necessidades de saúde; acesso regulado aos outros níveis de atenção e linhas de cuidado estruturadas.

As linhas de cuidado expressam os fluxos assistenciais que devem ser garantidos ao usuário, no sentido de atender às suas necessidades de saúde, definem as ações e os serviços que devem ser desenvolvidos nos diferentes pontos de atenção de uma rede (nível primário, secundário e terciário) e nos sistemas de apoio, desenhando o itinerário terapêutico dos usuários na rede e devem fornecer uma referência para prever um conjunto mínimo de atividades e procedimentos necessários e estimar seus custos. Na gestão, as linhas de cuidado podem orientar os gestores públicos a planejar, programar e avaliar as modalidades de atendimento que o sistema de saúde precisa oferecer à população, os procedimentos necessários (exames, tratamentos, etc) para prevenir e detectar precocemente os agravos à saúde e quais tipos de serviços assistenciais os sistemas de saúde locais devem oferecer para o controle dos diferentes agravos à saúde(36). A filosofia das linhas de cuidado estabelece que 
para cada segmento de cuidado, deve haver uma pactuação e um trabalho em equipe coletivo para construção dos fluxos de acesso e cuidado aos usuários. Como exemplo temos a linha de cuidado do câncer e das doenças crônicas não transmissíveis (DCNT).

No Estado de São Paulo, o processo de construção das Redes Regionais de Atenção à Saúde (RRAS) iniciou-se em 2011 e efetivou-se com a constituição de 17 RRAS, dentre elas a RRAS 13 (Ribeirão Preto).

Deve-se ter presente que toda esta estrutura proposta está em constante transformação, não estando instaladas de modo completo ou homogêneo entre as diversas regiões. Em que pese esta limitação, todas as linhas de cuidado guardam entre si o princípio do Acesso à Saúde, que é garantido, basicamente, por duas portas de entrada: a atenção básica e a emergência. A atenção básica é representada principalmente pela estratégia de postos de saúde e Medicina de Família, que estão localizadas próximas ao domicílio do paciente e garantirão a referência para outras instâncias do SUS quando necessário. A via de Acesso emergência é representada por várias instâncias, como o PréHospitalar Móvel (SAMU - Serviço de Atendimento Médico às Urgências) e Fixo (UPA - Unidades de Pronto-Atendimento) e pelo Serviço Hospitalar de Emergência (SHE).

\section{Características e Conceitos relativos aos Serviços Hospitalares de Emergência (SHE)}

Os Serviços Hospitalares de Emergência (SHE) são instâncias caracterizadas por 1) concentração de alta tecnologia e pessoal qualificado para lidar com situações de emergência; 2) que funcionam continuamente (vinte e quatro horas por dia); e 3) cujo acesso deve ser idealmente realizado através de técnicas de gerenciamento de fluxo como a Regulação Médica e a Estratificação de Risco.

Os motivos da concentração de alta tecnologia nos SHE já foram descritos e suas implicações para a logística da rede de atendimento às emergências. Uma distinção importante a ser feita e que será utilizada ao longo deste trabalho é entre os termos urgência e emergência. Embora sejam sinônimos nas bases gramaticais, em termos de Cuidado à Saúde, a urgência é um termo mais abrangente que caracteriza a necessidade de atendimento imediato percebida pela população leiga. Já a emergência é a condição tempo-sensível que se não for atendida de modo coordenado e imediato pode ocasionar morte ou incapacidade permanente, sendo geralmente percebida pelo profissional de saúde(21).

Já a segunda característica, funcionamento contínuo da porta de entrada representada pelos SHE contrasta com os horários regulares da Atenção Básica. Isto gera um viés de direcionamento de 
pacientes para os SHE, por situações não-emergenciais, com sobrecarga para o sistema. Ou seja, além da uma diferença conceitual entre o que é percebido como grave pela população leiga e o que realmente é grave em termos de atendimento demandada na estrutura hierarquizada do SUS, somase a facilidade de acesso aos SHE. Isto ocasiona a aglomeração (superlotação) e impõe a necessidade de implementação de soluções para gerenciamento de fluxo, como a Regulação Médica e a Classificação de Risco, para assegurar o acesso dos pacientes em condição de emergência aos SHE.

Para a compreensão da terceira característica, as estratégias de gerenciamento de fluxo, é necessário a definição de fluxo. Esta definição é motivo de muito debate na literatura pertinente, mas para efeitos desta dissertação será utilizada a definição proposta por Mayer et al.(37) na qual Fluxo é acrescentar valor aos processos e serviços, aumentando os benefícios, diminuindo gastos ou pela combinação dessas duas estratégias, no atendimento de pacientes ao longo dos serviços e filas de espera que compreendem o moderno sistema de saúde.

Embora existam diversas técnicas de gerenciamento de fluxo, duas merecem destaque. A Regulação Médica é uma solução de macroalocação de recursos, que busca direcionar os pacientes para as instâncias corretas do SUS(38). Do ponto de vista legal, estão previstas três instâncias de Regulação (Urgência, Interhospitalar e de SADT - Serviços de Auxílio ao Diagnóstico e Terapêutica), muito embora por questões de necessidade a Regulação de Emergência tenha sido a primeira a ser instalada e as demais esferas sejam incipientes, o que tem gerado confusão e ineficácia no processo regulatório.

A ausência ou funcionamento inadequado do SUS tem implicado em sobrecarga crescente aos SHE, que ainda podem ser classificados como não-regulados ("porta aberta") ou regulados. A sobrecarga impõe a utilização de estratégias de microalocação de recursos como a Estratificação de Risco. O processo de Estratificação de Risco está disponível através de diversas escalas e seu uso tem sido intensamente debatido na literatura quanto ao valor que pode agregar.

A sobrecarga ou aglomeração (“crowding”) é um fenômeno multifatorial, definido quando "o número de pacientes é maior do que a equipe disponível para atendimento (leitos disponíveis) e o tempo para atendimento é maior do que o razoável" de acordo com a American College of Emergency Physicians (ACEP) Crowding Resources Task Force in 2002. Muito debate se estabelece acerca desta definição, pois apesar de correta, não acrescenta valor no sentido de esclarecimento das causas para que se possa propor soluções(39). De Freitas et al realizaram revisão recente que busca agregar as diversas soluções potenciais para o gerenciamento deste problema(40).

Sendo assim, um número crescente de pacientes visita os serviços de emergência todos os anos: quase $20 \%$ da população dos EUA a cada ano (41) ou 400 visitas por 1000 habitantes no Reino Unido (42). No Brasil a prática assistencial, apesar da falta de evidências científicas neste contexto, vem demonstrando o aumento do número de atendimento a pacientes que se enquadram tanto para 
acompanhamento conjunto com ECP, quanto para atendimento exclusivo e em processo de terminalidade.

Aliado a esse fato temos a falta de preparo das equipes de atendimento dos serviços de urgência para um atendimento que contemple a proporcionalidade adequada à fase de doença dos pacientes, o que colabora para a ausência da qualidade dos serviços prestados, o aumento do tempo de internação e a falta de otimização dos recursos humanos e tecnológicos do sistema de saúde(43).

\section{Unidade de Emergência do HCFMRP/USP}

A Unidade de Emergência do Hospital das Clínicas da Faculdade de Medicina de Ribeirão Preto da Universidade de São Paulo (U.E.-HCFMRP/USP) faz parte do Complexo do HCFMRP/USP, sendo um hospital público que atende exclusivamente ao Sistema Único de Saúde e com acesso regulado (44).

Na região do Aquífero Guarani, a U.E.-HCFMRP/USP compõe uma das portas de entrada hospitalar, classificada como hospital especializado tipo II, sendo referência não só para a população da Divisão Regional de Saúde XIII (DRS XIII) (1.342.815 hab), como para a RRAS 13 (3.307.320 hab) e outras RRASs do Estado de São Paulo, em algumas especialidades. Possui habilitação em alta complexidade nas linhas prioritárias de ortopedia, neurocirurgia, cardiovascular, dentre outras (45).

A U.E-HCFMRP/USP conta na sua estrutura com: 171 leitos, sendo 135 leitos gerais, 36 leitos de CTI e 7 leitos de recuperação anestésica e 08 salas cirúrgicas. Em 2017 contou com 49.153 atendimentos, sendo 39.144 atendimentos de consultas e procedimentos de ambulatório e 10.009 internações, com uma taxa de ocupação de $103,7 \%$ e média de permanência em 6,8 dias.(44).

Sendo assim, configura-se como um hospital de urgência responsável por atender pacientes previamente saudáveis com quadros agudos, em grande parte da natureza clínica ou traumática (que envolve a violência em suas mais diversas formas) e pacientes com doenças crônicas em quadro de exacerbação. Para este serviço também são encaminhados pacientes que não encontram resolução da rede básica de saúde, para realização de investigação diagnóstica. 


\section{SOLUCOẼS PROPOSTAS PARA CONTORNAR A AGLOMERAÇÃO EM SHE}

De acordo com o que já foi descrito neste estudo vimos que os SHE estão sofrendo um processo de aglomeração constante por diversas razões. Várias estratégias foram sendo pensadas ao longo dos anos para discutir esta questão.

Podemos categorizar a problemática de acordo com a natureza do problema: questões externas, que estão relacionadas à organização do sistema de saúde e a forma de atendimento, uma vez que, como vimos o SHE é uma das únicas portas de entrada $24 \mathrm{~h}$ por dia, e relacionados à qualidade da triagem e dos encaminhamentos e questões internas relacionadas à organização do atendimento.

Em um estudo de revisão Freitas et al(40), aponta que a otimização do fluxo do atendimento pode ser uma das medidas para melhorar o atendimento de urgência e para tanto, descreveu e avaliou intervenções para melhorá-lo.

Em relação às estratégias vimos aquelas relacionadas à questões externas e outras internas das instituições: a utilização de um sistema informatizado para solicitar vaga, o protocolo de capacidade total que é um método de transferência de pacientes para outras áreas do hospital quando os SHE atingem sua capacidade máxima, utilização de pessoas com função administrativas para auxiliar com aspectos não clínicos do atendimento, como documentação das anotações e recuperação de investigações, o registro beira leito, a categorização de pacientes com características similares em locais distintos, onde eles podem receber cuidado, uma via rápida de atendimento separado para pacientes com menor queixas, classificação dos pacientes de acordo com a urgência de doença e locais de atendimentos diferentes no pronto atendimento para diferentes perfis de pacientes: com queixas ambulatoriais que podem ser tratadas sem usar um leito, pacientes que necessitam de um curto período de observação e pacientes com condições médicas complexas que provavelmente requerem internação

Outras estratégias encontradas foram dispostas em grupos devido a características semelhantes. Um grupo refere-se aos serviços diagnósticos, destacando a disponibilidade de realização de exames no pronto atendimento e permissão do enfermeiro fazer uma triagem avançada e solicitar exames. Ainda neste grupo temos intervenções envolvendo atuação dos enfermeiros, onde conta com enfermeiro qualificado para avaliar, diagnosticar e tratar certas queixas médicas ou atendimento iniciado pelo enfermeiro na triagem e a solicitação de radiografias por enfermeiros, e ainda enfermeiros com iniciativa clínica podendo iniciar tratamentos. Temos ainda, intervenções baseadas na atuação dos médicos: médico orientando a triagem para agilizar o atendimento do paciente, médicos e a equipe de triagem trabalhando juntos para gerenciar o aceite de pacientes na triagem e a 
presença de um médico experiente na triagem para auxiliar no tratamento de pacientes antes de serem atendidos no SHE.

Algumas intervenções requerem o direcionamento de ações administrativas e organizacionais como reorganização estrutural, implementação de coordenadores, mudança de pessoal e ampliação de horários mais longos para outros serviços. E temos ainda intervenções que abrangem mais de um componente como, por exemplo, alterações de pessoal e sua reorganização e a reestruturação conjunta do SHE.

O Estudo concluiu que, embora todas as estratégias consigam melhorar o tempo de internação, a heterogeneidade e limitações do estudo, como a não padronização das métricas entre os serviços e as diferenças contextuais contribuíram para que estas não tivessem uma significância importante com evidências limitadas e efeitos inconsistentes.

A única estratégia que se mostrou efetiva foi a definição de fluxos diferentes, considerando uma via rápida para perfis de pacientes diferentes, no entanto, a complexidade da problemática nos faz pensar que a combinação destas estratégias de acordo com a configuração do SHE e a estrutura do sistema de saúde podem ser válidas.

\section{Soluções implantadas na U.E.-HCFMRP-USP}

Neste contexto, a aglomeração dos SHE tem sido muito presente nos serviços, e consequentemente na U.E-HCFMRP/USP, no entanto, ao longo dos anos estratégias foram sendo implantadas para a minimização deste problema.

\section{Sistema de Regulação de Urgência e Emergência (SRUE)}

Uma delas foi a implantação do Sistema de Regulação de Urgência e Emergência (SRUE) baseado em sistema informatizado(22).

A DRS XIII foi pioneira na Instalação de um Sistema de Regulação Médica para organizar o fluxo dos pacientes, no entanto, a comunicação inicial era realizada por telefone e após 10 anos de sua implantação, inadequações ainda geravam sobrecarga no atendimento em instituições e prejuízo para os usuários, o que motivou a implantação do SRUE para comunicação imediata entre as unidades participantes do processo de regulação médica.

O fluxo se inicia quando o médico solicitante preenche um formulário de solicitação de vaga, os dados são enviados ao médico regulador por via eletrônica, que avalia as informações, categoriza como baixa, moderada ou alta prioridade, ou como "vaga zero", e encaminha a solicitação ao hospital 
mais adequado que aceita, recusa ou solicita mais informações, gerando um processo de negociação sigiloso e documentado.

O SRUE tornou-se uma ferramenta importante para análise epidemiológica e organizacional que pode contribuir para monitoramento da demanda e melhor direcionamento dos casos.

\section{Leitos de Longa Permanência}

A permanência prolongada de pacientes crônicos com alta dependência em SHE também é um dos problemas que impactam na aglomeração destes serviços.

Para resolver esse problema, buscou-se a instalação de leitos de longa permanência, que são leitos alocados em hospitais de pequeno porte, que enfrentam dificuldades econômicas para subsistência e têm baixa taxa de ocupação(46).

A Coordenação da U.E.-HCFMRP-USP, o DRS XIII, a Prefeitura de Ribeirão Preto e o Serviço de Atendimento Móvel de Urgência (SAMU) Regional identificaram três hospitais para estabelecer parcerias, foram realizadas visitas técnicas in loco e estabelecidos protocolos de encaminhamento de pacientes de longa permanência. Os critérios para encaminhamento foram baseados nas condições de atendimento e as responsabilidades de cada instituição, baseando-se no benefício para ambas as partes, a liberação de mais leitos no SHE para pacientes de alta complexidade e ganho financeiro para os hospitais-parceiros. Além disso, esses hospitais receberam capacitação de seus funcionários, ficando acordado que caso houvesse necessidade de retorno do paciente ao hospital terciário, isso seria feito independentemente da Regulação Médica.

A partir de abril de 2014, o projeto foi sancionado e apoiado financeiramente pela Secretaria da Saúde do Estado de São Paulo e acontece até os dias atuais.

O processo de transferência se inicia com a concordância do paciente e seus familiares, após é feita solicitação de vaga para o município-parceiro, e quando há o aceite da transferência, o paciente é encaminhado com relatório médico, de enfermagem, nutricional, fisioterapêutico, psicológico e do serviço social. O hospital terciário e o DRS XIII mantêm controle de todos os pacientes internados e este só deixa de ser acompanhado quando deixa o hospital parceiro (por óbito ou alta), tornando esses hospitais parceiros uma extensão da unidade terciária de origem.

Este processo teve impacto considerável no aumento de vagas oferecidas pelo SHE para áreas de estrangulamento do sistema, como a Neurologia e Terapia Intensiva, notando-se a tendência de aumento de vagas gerais de atendimento, totalizando 9,3\%, além de abrir possibilidade de discussão para de que cada município possa ser responsável em fornecer esse apoio para pacientes de longa permanência, transferindo-os para instâncias primárias do SUS localizadas nos municípios de residência do paciente. 


\section{Sistematização da Solicitação de leitos em terapia intensiva}

Outra estratégia adotada na U.E-HCFMRP/USP para auxiliar nos fluxos internos e melhorar sua capacidade operacional foi organizar a priorização de pacientes para Unidade de Terapia Intensiva, com a criação de um sistema de informação para a organização da fila de espera por leitos, e o objetivo inicial foi avaliar sua utilização sob a perspectiva da mortalidade e permanência hospitalar(47).

O sistema funciona por meio de sistema informatizado. A requisição contém informações diagnósticas do paciente, motivo da solicitação e marcadores de gravidade, como necessidade de suporte ventilatório, presença de choque circulatório e rebaixamento do nível de consciência. Após os pacientes são avaliados por médicos intensivistas, à beira do leito, e classificados quanto à prioridade conforme as diretrizes da Society of Critical Care Medicine (SCCM), de acordo com a gravidade e benefício da utilização do leito da terapia intensiva e em caso de pacientes com mesmo grau de prioridade clínica, são priorizados aqueles provenientes de locais estratégicos para facilitar o fluxo dessas unidades. E ainda permanecendo a semelhança o desempate é realizado pelo tempo da requisição de vaga na terapia intensiva, priorizando-se os mais antigos.

Este novo sistema de informação foi eficaz na medida em que envolveu o compartilhamento de responsabilidades entre médicos e gestores e facilitou o suporte técnico durante a tomada de decisões, reduziu o atrito entre os intensivistas e os outros médicos do hospital, além de prover transparência na gestão da fila e como resultado pode promover a redução da mortalidade hospitalar e ter impacto na permanência hospitalar.

\section{Núcleo Interno de Regulação}

A implantação de um Núcleo Interno de Regulação (NIR) foi uma das estratégias de gestão criadas pela Política Nacional de Atenção Hospitalar do Ministério da Saúde (PNHOSP) em 2013 e o HCFMRP/USP atendendo a esta política, na necessidade de aprimorar os fluxos de saúde, implantou de modo customizado em suas duas unidades NIR's, na unidade hospitalar (eletivo) e na U.E-HCFMRP/USP(23).

Na U.E-HCFMRP/USP a equipe de trabalho do NIR foi composta por 2 enfermeiros, 01 médico e 01 assistente social, com horário de funcionamento em horário comercial, de segunda à sexta-feira, das 07 às 19h. As principais funções atribuídas foram: intercomunicação entre os diversos setores clínicos e enfermarias e Controle de Leitos, setor de Farmácia e Nutrição, com objetivo de redução do tempo de permanência do paciente na instituição e administração dos leitos. 
Para tanto, algumas ferramentas, protocolos e projetos foram utilizados: a produção de um Kanban para gerenciamento clínico e administrativo dos atendimentos, a implantação do protocolo de MEWS para gerenciamento clínico dos casos, utilização de Projeto de Desospitalização e Monitorização do tempo de bloqueio de leito.

Como pontos de dificuldades e desafios a serem trabalhados foram a intervenção para rever o mosaico cirúrgico, a ampliação comunicação com equipe médica (sistema de telefonia) e agilização dos processos internos como por exemplo, a viabilização de realização de exames, tendo em vista os pacientes com tempo de internação prolongado.

Ainda que a implantação tenha ocorrido antes da estruturação do Manual do Ministério de Saúde(48), na avaliação percebeu-se que todos os passos sugeridos pelo manual foram contemplados, no entanto, algumas necessidades apontadas no manual precisam ser discutidas e implementadas, especialmente referentes aos três pilares do NIR proposto pelo Ministério da Saúde: Práticas de Regulação, Articulação com a RAS e Monitoramento.

No entanto, o ponto positivo é que já estão funcionando como agentes mediadores da comunicação entre as equipes de saúde no atendimento de situações complexas e comunicação entre diversos profissionais para resolução de demandas multiprofissionais. Indicadores estão sendo monitorados: indicadores de processo, como tempo de internação; indicadores de produção, como capacidade instalada por taxa de ocupação dos leitos e indicadores de desempenho, como monitorização de pacientes residentes no hospital com iniciativa já relatada de desospitalização(46).

Além disso, já existe um fórum no Departamento Regional de Saúde XIII com iniciativas de comunicação entre os NIRs dos hospitais, que estão favorecendo o fortalecimento da rede.

Vimos que a U.E-HCFMRP/USP vem trabalhando com estratégias de enfrentamento da realidade da aglomeração dos SHE, através de melhorias gerenciais internas, como a implantação do NIR e Sistematização da Solicitação de Leitos em Terapia Intensiva e contribuições em conjunto com a rede de saúde local, como a implantação do Sistema de Regulação de Urgência e Emergência e dos Leitos de Longa Permanência.

No entanto, devido à complexidade e multifatorialidade do problema, desafios ainda persistem, sendo assim, este estudo foi direcionado à adoção da implantação da ECP como outra possibilidade diante da questão. A necessidade de trabalhar a abordagem de Cuidados Paliativos nestes serviços pode ser uma das formas para dar visibilidade a esses casos nos serviços de saúde, adequar o atendimento prestado e mostrar a necessidade de melhor adequação do sistema de saúde, considerando a criação de políticas públicas que atendam a essa demanda. 


\section{CUIDADOS PALIATIVOS NO SERVIÇO HOSPITALAR DE EMERGÊNCIA (SHE)}

Nos últimos anos, têm sido crescentes a implantação de novas estratégias para aprimorar o cuidado e diminuir o dano descrito. Uma destas estratégias foi o surgimento e desenvolvimento dos Cuidados Paliativos em serviços de saúde dedicados aos cuidados de condições crônicodegenerativas. No entanto, estes serviços muitas vezes só funcionam em horários comerciais, não estando disponíveis quando ocorre o óbito ou quando há acentuação de sintomas, novamente implicando em direcionamento inadequado para SHE.

Um estudo recente que realizou avaliações econômicas de interconsulta em cuidados paliativos em adultos hospitalizados com doenças graves (câncer; insuficiência cardíaca, hepática ou renal; doença de obstrução pulmonar crônica; AIDS/HIV) em internação hospitalar, mostrou que o atendimento em cuidados paliativos pode reduzir custos para adultos hospitalizados com doenças graves e complexas. Além disso, demonstrou que pacientes com doenças complexas morrem em hospitais de cuidados agudos, com prevalência de internação em unidade de terapia intensiva nas últimas semanas de vida, indicando cuidados inconsistentes com as preferências do paciente e desproporcionalidade de tratamentos (49).

O Ministério da Saúde expressa preocupação sobre o atendimento de pessoas com condições crônicas, danos múltiplos e necessidade de cuidados prolongados, exigindo assistência contínua. Trabalho recente estimou a proporção de indivíduos que morrem em nosso país de doenças que teriam indicação para Cuidados Paliativos de 24,6\% até 85,2\%(13). Mesmo que se considere que o que se deveria ofertar deve estar no ponto médio entre estes valores, ofertar Cuidados Paliativos no nosso modelo atual de sistema de saúde é uma tarefa difícil. O primeiro passo para modificar esta realidade seria reconhecer indivíduos com benefício dessa abordagem, independentemente do seu diagnóstico, e incluí-los em programa de cuidados paliativos, já que há fortes evidências do benefício para melhor qualidade de vida, com aumento inclusive na sua sobrevida (50).

Torna-se necessário, portanto, que os SHE se integrem aos serviços de Cuidados Paliativos para garantir a continuidade do cuidado. Mas para que isto seja possível, deve-se compreender o que se entende por Cuidados Paliativos e qual o grau de sua inserção no SHE.

A abordagem dos cuidados paliativos no SHE tornou-se uma necessidade devido a mudanças no perfil de atendimento e mudanças epidemiológicas. O SHE sempre foi idealizado como o serviço para atendimento de pacientes em situações agudas cujo objetivo é a manutenção da vida (51).

As mudanças citadas nos levam a repensar o SHE não só como local de salvar vidas, mas também de oferecimento de cuidados paliativos. Os motivos desta necessidade são vários, dentre eles 
a organização e efetividade do sistema de saúde, no qual este serviço continua sendo o ponto de entrada do sistema de saúde para muitos pacientes (52) e ainda, que pacientes com demanda de Cuidados Paliativos, especialmente na fase de terminalidade, serão ocasionalmente transportados para serviços de emergência.

As mudanças demográficas levaram ao aumento do uso destes serviços por pacientes com doença crônica avançada, revelando que mais de 75\% dos idosos são atendidos nos últimos 6 meses de vida e $51 \%$ têm pelo menos uma consulta no último mês de vida. No entanto, há também uma alta prevalência de necessidades não atendidas de cuidados paliativos entre estes pacientes. Durante os períodos de agravamento dos sintomas e grande sofrimento psíquico, os pacientes podem ter mais contato com os profissionais de emergência do que com outros profissionais de cuidados primários, sendo este o local de atendimento, limitado pelos recursos de saúde disponíveis na comunidade. Por fim, decisões críticas sobre a trajetória e disposição de um paciente são tomadas durante o atendimento na emergência, o que poderia fornecer uma oportunidade para encaminhamento adequado e oportuno a uma equipe de cuidados paliativos (ECP)(53).

O treinamento das equipes de emergência concentra-se em medidas de prolongamento da vida o que pode ser um limitador, bem como a dificuldade em lidar com indivíduos em sua fase final. Para as equipes de saúde que atuam em situações de emergência é difícil assumir que um paciente tenha demanda de cuidados paliativos, pois a procura a esse serviço pode equivaler a um desejo de tratamento agressivo ou prolongamento da vida (54).

Existe ainda certa frustração de médicos de emergência ao atender pacientes que necessitam de cuidados paliativos no SHE, devido ao fato de que este tipo de abordagem não segue um algoritmo simples como em outros protocolos de atendimento, mas depende de recursos a serem mobilizados e das demandas dos pacientes, descrito como uma necessidade de um "código de conforto" que atenda a essas demandas. Outra dificuldade relatada é a falta de acesso a informações sobre as preferências dos pacientes, no processo de comunicação e no estabelecimento de metas. Um estudo sugere que o contato com serviços de atenção primária e a inclusão de especialista em cuidados paliativos são parcerias que podem auxiliar nestes processos de comunicação e melhor definição das metas(29).

Neste contexto, ainda existem equívocos e dificuldades sobre os conceitos de cuidados paliativos que impactam no entendimento sobre a abordagem na emergência. Um deles é que cuidados paliativos não são o mesmo que terminalidade. Ainda que esta seja uma de suas áreas principais de atuação, não se pretende o prolongamento da vida, mas a qualidade do tempo de vida. Outro equívoco é que cuidados paliativos não são exclusivos de uma unidade de saúde, por isso deve perpassar toda a rede de atendimento e o processo de comunicação ente seus componentes devem ser efetivos. 
A dificuldade de abordagem na emergência também pode ser explicada pelas diferenças das expectativas entre pacientes, familiares e equipe, tendo em vista a falta de informações suficientes sobre os pacientes, para o embasamento de decisões, quando são encaminhados para este serviço e problemas culturais, logístico e de treinamento de equipe para oferecer cuidados paliativos(51).

Mesmo quando um paciente ou os familiares solicitam cuidado curativo é necessária uma avaliação para entender as preocupações que provocaram uma mudança nos objetivos de cuidados. Frequentemente, tais pedidos surgem do medo sobre o processo de morte ou a culpa sobre decisões médicas anteriores para limitar os tratamentos que prolongam a vida(54).

De acordo com revisão sistemática recente sobre cuidados paliativos no SHE, apesar deste ambiente ter o objetivo primário de avaliação rápida e atendimento agudo, o médico de emergência tem o dever de atender às necessidades do paciente paliativo, considerando o conforto e cuidados específicos. Sendo assim, a prestação deste serviço é um objetivo legítimo do SHE e o fracasso em reconhecer esta necessidade e obter as habilidades necessárias acarreta a má implementação dos cuidados paliativos nesse ambiente(55).

Estudo australiano avaliou a necessidade das equipes do SHE em relação a cuidados paliativos e foi observado que apesar dos profissionais expressarem confiança em relação ao manejo de sintomas, elas subestimam o papel de uma abordagem paliativa em diagnósticos não relacionados ao câncer e procuram mais educação em áreas como comunicação sobre o fim da vida e questões éticas, evidenciando a falta de preparo destas equipes para lidar com pacientes deste perfil(56).

Como propostas para a inserção de cuidados paliativos na emergência podem ser listadas: a adequação da rede de saúde com locais dedicados; programas de treinamento que incluem competências básicas de cuidados paliativos adicionados aos programas de residência médica em emergência; protocolos de atendimento que incluem emergências em cuidados paliativos; materiais educacionais e cursos adicionados à educação médica contínua; arranjos destinados a remover barreiras logísticas nos serviços; promoção de diretivas antecipadas e ordens de não-ressuscitação no sistema de saúde; e equipes especiais de cuidados paliativos (51).

Como vimos à necessidade de cuidados paliativos no SHE já vem sendo discutida em outros países, como por exemplo a Austrália, o Reino Unido, e os Estados Unidos(55), que reconhecem e discutem cuidados paliativos como parte do SHE e a necessidade de treinamento das equipes para este tipo de atendimento. Além destes, um estudo do Taiwan, muito semelhante ao presente estudo, demonstrou a implantação de uma equipe de cuidados paliativos em SHE(57).

$\mathrm{O}$ atendimento em cuidados paliativos em SHE é uma realidade necessária, considerando as mudanças epidemiológicas no perfil dos pacientes como o envelhecimento populacional e aumento das doenças crônicas, pois o SHE ainda constitui uma porta de entrada do sistema de saúde, que 
apesar de ser um local com objetivo de prolongamento da vida, deve ter também como objetivo o atendimento digno dos pacientes paliativos que chegam a este serviço.

Outra questão importante quanto à utilização do SHE são as motivações, além dos sintomas físicos que levam os pacientes a buscarem o SHE. Um estudo qualitativo realizado com pacientes com diagnóstico de câncer avançado abordou a sistemática das decisões tomadas para procurar atendimento no SHE, mostrando que a decisão é tomada por: ansiedade relacionada à doença, aqueles com maior ansiedade relacionada ao diagnóstico de câncer interpretaram seus sintomas como mais graves ou requerendo atenção imediata; padrões prévios de comportamento, , os participantes não procuravam os serviços anteriormente utilizados, sentimentos de segurança e familiaridade com o ambiente hospitalar e dificuldades de acesso aos serviços de saúde comunitários especialmente com urgência e/ou fora do horário do atendimento. Este estudo sugere que o tratamento de questões emocionais e psicológicas, como sentimento de vulnerabilidade e falta de controle, é essencial visando reduzir a ansiedade, o que pode modificar a percepção do sintoma, sua interpretação e os níveis de sofrimento. Educar pacientes quanto aos sintomas de fim de vida pode reduzir o número de visitas do SHE junto com maior acesso aos serviços de saúde da comunidade(58).

Podemos concluir então que, sintomas incontroláveis, questões emocionais e psicológicas, necessidade de investigação e intervenção que não tem local para atendimento na rede e limitação de acesso de serviços de cuidados paliativos resultam em pacientes onde o único local de atendimento que atenda suas necessidades seja o $\operatorname{SHE}(59)$.

O que demonstra que o SHE, apesar de pouco preparado para este tipo de atendimento, considerando o risco de sofrimentos físicos e psicológicos desnecessários e intervenções invasivas não congruentes com os desejos dos pacientes, este ainda é o local que identifica as necessidades de cuidados paliativos de forma mais abrangente(53).

No entanto os estudos sobre esta realidade ainda não existem no Brasil, o que garante a originalidade e o pioneirismo deste estudo.

\section{Processo de Formação da Equipe de Cuidados Paliativos (ECP) na U.E. - HCFMRP/USP}

Um grupo formado por profissionais com o apoio da Coordenadoria da U.E.-HCFMRP/USP, inquieto diante das demandas destes pacientes e sentindo a falta de resolutividade de sua prática no cotidiano da assistência, buscando o aprimoramento das formas de cuidado, se uniram e através de reuniões de reflexão com profissionais de referência de alguns setores do serviço, promoveram discussões sobre a temática em comparação com os casos atendidos sob esta perspectiva. 
Posteriormente, fundamentou-se teórica e tecnicamente em artigos científicos e investiu em outras estratégias de capacitação, como a participação em eventos, visitas técnicas a serviços especializados, discussões multiprofissionais e transdisciplinares de casos e temas específicos com a utilização de recursos audiovisuais.

A partir do fortalecimento e amadurecimento do conhecimento do grupo, a proposta de criação de uma equipe de interconsulta em Cuidados Paliativos foi apresentada e acatada pela direção do serviço, que disponibilizou a contratação de um profissional médico especialista para assessoria na implantação e proporcionou o investimento em formação acadêmica, Lato Senso, para integrantes da equipe.

A equipe foi composta por um médico com especialização em cuidados paliativos, assistente social, psicólogo, farmacêutico, terapeuta ocupacional e serviço de capelania, realizado por um padre, um pastor e um religioso espírita, para oferecimento de apoio espiritual aos pacientes e seus familiares internados.

No Brasil, iniciativas de implantação de Cuidados Paliativos no SHE ainda são incipientes. A U.E.-HCFMRP/USP implantou este serviço há cerca de três anos e a avaliação desta estratégia na nossa realidade é oportuna.

\section{SERVIÇO SOCIAL E CUIDADOS PALIATIVOS}

Neste contexto o trabalho enquanto assistente social na U.E-HCFMRP/USP, trouxe a reflexão de várias questões importantes ao considerar todos os reflexos das questões sociais e de saúde da modernidade já desatacadas neste estudo.

O trabalho neste cenário torna propício o contato com realidades de pacientes com perfil paliativo diariamente, questionando nossas práticas e o tipo de atendimento adequado oferecido pelo sistema de saúde, ao considerar a otimização da rede de saúde como política pública, a proporcionalidade do tratamento que é oferecido para a população, o direito a uma nova forma de cuidado, mais humano e adequado e que propicia a valorização da autonomia do paciente, a consideração dos seus valores e crenças e a forma de sua inserção social de acordo com seu contexto social e familiar. 


\section{Atuação do Assistente Social no Ambiente Hospitalar}

O serviço social é uma profissão interventiva que atua diretamente no reflexo das questões sociais, através da emancipação dos sujeitos, pela orientação e viabilização dos direitos sociais, com objetivo da garantia destes direitos e proteção dos indivíduos, cuja inserção social, encontra-se fragilizada pela luta de classes(60,61). Deve cumprir a árdua tarefa do diálogo e intersecção das políticas de saúde e sociais neste contexto(62).

Portanto, a atuação profissional na saúde deve estar pautada no enfrentamento das expressões da questão social que repercute nos diversos níveis de complexidade da saúde, desenvolvendo suas ações profissionais nas dimensões: assistencial, em equipe, socioeducativa, de mobilização, participação e controle social, investigação, planejamento e gestão, assessoria, qualificação e formação profissional(63).

Sendo assim, atua na orientação e viabilização dos direitos sociais, através da identificação do contexto social do paciente, da situação e dinâmica das relações familiares, da condição de trabalho e socioeconômica, das condições de moradia e da rede de suporte social. Faz a interlocução destas condições com a situação de saúde do paciente considerando a inclusão do paciente e familiar no atendimento como parte ativa na participação das decisões dos planos de cuidado e nas mediações intra-hospitalar entre a equipe de saúde e os pacientes e familiares, e extra-hospitalar com a rede de saúde e social.

Para entender e contextualizar a presença do serviço social na saúde e seu grau de inserção devemos levar em consideração a construção da saúde no Brasil como parte das conquistas sociais da Constituição Federal de 1988 e na Lei nº080/90 de criação do SUS e da Política Nacional de Humanização.

A regulamentação do SUS ressalta as expressões da questão social ao apontar que a saúde é direito de todos e dever do Estado, estabelecendo que políticas sociais e econômicas devam reduzir o risco de doença e garantir ao acesso universal e igualitário às ações e serviços para a promoção, proteção e recuperação da saúde(63).

De acordo com as premissas do SUS a saúde tem como fatores determinantes e condicionantes, a alimentação, a moradia, o saneamento básico, o meio ambiente, o trabalho, a renda, a educação, o transporte, o lazer e o acesso aos bens e serviços essenciais, portanto neste conceito de saúde está implícito que a forma de inserção social condiciona diretamente a saúde da população e cabe ao assistente social através de suas mediações e avaliação social traduzir os reflexos desta condição no ambiente hospitalar e auxiliar na organização dos familiares para receber o paciente frente às novas questões de saúde e vinculá-lo a rede de atendimento para continuidade dos cuidados necessários(64). 
A humanização na atenção à saúde através de uma política nacional busca contribuir para a solução de desafios que dificultam a qualidade da implementação do SUS e prevê ainda, através de seus princípios de transversalidade, indissociabilidade entre atenção e gestão e protagonismo, corresponsabilidade e autonomia dos sujeitos e coletivos, e a valorização dos usuários, trabalhadores e gestores no processo de produção de saúde(65).

Ao considerar os pacientes como sujeitos de direitos um dever das instituições de saúde é criar oportunidades de garantia de autonomia, a ampliação da sua capacidade de transformar a realidade em que vivem, direito ao esclarecimento adequado de sua situação de saúde e dos tratamentos disponíveis e opinar sobre seu processo de saúde. O assistente social se faz interlocutor do paciente neste contexto auxiliando a ele, seus familiares e a equipe de saúde neste processo de comunicação e nas inter-relações e mediações necessárias.

O assistente social tem um privilégio de dispor de uma visão ampliada e de um ângulo particular na observação das condições de saúde dos pacientes e uma competência distinta para direcionar o encaminhamento das ações, que o diferencia do médico, do enfermeiro, do nutricionista e dos demais trabalhadores que atuam na saúde(63).

Para facilitar a visualização prática do atendimento do assistente social no contexto hospitalar segue quadro que esquematiza essa atuação:

\section{Atuação do Assistente Serviço Social no Ambiente hospitalar}

\section{Acolhimento hospitalar}

$\checkmark$ Acolhimento e integração do paciente e família ao atendimento no ambiente hospitalar

$\checkmark$ Monitoramento de todo o atendimento até a alta hospitalar visando a continuidade das ações e do cuidado

$\checkmark \quad$ Escuta qualificada e diferenciada

$\checkmark$ Interlocução entre pacientes e familiares, a equipe multidisciplinar e a comunidade, estabelecendo mediações intra e extra equipe

\section{Atuação com Pacientes e Familiares}

Objetivo: Fortalecer vínculos enquanto sujeitos no processo de promoção, proteção, prevenção e recuperação da saúde, identificando a situação vivenciada pelo paciente e sua família com vistas a construir o perfil socioeconômico

$\checkmark$ Conhecimento da estrutura e funcionamento familiar

$\checkmark$ Anamnese social (composição dos membros familiares e posição ocupada pelo paciente dentro da família)

$\checkmark$ Identificação da situação trabalhista, habitacional e previdenciária

$\checkmark$ Verificação da situação trabalhista e previdenciária do paciente e dos membros da família

$\checkmark \quad$ Orientações e encaminhamentos referentes à Comunicado de Acidente de Trabalho (CAT), Auxílio doença, Ảposentadorias e Benefícios sociais instituídos (Benefício de Prestação Continuada e Bolsa Família, etc.)

$\checkmark \quad$ Verificação da disponibilidade da família para receber o paciente de acordo com suas novas necessidades

$\checkmark$ Auxílio na reorganização da família

Atuação com equipe multiprofissional

Objetivo: Atuar como facilitador entre os pacientes, familiares e profissionais frente às questões sociais e culturais que interferem direta ou indiretamente no tratamento

Treinamento do familiar junto com a equipe multidisciplinar 
Avaliação e Acompanhamento do treinamento junto com a equipe multidisciplinar

$\checkmark$ Discussão do momento mais adequado para a alta

$\checkmark$ Reuniões para discussão de casos

$\checkmark$ Participação na gestão das Unidades Funcionais

Definição das necessidades do paciente, de acordo com o grau de dependência, junto com a equipe multidisciplinar para a elaboração do plano de cuidados que o paciente necessitará e identificação dos materiais necessários para a alta

\section{Atuação com a comunidade}

Objetivo: Criar mecanismos e rotinas de ação que facilitem e possibilitem o acesso dos usuários aos serviços:

$\checkmark$ Identificação de instituições ou programas de atendimento que ofereçam suporte ao paciente

$\checkmark$ Auxílio na Transferência para hospitais secundários

$\checkmark \quad$ Identificação da rede de suporte a que o paciente pertence para verificar os recursos disponíveis nesta, de acordo com as necessidades do paciente

$\checkmark \quad$ Encaminhar e vincular o paciente e a família à rede, através de contatos telefônicos, orientações sobre encaminhamentos aos profissionais da equipe multidisciplinar

\section{Atendimentos a situações especiais}

$\checkmark$ Atendimento de familiares em situação de óbito

$\checkmark$ Atendimento de familiares em situação de Morte Encefálica

$\checkmark$ Atendimento de vitimizados

$\checkmark$ Identificação de desconhecidos

Toda a intervenção do assistente social se concretiza por meio de: entrevistas, contatos individuais, reuniões familiares, encaminhamentos, contatos telefônicos, orientações e esclarecimentos, discussão de casos em equipe, visitas multiprofissionais e assessoria social à direção do hospital.

\section{Atuação do Assistente Social em Cuidados Paliativos}

Os pacientes com perfil de cuidados paliativos exigem dos profissionais uma abordagem diferenciada tendo em vista a situação fragilizada complexa do paciente que acarreta em sua trajetória ruptura ou quebra de laços sociais, fragmentação da pessoa e de seus familiares e uma extrema dependência dos serviços de saúde e sociais da rede de atendimento(66).

Partimos do pressuposto que objetivo do atendimento em cuidados paliativos é a elaboração do plano de cuidados de forma personalizada à situação do pacientes e familiares atendidos, dos recursos institucionais internos e externos.

Considerando as principais dificuldades apresentadas para o trabalho de cuidados paliativos no Brasil que são a inclusão dos Cuidados Paliativos na atenção básica, o atestado de óbito em domicílio, a "cesta básica" de medicamentos, que é muito cara e o armazenamento, a distribuição e o 
descarte de remédios opiáceos que aliviam a dor(24), temos na figura do assistente social neste contexto sua extrema importância ao vislumbrar o horizonte destes direitos instituídos pela resolução n 41/2018(33), auxiliando na luta pela conquista destes espaços, condições e recursos necessários.

O serviço social no contexto de atuação em cuidados paliativos, além dos enfoques já destacados dos atendimentos do seu trabalho no ambiente hospitalar, desempenha a função de conhecer a experiência do pacientes e de seus familiares e o significado que atribuem ao processo de adoecimento, para identificar as potencialidades e recursos internos e externos, tendo uma visão complexa e sistêmica que fundamentalmente deve ser em equipe, de forma multiprofissional e interdisciplinar, fundamentado no processo de acolhimento e escuta empática dos pacientes e familiares(66).

Cabe ao assistente social na equipe de trabalho decodificar a realidade socioeconômica e os aspectos culturais, tornando-se o interlocutor entre paciente/família e equipe para se alcançar os objetivos em cuidados paliativos, especialmente uma morte digna e cuidado aos que ficam(67).

Considerando o caráter abrangente de visão do serviço social, na prática profissional com pacientes em cuidados paliativos, se utiliza da ferramenta de avaliação multidimensional para caracterizar as demandas destes em uma abordagem objetiva e subjetiva e considerando o que os pacientes e familiares nos trazem sem pré-julgamentos.

O diagrama multidimensional é um instrumento que considera os aspectos físicos, sociais, espirituais e emocionais e está dividido em quatro quadrantes: aspectos sociais e familiares, aspectos psicológicos, aspectos físicos e aspectos religiosos e espirituais(67).

Consideramos que esta avaliação deve levar em consideração os valores, crenças, experiências prévias, dinâmica e funcionamento familiar, a comunicação intrafamiliar, o ciclo evolutivo da família e as crises concorrentes(66).

O objeto da avaliação multidimensional, como em todo atendimento em cuidados paliativos se valendo de seu conceito, é o alívio do sofrimento com foco na melhoria da qualidade de vida através do manejo integral da unidade de cuidado, que são os pacientes e familiares tendo em vista a elaboração de estratégias de intervenção bio-psico-social e espiritual desenhado em um plano de cuidados(67).

Agregando-se como parte da equipe multiprofissional em cuidados paliativos, pela sua habilidade na escuta qualificada(24), atua ainda numa perspectiva de manutenção de um espaço de comunicação aberto, com caráter educativo da condição de saúde na perspectiva de auxiliar os pacientes e familiares a tendo as informações necessárias de sua condição e do que pode vir a acontecer, prever e planejar os acontecimentos(68). Para tanto sua atuação deve ser de reconhecer e diferenciar as necessidades do paciente, da família e da equipe para auxiliar e propor estratégias de atuação(69).

Ao integrar a equipe caberá ao assistente social conduzir as inter-relações entre usuários que apresentem indicação cuidados paliativos, familiares e demais membros da equipe de saúde, 
potencializando a perspectiva do direito, tendo em vista a qualidade de vida, o respeito às suas crenças e valores e vontades relacionadas ao estabelecimento do plano terapêutico para garantia sua autonomia(70).

No processo de comunicação o assistente social identifica temas que possam veicular na família e como se dá a comunicação entre os seus membros, os desejos do paciente, o grau de entendimento sobre a doença e o como compartilham essas informações(68).

O diagnóstico familiar e social tem o objetivo de avaliar o impacto da situação e traz questões importantes no contexto de cuidados paliativos, fazendo-se necessária outras abordagens como conhecer a situação do paciente e se o evento que levou a categorização do paciente em cuidados paliativos foi de forma crônica ou aguda, conhecer como funciona o processo de tomada de decisão familiar, qual a hipótese que fazem sobre a doença, qual o impacto que a situação causa nos membros da família e no paciente, quais os recursos de enfrentamento e de suporte que estes apresentam e quais as expectativas em relação ao tratamento e quanto ao atendimento da equipe.

Ao atuar na ressignificação da vida dos pacientes e familiares frente a essa situação de limitação e vislumbre do processo de terminalidade, os conflitos preexistentes e as situações não resolvidas vem à tona(69) e os legados familiares tem papel importante de sentido de continuidade para o paciente no significado que estes têm para seus familiares, sendo assim, o assistente social junto com a equipe multiprofissional deve promover espaços e situações que propiciem esse resgate familiar.

A figura e o papel de cuidador apresentam-se como outra demanda para atuação do serviço social, especialmente no que se refere à manutenção dos cuidados, casos de negligência e violência e sua rede de proteção social e na identificação de adoecimento dos cuidadores e a falta de condições físicas e emocionais para oferecer este cuidado.

Uma questão de extrema importância é o impacto emocional que deverá ser levado em consideração na atuação do assistente social, considerando a avaliação psicológica realizada pelo psicólogo da equipe, frente à organização familiar, pois não raro as famílias podem ter todas as condições materiais para receber o paciente no domicílio e continuar os cuidados, no entanto, não tem condições emocionais de assumir esta função, especialmente em casos de terminalidade.

Segue abaixo uma tabela com a sistematização da atuação do assistente social especificamente em cuidados paliativos. Para efeito didático dividimos a atuação de acordo com a principal demanda de atendimento sejam eles, alívio de sintomas, definição de prognóstico e terminalidade. Vale ressaltar que a atuação é dinâmica e por vezes se inter-relaciona nas fases de atendimento apresentadas. 
Atuação do Assistente Serviço Social em Cuidados Paliativos

\section{Pacientes com demanda somente para de Alívio de Sintomas}

$\checkmark$ Diálogo com pacientes e familiares sobre o processo de doença, prognóstico, tratamento

$\checkmark$ Estimulação dos pacientes e familiares sobre as Diretivas Antecipadas de Vontade e Planejamento social e familiar frente ao processo de adoecimento

$\checkmark$ Diagnóstico familiar para verificação da capacidade de cuidado

$\checkmark$ Diagnóstico trabalhista tendo em vista a capacidade funcional do paciente em manter as atividades

$\checkmark$ Orientações e encaminhamentos quanto a benefícios sociais instituídos

$\checkmark$ Mapeamento da rede socioassistencial do paciente

$\checkmark$ Encaminhamentos para a rede de saúde para obtenção de materiais, equipamentos e medicamentos necessários, bem como de serviço de atendimento domiciliar

$\checkmark$ Assessoria à equipe para o processo de alta hospitalar e continuidade de cuidados

$\checkmark$ Planejamento da alta hospitalar ou transferência para hospitais de retaguarda ou secundários

$\checkmark$ Orientação quanto a direitos específicos deste perfil de pacientes

\section{Pacientes com demanda de Prognóstico e Terminalidade}

$\checkmark \quad$ Favorecimento de ambiente para resgate de vínculos

$\checkmark$ Estímulo a ressignificação da vida frente ao processo de adoecimento através de comunicação entre familiares para alinhamento das expectativas

$\checkmark$ Assessoria a equipe no processo de terminalidade intra-hospitalar

$\checkmark$ Facilitação de realização de desejos e repasse de legados familiares

$\checkmark$ Assessoria com equipe no sentido da validação de suas crenças e valores

$\checkmark$ Acolhimento e contenção emocional dos familiares e equipe no processo de terminalidade

$\checkmark$ Liberação e Acompanhamento de visitas hospitalares

$\checkmark$ Orientações quanto a questões funerárias e comunicação de familiares no momento do óbito

$\checkmark$ Viabilização de suporte espiritual e religioso

Sendo assim, a atuação do assistente social neste contexto se faz essencial ao decodificar o social e suas nuances no contexto dos cuidados paliativos, ao contar com ferramentas de trabalho e apresentar o olhar diferenciado para toda a questão de saúde especialmente de limitação de vida e de ressignificação frente aos papéis sociais, considerando os instrumentos de organização familiar e da rede de saúde para viabilização de um atendimento de qualidade, auxiliando na criação de alternativas para que o cuidado se efetive junto às famílias quando possível, através dos recursos sociais, garantia do acesso aos direitos, benefícios e serviços. 


\section{JUSTIFICATIVA}

Considerando-se a necessidade de implantar soluções que auxiliem no gerenciamento do fluxo do SHE, a implantação de uma Equipe de Cuidados Paliativos (ECP) foi uma estratégia adotada na U.E.-HCFMRP-USP. A descrição pormenorizada da adaptação para a realidade brasileira desta estratégia é extremamente oportuna, considerando as modificações sócio epidemiológicas destacadas.

Esta implantação passou por aprimoramentos, frente à limitação de recursos disponíveis e influência da cultura organizacional da instituição. De particular importância foi a modificação da estratégia de triagem dos pacientes elegíveis para a intervenção da ECP, que passou de uma captação nas enfermarias para a SHE, possibilitando a comparação das duas estratégias. 


\section{OBJETIVOS}

1. Descrever o processo de implantação do serviço de cuidados paliativos na U.E.HCFMRP/USP;

2. Comparar a estratégia de intervenção de busca ativa em enfermarias com a estratégia no Serviços Hospitalar de Emergência (Sala de Urgência); 


\section{MÉTODOS}

Para atender ao primeiro objetivo, o estudo envolveu a descrição do desenvolvimento dos processos e do desenho do plano de trabalho da implantação do Serviço de Cuidados Paliativos da U.E.-HCFMRP/USP.

O segundo objetivo demandou a documentação sistematizada de dados demográficos, clínicos, das intervenções da Equipe de Cuidados Paliativos (ECP) e dos desfechos para dois períodos distintos, correspondentes a estratégias de busca ativa de pacientes nas enfermarias comuns e especializadas (Estratégia I) ou no Serviço Hospitalar de Emergência (Estratégia II). Como se tratou da única mudança significativa no processo de trabalho e será motivo de análise individualizada, as estratégias serão descritas em separado.

\section{Implantação da Equipe de Cuidados Paliativos da U.E.-HCFMRP- USP}

A ECP foi formada como uma equipe de atuação consultiva para auxílio nas discussões de caso, a partir da percepção do médico assistente ou de qualquer profissional da equipe de referência e, em alguns momentos, atuando com busca ativa de pacientes como forma educativa para as equipes. Dentro da estrutura da U.E.-HCFMRP/USP não foram destinados leitos específicos para pacientes com demanda de Cuidados Paliativos. A partir da solicitação da equipe de referência por pedido de interconsulta, o paciente era avaliado no leito da especialidade em que ele se encontrava. Outra forma de atendimento foi a busca ativa de pacientes em locais específicos, que se configurou como instrumento importante para mapeamento de demandas. A busca ativa foi o processo pelo qual a ECP se inseriu em visitas multiprofissionais ou discussões de casos para conhecimento dos pacientes e consequente sugestão de avaliação, tendo em vista os critérios de atendimento.

Vale ressaltar que ao longo do processo, com a capacitação e os protocolos de atendimento específicos instituídos, as equipes foram preparadas para o atendimento de demandas dos pacientes em cuidados paliativos, como por exemplo, alívio de sintomas.

A ECP não assumiu a coordenação dos cuidados, servindo como um grupo de suporte que discutia e orientava condutas. Em conjunto com os profissionais da clínica de origem, o paciente e seus familiares, era elaborado um plano de cuidados -APÊNDICE 2 - PLANO DE CUIDADOS UNIDADE DE EMERGÊNCIA (C. PALIATIVOS), tendo em vista a proporcionalidade dos cuidados e tratamentos em relação à atual condição clínica do paciente, visando à qualidade de vida, conforto e dignidade. 
Segue na Figura 1 o fluxograma de atendimento aos pacientes internados na U.E.HCFMRP/USP do HCFMRP/USP, com solicitação para ECP, definido conforme o desenho de trabalho desenvolvido pela equipe de interconsulta, através da metodologia Bizage Modeler:

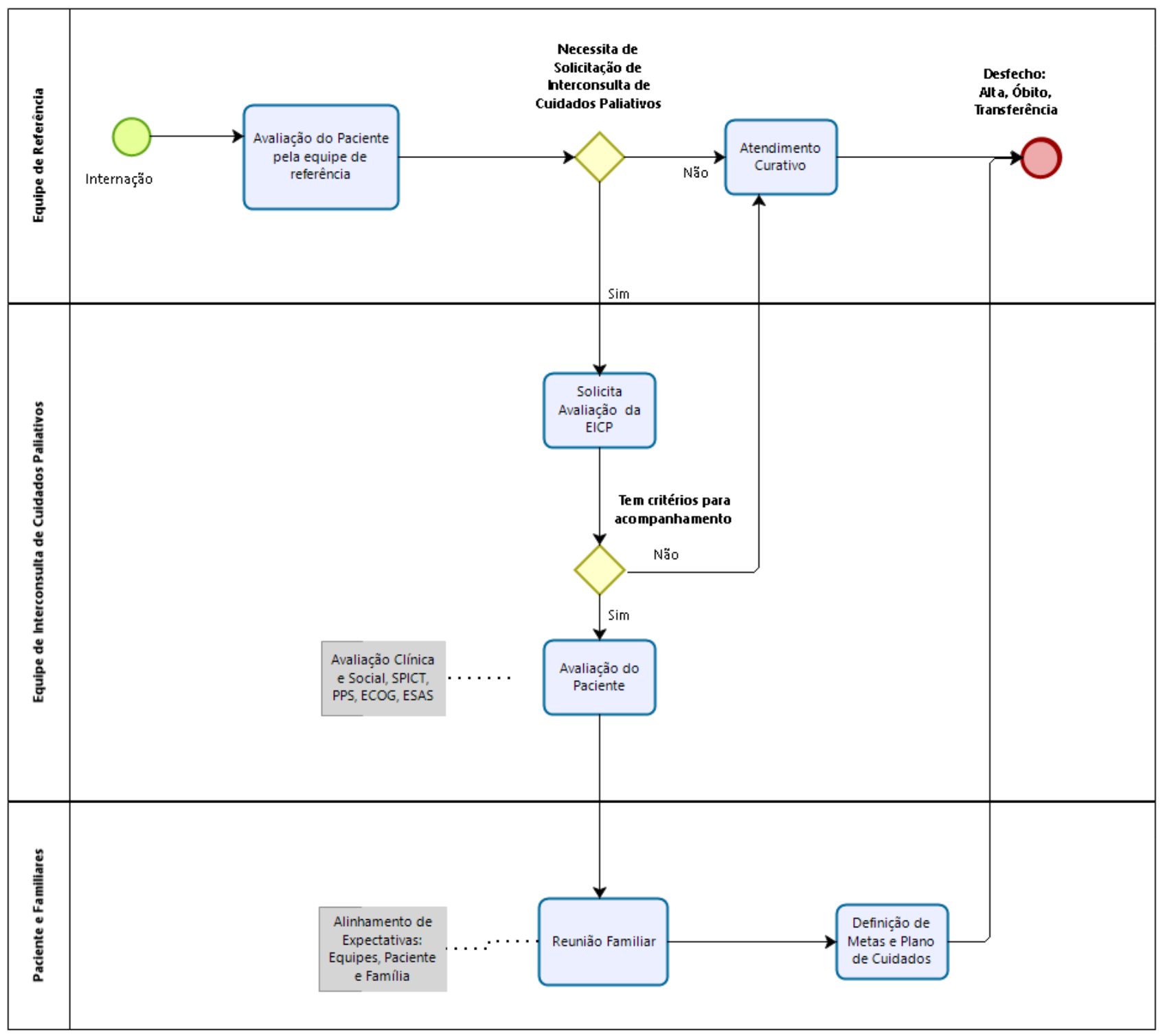

Figura 1-Fluxograma da atuação da Equipe de Cuidados Paliativos da U.E.-HCFMRP-USP SPICT - Supportive and Palliative Care Indicators Tool, PPS - Palliative Performance Scale, ECOG Performance Status, ESAS - Escala de Avaliação de Sintomas. 


\section{Avaliação dos Pacientes}

Os pacientes foram avaliados pela ECP de acordo com os critérios da metodologia Supportive and Palliative Care Indicators Tool (SPICT-BR)(71), sendo uma guia para identificação de pessoas sob o risco de deterioração e em terminalidade, associado com baixa funcionalidade, sendo este parâmetro determinado pela escala Palliative Performance Scale - PPS (72).

A avaliação dos pacientes foi o disparador para o atendimento de demandas de acordo com a finalidade da solicitação, considerando as linhas de ação dos cuidados paliativos.

Segue abaixo uma figura adaptada que correlaciona a fase de impacto da doença em que o paciente se encontra e o tipo de demanda categorizado pela ECP.

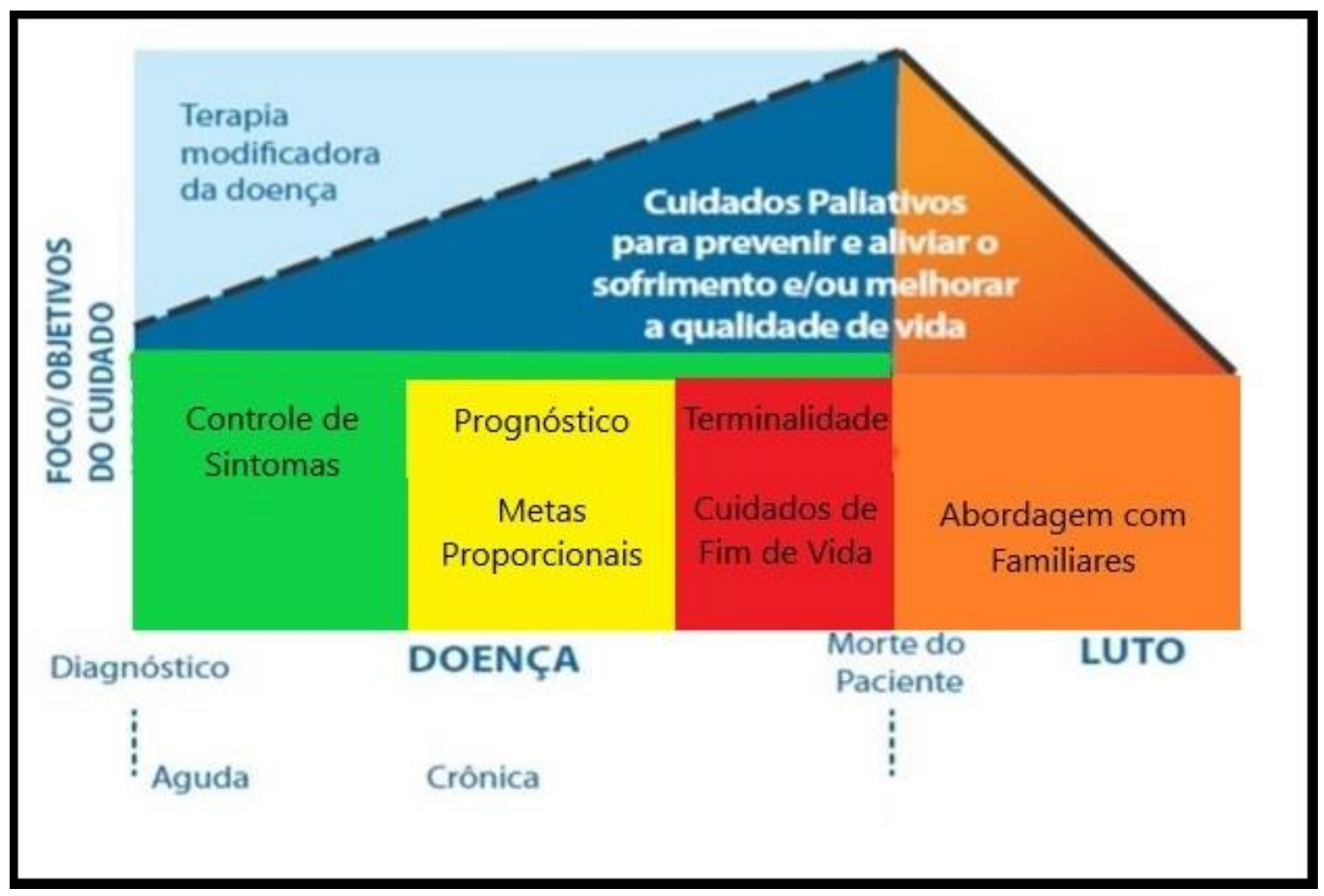

Figura 2 - Fases do Cuidado Paliativo de acordo com o foco do cuidado - adaptado de Azevedo D, Tommaso ABG, Burlá C, Santos G, Dias LM, Py L, et al. Vamos falar de Cuidados Paliativos. SBGG; 2015. 24 p. 3

Para esta categorização, considerou-se principalmente o objetivo do cuidado e do atendimento ao paciente. Alguns pontos, como o controle de sintomas, apesar de alocado na fase em que assume maior demanda, perpassa todas as outras fases. A definição de prognóstico está correlacionada à uma 
fase intermediária do impacto da doença, considerando a validação de medidas proporcionais e a terminalidade é quando se tem definido o prognóstico e o paciente exige cuidados de fim de vida.

Nas Figuras 3 e 4 seguem os quadros com os processos de atendimentos específicos direcionados de acordo com as demandas e suas necessidades.

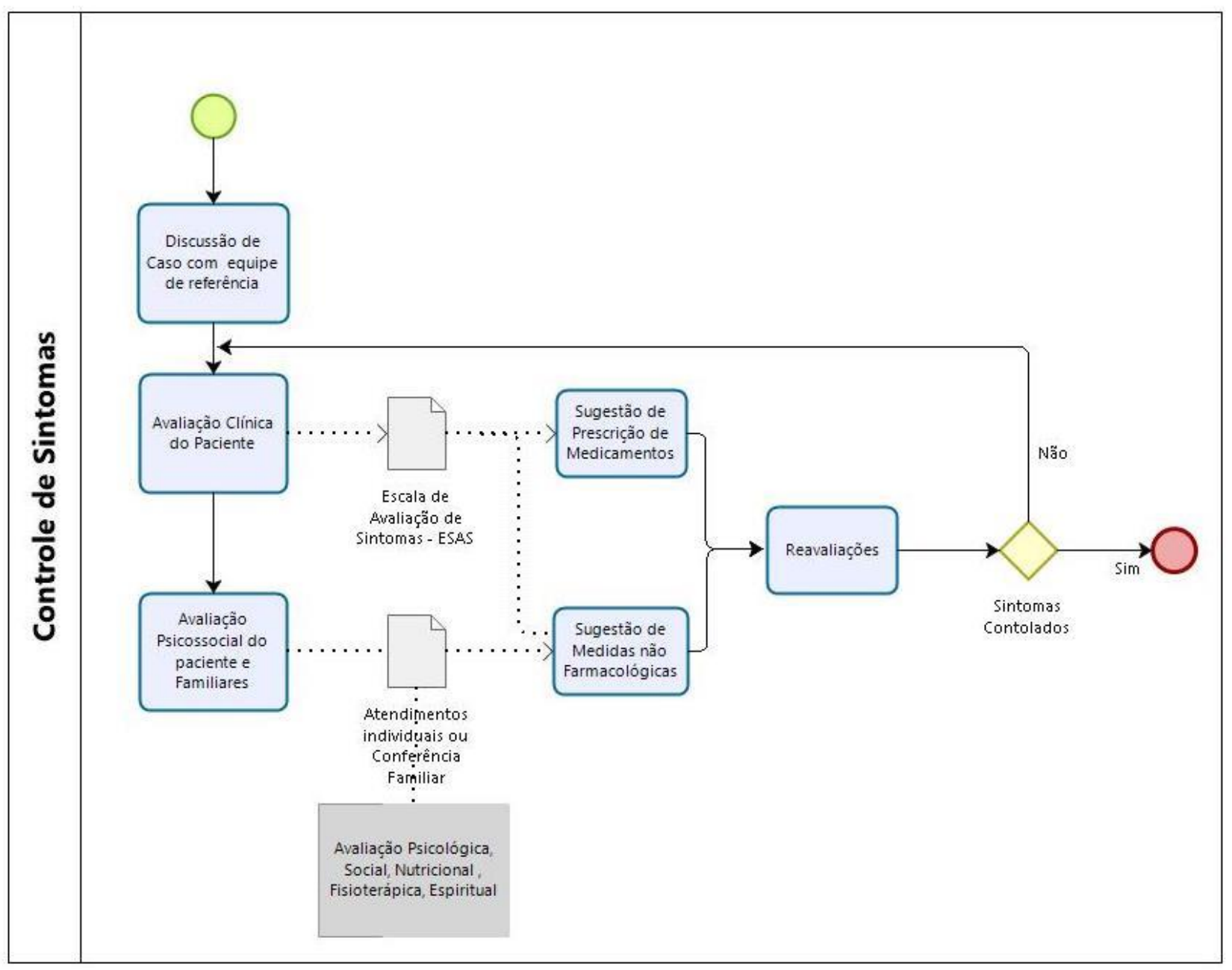

Figura 3 - Fluxograma com foco no Controle de Sintomas da ECP - U.E.-HCFMRP-USP 


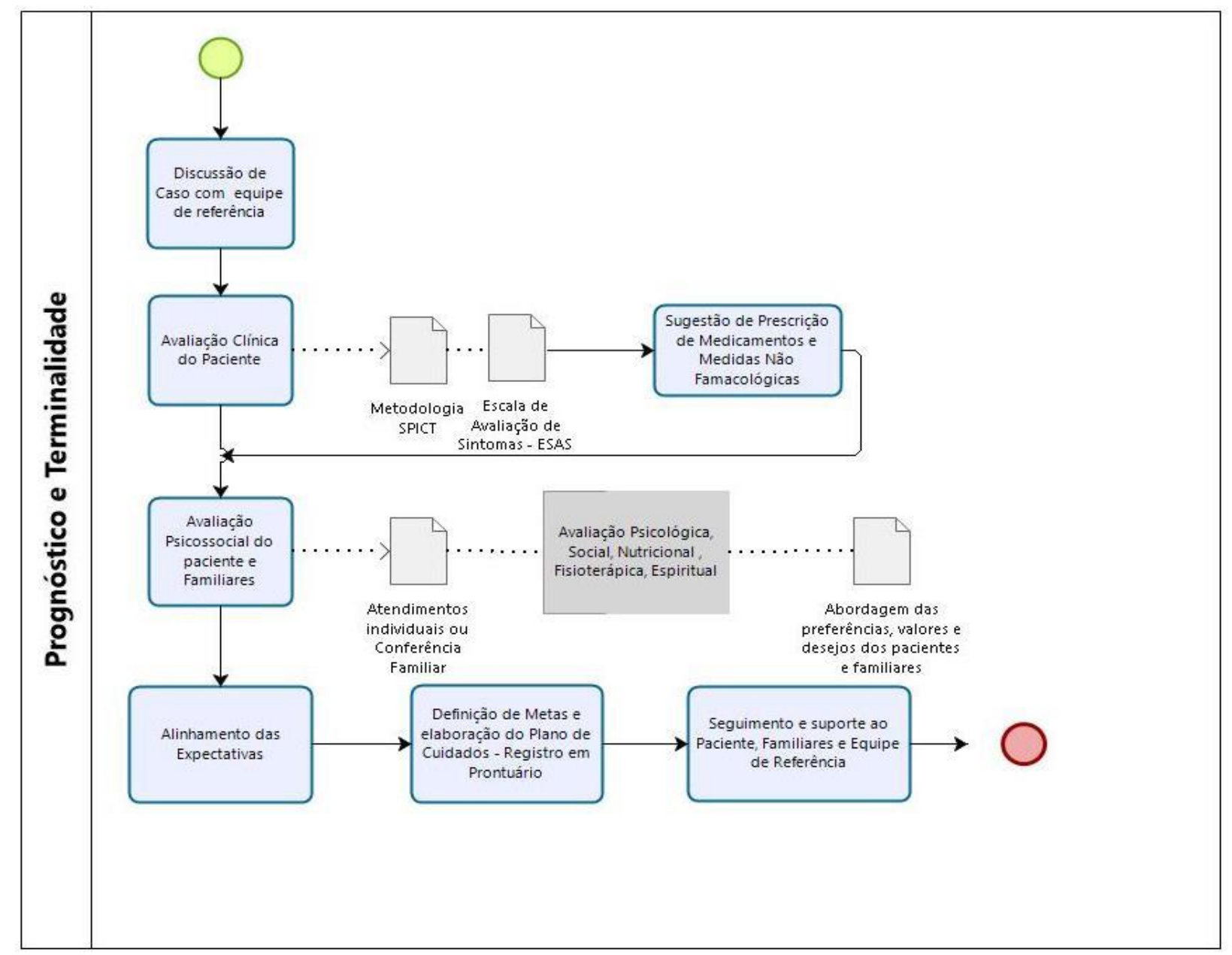

Figura 4 - Fluxograma para Prognóstico e Terminalidade da ECP - U.E.-HCFMRP-USP.

SPICT - Supportive and Palliative Care Indicators Tool, PPS-Palliative Performance Scale, ECOG - Performance Status, ESAS - Escala de Avaliação de Sintomas.

\section{Processo de Comunicação - Conferências Familiares}

Além da avaliação no leito e discussão com a equipe de referência, foi estabelecida como estratégia a realização das conferências familiares, que tem como objetivo ampliar a comunicação e a participação e integração da família durante a internação e nos cuidados do paciente, numa perspectiva de alinhamento das expectativas entre os pacientes e familiares e a ECP.

Nesse processo faz-se necessária a comunicação clara e objetiva como processo fundamental de educação em Cuidados Paliativos, tanto entre equipes quanto entre equipes e familiares(73). A 
comunicação é um dos pilares fundamentais do cuidado paliativo ao lado do atendimento em equipe e alívio de sintomas (74).

Para estas conferências são convocados familiares, sem limitação de número, mais próximos e/ou de referência para o paciente, com o objetivo de alinhar as expectativas de tratamentos e cuidados e da informação ser trabalhada dentro do núcleo familiar e validada entre eles. Além destes, participaram da conferência os profissionais da equipe de referência que estão cuidando do paciente (médico, enfermeiro, técnico de enfermagem, assistente social, e outros) com o objetivo de entender a proposta dos cuidados paliativos dentro do contexto de vida do mesmo, pois podem existir conflitos a serem trabalhados, referente à situação atual do paciente, ou conflitos familiares pré-existentes.

Neste fórum são transmitidas as informações do quadro clínico do paciente. A escuta ativa é a base da comunicação, pois promove o acolhimento respeitoso das dúvidas e expressões de sentimentos dos familiares. A equipe se disponibiliza ao apoio emocional e é proposta e discutida a inserção dos pacientes e familiares nas decisões e cuidados referentes ao paciente. Os valores e as crenças culturais e espirituais do paciente e família são na medida do possível, respeitados. Após estas reuniões e atendimentos individualizados aos pacientes, são elaborados os planos de cuidados levando em consideração a autonomia do paciente, balizada com os conhecimentos técnicos e bioéticos e documentados no prontuário médico do paciente.

\section{Educação Permanente dos profissionais}

A educação permanente das equipes foi realizada pela própria ECP, in loco e em reuniões semanais, abertas a todos os profissionais, alunos e residentes do serviço. Na ocasião, além da apresentação de aulas expositivas e dialogadas, estruturadas por eixos temáticos, casos e condutas foram discutidos, aproveitando o eixo temático da aula. Um tópico fundamental observado nas discussões de casos clínicos e treinamento dos profissionais são questões bioéticas que envolvem o cuidado com o paciente.

Para ampliar e estimular o debate em Bioética, a ECP organizou uma reunião mensal, com a participação de líderes religiosos com experiência em conflitos éticos e um docente da FMRP-USP especializado em Bioética(75). Nessas reuniões, abertas a todos os profissionais da U.E.HCFMRP/USP, foram discutidos casos atendidos e que levantaram questionamentos e dúvidas entre os profissionais acerca de condutas (76), o que colaborou para maior segurança da equipe na implementação de condutas sugeridas pela ECP aos pacientes. 


\section{Trabalho com a Rede de Saúde}

Em 2018 após a Implantação do Serviço de Cuidados Paliativos na U.E.-HCFMRP/USP a através da apresentação desta implantação nos fóruns da DRS XIII, especialmente na Rede de Urgência e Emergência (RUE), os profissionais da ECP juntamente com a diretoria do hospital consideraram a possibilidade de oferecimento de uma capacitação em cuidados paliativos para a rede de saúde, considerando que no contexto dos atendimentos da UE, muitos pacientes atendidos apresentavam demandas de cuidados paliativos que poderiam ser oferecidos no próprio município de origem e em unidades de menor complexidade e mais próximos dos familiares.

A partir de então, a ECP e a diretoria da U.E.-HCFMRP/USP se organizaram e desenharam uma proposta de capacitação para profissionais da RUE em cuidados paliativos. APÊNDICE 3 PROPOSTA DE CAPACITAÇÃO PARA PROFISSIONAIS DA REDE DE URGÊNCIA E EMERGÊNCIA EM CUIDADOS PALIATIVOS.

A proposta foi apresentada através do Centro de Desenvolvimento e Qualificação para o SUS CDQ - Núcleo de Humanização e Educação Permanente da DRS XIII e foi aprovado nos 3 colegiados de Gestão: Aquífero Guarani, Horizonte Verde e Vale das Cachoeiras para utilização da verba para viabilização desta capacitação.

\section{Estratégias de Busca da ECP}

\section{População e amostra}

A proposta foi a avaliação da implantação do serviço de cuidados paliativos na U.E.HCFMRP/USP através do mapeamento das ações clínicas, administrativas e educacionais adotadas para a implantação.

Realizou-se ainda, a análise dos dados quantitativos através de análises estatísticas dos números dos atendimentos dos 3 primeiros anos (2014 a 2017), considerando a Estratégia I - busca ativa nas enfermarias e Estratégia II - busca ativa na Sala de Urgência. Vale ressaltar que a U.E.HCFMRP/USP divide sua estrutura de atendimento entre Sala de Urgência, local destinado à avaliação inicial do paciente, que serve de base de comparação para outros serviços de SHE, e enfermarias, onde os pacientes ficam internados e por dificuldades de transferência para outros serviços e acabam por terminar o tratamento neste local até a alta hospitalar. 
Foram incluídos todos os pacientes acima de 18 anos que deram entrada na U.E.HCFMRP/USP neste período e que foram atendidos pela ECP.

\section{Coleta e Análise dos dados}

A coleta de dados foi realizada desde o início das atividades da implantação e da avaliação dos pacientes através de pedido de interconsulta no sistema ATHOS (HCFMRP/USP) e preenchimento de ficha própria para sistematização dos dados, que foi construída pela ECP para coleta de dados demográficos e clínicos, com escalas de avaliação validadas na literatura para levantamento do perfil dos pacientes. APÊNDICE 1 - LEVANTAMENTO DE PACIENTES POTENCIALMENTE PARA CUIDADOS PALIATIVOS. Os dados foram catalogados em tabela do Microsoft Excel®.

Foram elencados para análise os dados demográficos: idade, sexo, condição clínica e clínica de origem e dados sobre a localização do paciente no hospital (sala de urgência, enfermarias ou Centro de Terapia Intensiva/Unidade Coronariana - CTI/UCO). A sala de urgência do hospital é por onde o paciente entra para atendimento, sendo caracterizada pelo atendimento inicial para definição das demandas de atendimento e encaminhamento para outros setores, as enfermarias são os locais para internação do paciente e o CTI/UCO é local de atendimento para atendimento de pacientes com demandas graves e que necessitam tratamento intensivo.

Os desfechos foram definidos conforme a saída do paciente da U.E.-HCFMRP/USP, sendo eles: alta, óbito ou transferência.

Para avaliação específica em cuidados paliativos foi aplicada a escala Palliative Performance Scale - PPS(72) e a Performance Status do Eastern Cooperative Oncology Group-PS - ECOG(77). Estas escalas demonstram a funcionalidade dos pacientes. A PPS avalia as categorias de deambulação, atividade e evidência da doença, autocuidado, ingesta e nível da consciência dos pacientes de acordo com pontuação de $10 \%$ a $100 \%$, sendo que a pontuação de $10 \%$ é considerada a menor possível, indicando que o paciente tem comprometimento funcional grave. A ECOG é dividida em 5 níveis de avaliação de 0 a 4, sendo classificado no nível 0 o paciente completamente ativo e capaz de realizar todas as atividades sem restrição e no nível 4 paciente completamente incapaz de realizar autocuidados básicos, totalmente confinado ao leito ou à cadeira. 
Com o objetivo de monitorar a implantação do serviço, a ECP criou os indicadores de percepção, seguimento e o total de dias de internação medidos em número de dias. $\mathrm{O}$ indicador de percepção é medido pela diferença entre a data da internação até a data do pedido de interconsulta, demonstrando a sensibilidade da equipe da emergência para perceber o paciente com perfil para avaliação em cuidados paliativos; o de seguimento é a diferença entre a data do pedido de interconsulta e a data do desfecho e pode demonstrar a efetividade da equipe em auxiliar a definição de condutas para o paciente e o de total da internação é a diferença entre a data da internação e a data o desfecho e demonstra o tempo total de internação do paciente.

A partir de 2016, baseado na prática diária da equipe de interconsulta foi sentida a necessidade de categorização da demanda principal que levou a solicitação do atendimento. Foram elencados como categorias de atendimento: controle de sintomas, prognóstico ou terminalidade.

O Controle de sintomas é um dos objetivos do cuidado paliativo e é realizado tendo em vista a experiência do profissional em tratar sintomas que se exacerbam com a evolução da doença, com o objetivo de propiciar conforto ao paciente. Os pacientes desta categoria são pacientes internados em decorrência do agravamento de sintomas da doença.

A categoria de prognóstico foi utilizada para categorizar os pacientes quando a ECP foi chamada para definição do estágio e possibilidade de tratamento da doença ou o conjunto delas e o impacto na proporcionalidade do tratamento curativo e paliativo.

E o processo de terminalidade é caracterizado quando o paciente está em processo iminente de morte, intensificando-se o controle de sintomas, com o objetivo de oferecer ao paciente um processo de morte mais tranquilo e digno.

\section{Métodos Estatísticos}

As variáveis categóricas foram expressas em porcentagem e as variáveis quantitativas em média e desvio padrão, como medidas de tendência central. Nos casos em que se observar distribuição com padrão não-normal, ou caso haja ocorrência de valores distoantes ("outliers") que possam influenciar as medidas de tendência central, utilizou-se a mediana e o intervalo interquartil. Para a comparação das variáveis categóricas, utilizou-se o teste de Fisher para a diferença entre dois grupos e o teste do Qui-Quadrado para a diferença entre vários grupos. 
Para a comparação das variáveis contínuas não-pareadas, foi utilizado o teste $t$ de Student paramétrico ao se comparar dois grupos e análise de variância (ANOVA) para a comparação entre três ou mais grupos, aplicando-se o pós-teste de Bonferroni para múltiplas comparações. A comparação de variáveis contínuas pareadas foi realizada pelos mesmos testes, aplicando-se a correção necessária. Para a correlação entre variáveis contínuas, foi utilizado teste paramétrico de correlação. A comparação entre os grupos para desfechos de tempo para evento foi utilizada análise de sobrevida.

Para análise multivariada, utilizou-se análise multivariada de Cox. Foram construídos modelos incrementais partindo do desfecho e da intervenção (Modelo 1) e foram acrescentadas variáveis que apresentaram significância na análise univariada. $\mathrm{O}$ acréscimo foi realizado em grupos representando demografia, estado clínico e instrumentos de identificação do Grupo de Cuidados Paliativos. A estratégia de modelos incrementais foi utilizada para analisar a possibilidade de colinearidade. Os modelos foram sendo construídos e comparados até o modelo final.

Para todos os testes utilizados, considerou-se significância estatística um valor de $p<0,05$. A análise dos dados e construção dos gráficos apresentados nos resultados será realizada utilizando os programas Excel®, Minitab® e Stata versão 10®.

\section{Aspectos Éticos}

O projeto foi aprovado no Comitê de Ética em Pesquisa do HCFMRP/USP (CAAE: 90562418.5.0000.5440) sob o parecer $n^{\circ}$ 2.689.685. Feita a dispensa do TCLE a fim de seguir todos os passos da RESOLUÇÃO N 466, DE 12 DE DEZEMBRO DE 2012 -CONEP - ANEXO 1. 


\section{RESULTADOS}

\section{Implantação do serviço de cuidados paliativos na U.E.- HCFMRP/USP}

Na fase de implantação, que teve início em fevereiro de 2014 e foi até agosto do mesmo ano, foi montado um grupo de estudos no qual foram realizadas 28 reuniões com estudo bibliográfico e explanações das diferentes categorias profissionais referentes ao tema, enfocando desde o conceito usual de cuidados paliativos, inserção de cada profissional no contexto de trabalho em cuidados paliativos, incluindo aspectos éticos e legais apresentados por profissionais especialistas na área. De acordo com as reflexões do grupo de estudos, surgiu a necessidade de alguns profissionais conhecerem outros serviços de cuidados paliativos, sendo realizada visita ao Hospital Estadual de Américo Brasiliense, onde a equipe se reuniu com a equipe de atendimento da ala de cuidados paliativos.

Em julho de 2014, decidiu-se por iniciar um rastreamento de possíveis pacientes elegíveis para cuidados paliativos na enfermaria de clínica médica através da realização de uma visita multiprofissional. O grupo evidenciou a necessidade da elaboração e adoção um instrumento de avaliação multiprofissional para aplicação nestes pacientes - APÊNDICE 2 - PLANO DE CUIDADOS - UNIDADE DE EMERGÊNCIA (C. PALIATIVOS). Em agosto de 2014 formou-se o primeiro grupo de interconsulta multiprofissional, no qual junto com a Coordenadoria da U.E.HCFMRP/USP, foi elaborado um documento com as diretrizes de atendimento através de solicitação por pedido de interconsulta - APÊNDICE 8 - OFÍCIO CIRCULAR 02/2014 - IMPLANTAÇÃO DE INTERCONSULTA DA EQUIPE DE CUIDADOS PALIATIVOS. Em setembro de 2014, em resposta a identificação de casos, a coordenadoria desta instituição propôs a contratação de um profissional médico para assessorar o início e formação da equipe com um projeto de implantação(78). Em dezembro deste mesmo ano os primeiros dados foram apresentados, o que validou a necessidade de formação oficial da equipe e contratação de profissional médico especialista na área exclusivo. A partir de abril de 2015, com a incorporação de um médico com formação em Cuidados Paliativos, voltado exclusivamente para o atendimento deste perfil de pacientes, o Serviço de Cuidados Paliativos expandiu sua atuação e consolidou-se até os dias atuais como prática diária. Além disso, foi detectada pela instituição a necessidade de realização uma aula de sensibilização para todos os colaboradores da U.E.-HCFMRP/USP para difusão dos conceitos de cuidados paliativos 
institucionalmente, onde foram incluídos em torno de 250 colaboradores através da organização do processo pela Educação Permanente da unidade.

As ações do grupo geraram altas demandas por formas de organização do serviço institucional, que culminaram na criação e implantação de protocolos diretamente ligados à assistência paliativista, como o protocolo sedação paliativa - APÊNDICE 4 - PROTOCOLO DE SEDAÇÃO PALIATIVA e de infusão de medicações e soluções por hipodermóclise- APÊNDICE 5 - PROTOCOLO DE INFUSÃO DE MEDICAÇÕES E SOLUÇÕES POR HIPODERMÓCLISE e elaboração de um folder de perguntas e respostas sobre os conceitos básicos de cuidados paliativos tanto para abordagem das equipes, como para instrumentalização junto aos pacientes e familiares- APÊNDICE 6 - FOLDER DE ORIENTAÇÃO - EQUIPE DE CUIDADOS PALIATIVOS. A partir do protocolo de hipodermóclise, uma nova necessidade foi evidenciada: a prescrição eletrônica da via medicamentosa "hipodermóclise", iniciada no sistema de prescrição eletrônica de todo complexo do HCRP, a partir de janeiro de 2016. Essas ações institucionais solidificaram os Cuidados Paliativos como parte da política assistencial do HCFMRP-USP.

A síntese do histórico da implantação está ilustrada na Tabela 1.

Tabela 1 - Histórico da Implantação do Serviço de Interconsulta da Equipe de Cuidados Paliativos da U.E. - HCFMRP-USP

Data

Etapas desenvolvidas

\begin{tabular}{llll}
\hline 2008 - Inquietação & $\checkmark$ & Reconhecimento da demanda \\
& $\checkmark$ & $1^{\circ}$ Contato da Equipe Multiprofissional com a filosofia de Cuidados Paliativos \\
2013 - Grupo de Estudos & $\checkmark$ & Estudos informais e visitas a serviços de referência \\
& $\checkmark$ & Apoio Coordenadoria da UE \\
& $\checkmark$ & Formalização do Grupo de Estudos \\
2013 - Grupo de & $\checkmark$ & Convite a profissionais especialistas \\
Interconsulta Informal & $\checkmark$ & Levantamento de demanda de pacientes \\
& $\checkmark$ & Visita Multiprofissional e Discussão dos Casos \\
2014 - Oficialização do & $\checkmark$ & Projeto de implantação - Definição de Critérios de Elegibilidade \\
Início do Processo de & & & \\
Implantação do Serviço & $\checkmark$ & Consultoria Com Médico Paliativista \\
& $\checkmark$ & Aulas Teóricas - inserção de conceitos paliativos na Urgência \\
& $\checkmark$ & Busca Ativa - visitas em locais específicos \\
2015 - Formalização da & $\checkmark$ & Monitoramento dos dados \\
Equipe de Interconsulta & $\checkmark$ & Contratação de Profissionais Exclusivos \\
e Capacitação & $\checkmark$ & Equipe formada por: médico, psicólogo, assistente social e terapeuta ocupacional \\
& $\checkmark$ & Capacitação de 4 profissionais - Instituto Pallium \\
& $\checkmark$ & Formação do Grupo de Bioética - discussão de princípios legais, religiosos e \\
& & bioéticos \\
& $\checkmark$ & Aulas multiprofissionais semanais para as equipes \\
& $\checkmark$ & Seminários com residentes médicos: conceitos básicos aplicados a caso clínico \\
& & & Simpósio Hospital Estadual de Ribeirão Preto \\
& &
\end{tabular}




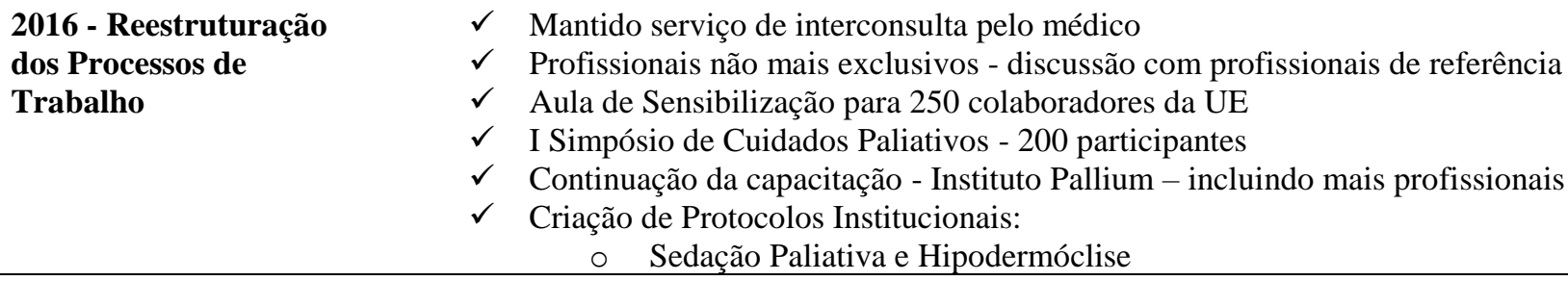

\section{Cuidados Paliativos - Rede de Urgência e Emergência da DRS XIII}

Como produto da capacitação com os profissionais da rede foram elaborados 20 projetos de intervenção, conforme demonstrado na Tabela 2, com o intuito de colaborar com a interrelação dos conceitos paliativos aplicados à cada realidade local.

Através deste processo foi criada uma rede de discussão através de aplicativo de celular, para discussão e troca de experiências e aprofundamento no assunto e a interlocução dos profissionais da rede de saúde como um todo, com o objetivo de facilitando os processos de referência e contra referência dos pacientes com este perfil.

Através do oferecimento da capacitação para os profissionais das unidades básicas, pronto atendimentos e hospitais secundários foi possível a interrelação com a rede de saúde e discussão de proposta de atendimentos para pacientes em cuidados paliativos. 
Tabela 2 - Projetos da Capacitação da Rede de Urgência e Emergência em Cuidados Paliativos da

Divisão Regional de Saúde - DRS XIII

\section{Colegiado de Gestão Regional - Vale das Cachoeiras - 7 Projetos}

\begin{tabular}{l|cc}
\hline Cajuru & $\checkmark$ & $\begin{array}{c}\text { "Educação para a morte: um projeto pedagógico/filosófico para a sensibilização de alunos do } \\
\text { ensino médio sobre a Finitude, a Impermanência, a Morte e o Morrer". }\end{array}$ \\
& $\checkmark$ & "A importância da família e da equipe de saúde para o paciente em fase final". \\
\hline Batatais & $\checkmark$ & "Equipe de Cuidados Paliativos". \\
& $\checkmark$ & "Projeto de Intervenção Interdisciplinar em Cuidados Paliativos da Unidade de Cuidados \\
Brodowski & $\checkmark$ & "Humanização e Cuidados Paliativos". \\
\hline Santa Cruz da & $\checkmark$ & "Implantação de Cuidado Paliativo na Atenção Básica no Município de Santa Cruz da \\
Esperança & esperança". \\
\hline
\end{tabular}

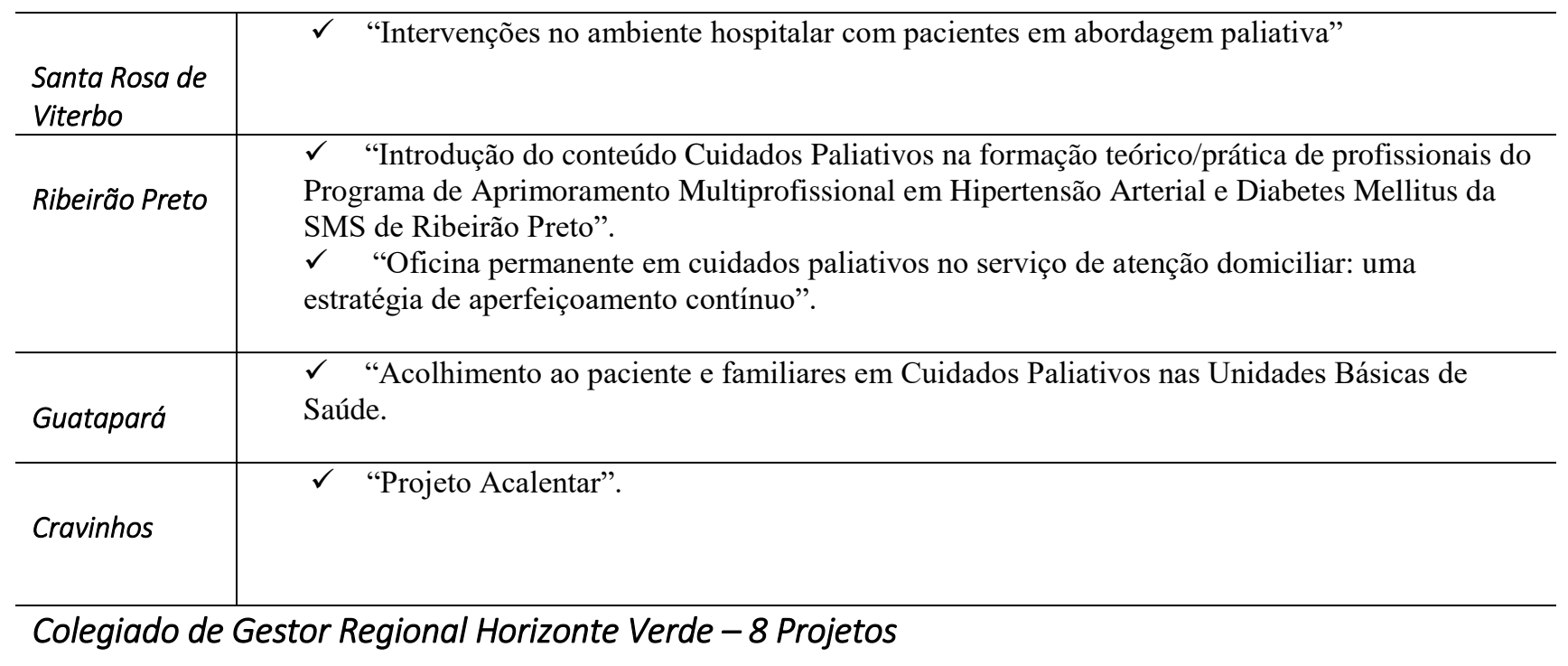

\begin{tabular}{|c|c|}
\hline Pitangueiras & $\checkmark \quad$ “Acolhimento das Famílias de Pacientes em Tratamento Paliativo". \\
\hline Sertãozinho & $\begin{array}{l}\checkmark \quad \text { "Cuidados Paliativos no Serviço de Atenção Domiciliar de Sertãozinho: uma questão de } \\
\text { humanidade". }\end{array}$ \\
\hline Guariba & $\begin{array}{l}\checkmark \quad \text { "O papel da equipe multiprofissional para pacientes inclusos no Serviço de Longa } \\
\text { Permanência na Santa Casa De Guariba }\end{array}$ \\
\hline Pontal & $\begin{array}{l}\checkmark \quad \text { "Habilidades de Comunicação em apoio emocional e espiritual". } \\
\checkmark \quad \text { "Cuidados Paliativos: o cuidado holístico além da cura, uma abordagem multidimensional } \\
\text { frente às necessidades humanas". }\end{array}$ \\
\hline Monte Alto & $\begin{array}{l}\checkmark \quad \text { "Capacitação em cuidados paliativos no setor de urgência e emergência com extensão para } \\
\text { atenção básica e hospitalar". }\end{array}$ \\
\hline Pradópolis & $\checkmark \quad$ "Instituir Equipe de Cuidados Paliativos no Município de Pradópolis" \\
\hline Jaboticabal & $\checkmark \quad$ "Cuidados Paliativos: Assistência Integrada". \\
\hline
\end{tabular}




\section{Perfil dos pacientes atendidos}

Foram incluídos no estudo 587 (48,8\%) pacientes na Estratégia I e 616 (51,2\%) pacientes na Estratégia II, somando um total de 1203 pacientes. Os dados estão sumarizados na Tabela 3. Observamos tanto na Estratégia I como na II a prevalência do sexo masculino com mediana de idade em 64,7 anos na I e 66,2 na II, com desvio padrão de 16,4 anos e 16,2 anos respectivamente.

Quando observamos as clínicas de origem do paciente vemos que a clínica médica representa a mais prevalente com 39,3\% na I e 57,9\% na II e obteve aumento em torno de $18 \%$ no seu percentual. No entanto, com a mudança na seleção dos pacientes da I a II vimos que o CTI teve queda na representatividade de $20,4 \%$ para $7,6 \%$, enquanto que a cirurgia e a ginecologia praticamente mantiveram o percentual de atendimento na cirurgia representou na I 10,7\% e na II 10,5, a ginecologia representou $4,6 \%$ na I e $3,9 \%$ na II.

Quanto às condições clínicas, a prevalência foi das clínicas gerais tanto na I $(42,7 \%)$ como na II (40,2\%), logo abaixo temos a Oncologia na I com 27,7\% com ligeiro aumento de aproximadamente $5 \%$ na II com $32,4 \%$ ). Após temos o AVC com $24 \%$ na I e com queda de 5\% para a II com 19,8\%, sendo que a categoria outros permanece bem próxima nas duas Estratégias I $(5,4 \%)$ e II $(19,8 \%)$

Houve redução no CTI/UCO da I (20,9\%) para II $(9,2 \%)$, queda na enfermaria da I $(60,8 \%)$ para a II $(42,5 \%)$ e aumento significativo da I $(18,2 \%)$ para a II $(48,2 \%)$ na sala de urgência.

Tabela 3 - Caracterização demográfica e clínica dos pacientes atendidos pela Equipe de Cuidados Paliativos da U.E.-HCFMRP/USP de acordo com a Estratégia de Identificação dos pacientes.

\begin{tabular}{lrrr} 
& ESTRATÉGIA I - 587 (48,8\%) & ESTRATÉGIA II - $\mathbf{6 1 6} \mathbf{( 5 1 , 2 \% )}$ & P \\
\hline Gênero Masculino (\%) & $321(54,7)$ & $348(56,5)$ & 0,528 \\
Idade em anos (desvio padrão) & $64,7(16,4)$ & $66,2(16,2)$ & 0,808 \\
Clínica de Origem (\%) & & & $<0,01$ \\
Cirurgia & $63(10,7)$ & $65(10,5)$ & \\
Clínica Médica & $231(39,3)$ & $375(57,9)$ & \\
Neurologia & $146(24,8)$ & $123(19,9)$ & \\
CTI & $120(20,4)$ & $24(7,6)$ & \\
Ginecologia/Obstetrícia & $27(4,6)$ & & $<0,01$ \\
CTI/UCO & & $57(9,2)$ & \\
Enfermaria & $123(20,9)$ & $262(42,5)$ & \\
Sala de Urgência & $357(60,8)$ & $297(48,2)$ & \\
Local de Atendimento (\%) & $107(18,2)$ & & 0,07 \\
Clínicas Gerais & & $248(40,2)$ & \\
Oncologia & $251(42,7)$ & $200(32,4)$ & \\
AVC & $163(27,7)$ & $122(19,8)$ & \\
Outros & $141(24,0)$ & $46(7,4)$ & \\
\hline
\end{tabular}


No desfecho, conforme Tabela 4, o percentual de óbitos praticamente não foi alterado apresentando 48,4\% na Estratégia I e 50,6 na Estratégia II, não tendo alteração significativa também do percentual dos óbitos intra ou extra-hospitalar. No percentual de altas houve uma ligeira queda de $29,6 \%$ para $25,3 \%$ e aumento de $2 \%$ das transferências.

Tabela 4 - Caracterização dos desfechos dos pacientes atendidos pela Equipe de Cuidados Paliativos da U.E.-HCFMRP/USP de acordo com a Estratégia de Identificação dos pacientes.

\begin{tabular}{|c|c|c|c|}
\hline & $\begin{array}{c}\text { ESTRATÉGIA I - } 587 \\
(48,8 \%)\end{array}$ & $\begin{array}{c}\text { ESTRATÉGIA II - } 616 \\
(51,2 \%)\end{array}$ & $\mathbf{p}$ \\
\hline Desfecho (\%) & & & 0,234 \\
\hline Alta & $174(29,6)$ & $156(25,3)$ & \\
\hline Transferência & $129(22,0)$ & $148(24,0)$ & \\
\hline Óbito & $284(48,4)$ & $312(50,6)$ & \\
\hline Óbito (\%) & & & 0,521 \\
\hline Intra-Hospitalar & $284(68,2)$ & $312(66,2)$ & \\
\hline Extra-Hospitalar & $132(31,7)$ & $159(33,7)$ & \\
\hline
\end{tabular}

Quando observamos os indicadores apresentados na Tabela 5 vimos que: a percepção iniciou em 10,9 dias e reduziu para 9,1 dias, o de seguimento no início era de 12,7 dias e se manteve em 12,3 dias, no entanto, a duração da internação que era de 24,3 dias e baixou para 20,7 dias, havendo uma queda de $15 \%$ na duração da internação. Excluindo os pacientes que foram a óbito também houve redução em todos os indicadores. Considerando a exclusão dos outliers, conforme demonstra a Figura 5 no Box Plot, todos os indicadores apresentaram queda na diferença entre as estratégias.

Os atendimentos foram distribuídos de acordo com o objetivo do atendimento e foram agrupados pelas categorias de controle de sintomas, definição de prognóstico e atendimento na terminalidade. A função de definição de prognóstico correspondeu ao maior número dos atendimentos somando $56,7 \%$, os atendimentos para acompanhamento da terminalidade $26 \%$ e para controle de sintomas $17,3 \%$.

Para classificar a dependência funcional foi utilizada a escala Palliative Performance ScalePPS e a grande maioria dos pacientes apresentavam na internação o PPS de 10 igualmente nas duas estratégias, representando 77,3 na I e 70,1 na II, o que demonstra comprometimento funcional grave dos pacientes com total dependência para as atividades de vida diária, havendo um ligeiro aumento de 5\% nos PPS acima de 40 na Estratégia II. Outra escala utilizada foi o ECOG Performance Status e a grande maioria dos pacientes, $89,9 \%$ e 85,9, apresentaram ECOG 4, demonstrando a gravidade dos pacientes atendidos, considerando estes como pacientes completamente incapazes de realizar auto-cuidados básicos, totalmente confinados ao leito ou à cadeira. 
Apesar de regulado, o acesso à U.E.-HCFMRP-USP de pacientes que já estiveram internados é praticamente uma regra do complexo regulador, principalmente se ocorre precocemente após a alta hospitalar. Ao se realizar a transição para a Estratégia II, observou-se incremento do número de retornos dos pacientes incluídos de 10,9\% para 20,7\% (p<0,01).

Tabela 5 - Caracterização dos indicadores da Equipe de Cuidados Paliativos da U.E.HCFMRP/USP de acordo com a Estratégia de Identificação dos pacientes.

\begin{tabular}{|c|c|c|c|c|}
\hline & & ESTRATÉGIA I - 587 (48,8\%) & ESTRATÉGIA II - 616 (51,2\%) & $\mathbf{p}$ \\
\hline \multicolumn{5}{|c|}{ Percepção } \\
\hline & Total & $10,9(19,8)$ & $9,1(17,5)$ & $<0,01$ \\
\hline & $\begin{array}{l}\text { Excluindo óbito } \\
\text { intra }\end{array}$ & $11,5(24,8)$ & $8,3(16,8)$ & $<0,01$ \\
\hline \multicolumn{5}{|c|}{ Seguimento } \\
\hline & Total & $12,7(14,7)$ & $12,3(27,5)$ & $<0,01$ \\
\hline & $\begin{array}{l}\text { Excluindo óbito } \\
\text { intra }\end{array}$ & $9,7(12,5)$ & $7,8(13,3)$ & 0,289 \\
\hline \multicolumn{5}{|c|}{ Duração da Internação } \\
\hline & Total & $24,3(30,4)$ & $20,7(37,1)$ & $<0,01$ \\
\hline & $\begin{array}{l}\text { Excluindo óbito } \\
\text { intra }\end{array}$ & $20,0(19,9)$ & $17,6(24,1)$ & $<0,01$ \\
\hline PPS & & & & $<0,01$ \\
\hline & 10 & $454(77,3)$ & $432(70,1)$ & \\
\hline & 20 a 30 & $83(14,1)$ & $99(16,0)$ & \\
\hline & $>40$ & $50(8,5)$ & $85(13,8)$ & \\
\hline$E C O G=4$ & & $528(89,9)$ & $529(85,9)$ & 0,03 \\
\hline \multicolumn{5}{|c|}{$\begin{array}{l}\text { Regresso à U.E. após alta para } \\
\text { nova consulta }\end{array}$} \\
\hline & $>1$ & $64(10,9)$ & $128(20,7)$ & 0,01 \\
\hline \multicolumn{5}{|l|}{ Demanda } \\
\hline & Sintomas & & $106(17,3)$ & \\
\hline & Prognóstico & & $347(56,7)$ & \\
\hline & Terminalidade & & $159(26,0)$ & \\
\hline
\end{tabular}

1-Percepção: índice em dias que representa a diferença entre a data da internação e a data do atendimento da ECP. 2-Seguimento: índice em dias que representa a diferença entre a data do atendimento da ECP e a data do desfecho.

3-Total Internação: índice em que representa a diferença entre a data da internação e a data do desfecho. 


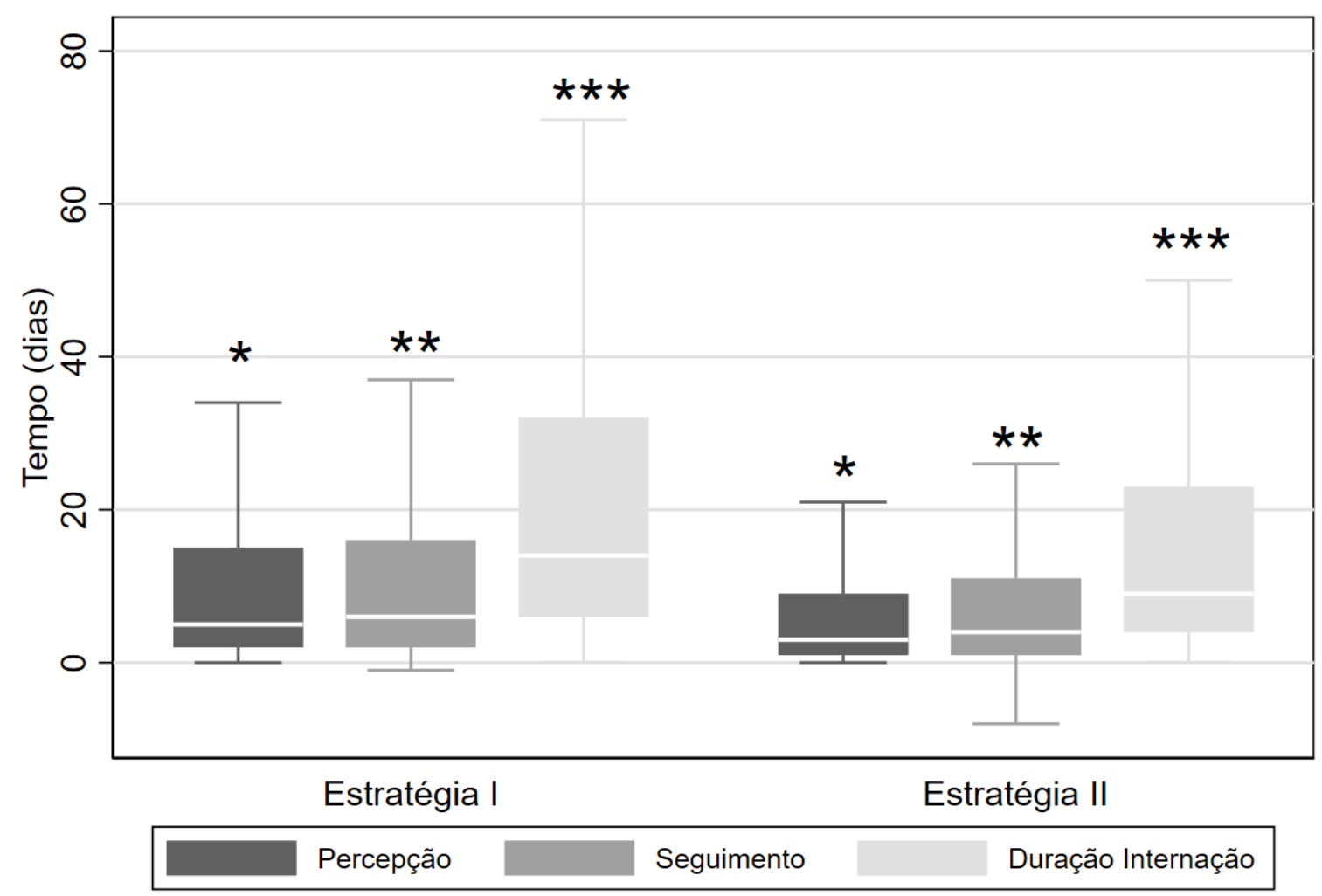

Nota - Excluído valores "outliers"

Figura 5 - Box Plot dos Indicadores da ECP da U.E.-HCFMRP-USP de acordo com a Estratégia de Identificação dos pacientes.

(*) Comparação do indicador de Percepção entre as Estratégias I e II - p<0,01.

(**) Comparação do indicador de Seguimento entre as Estratégias I e II - p<0,05.

(***) Comparação da Duração da Internação entre as Estratégias I e II - p<0,01.

A Figura 6 apresenta a curva de sobrevida de Kaplan-Meier em dias para a mortalidade intrahospitalar e após a alta, comparando as Estratégias I e II. Um primeiro fato a ser constatado é que independentemente da Estratégia adotada, a mortalidade de 60 a 100 dias destes pacientes é elevada, sendo que apenas $20 \%$ dos pacientes hospitalizados permaneciam vivos ao final de 100 dias e cerca de $25 \%$ ao final de 60 dias após a alta.

Para a mortalidade intra-hospitalar, observou-se diferença significativa na sobrevida dos pacientes, sendo que 50\% dos pacientes permaneciam vivos com 35 dias de internação, enquanto que para a Estratégia II este número reduziu para 20 dias de internação (LogRank <0,01). Quanto à mortalidade pós-alta hospitalar, na Estratégia II 50\% dos pacientes faleceram após 10 dias da alta hospitalar, enquanto na Estratégia I, este número foi de 40 dias (LogRank < 0,01). 


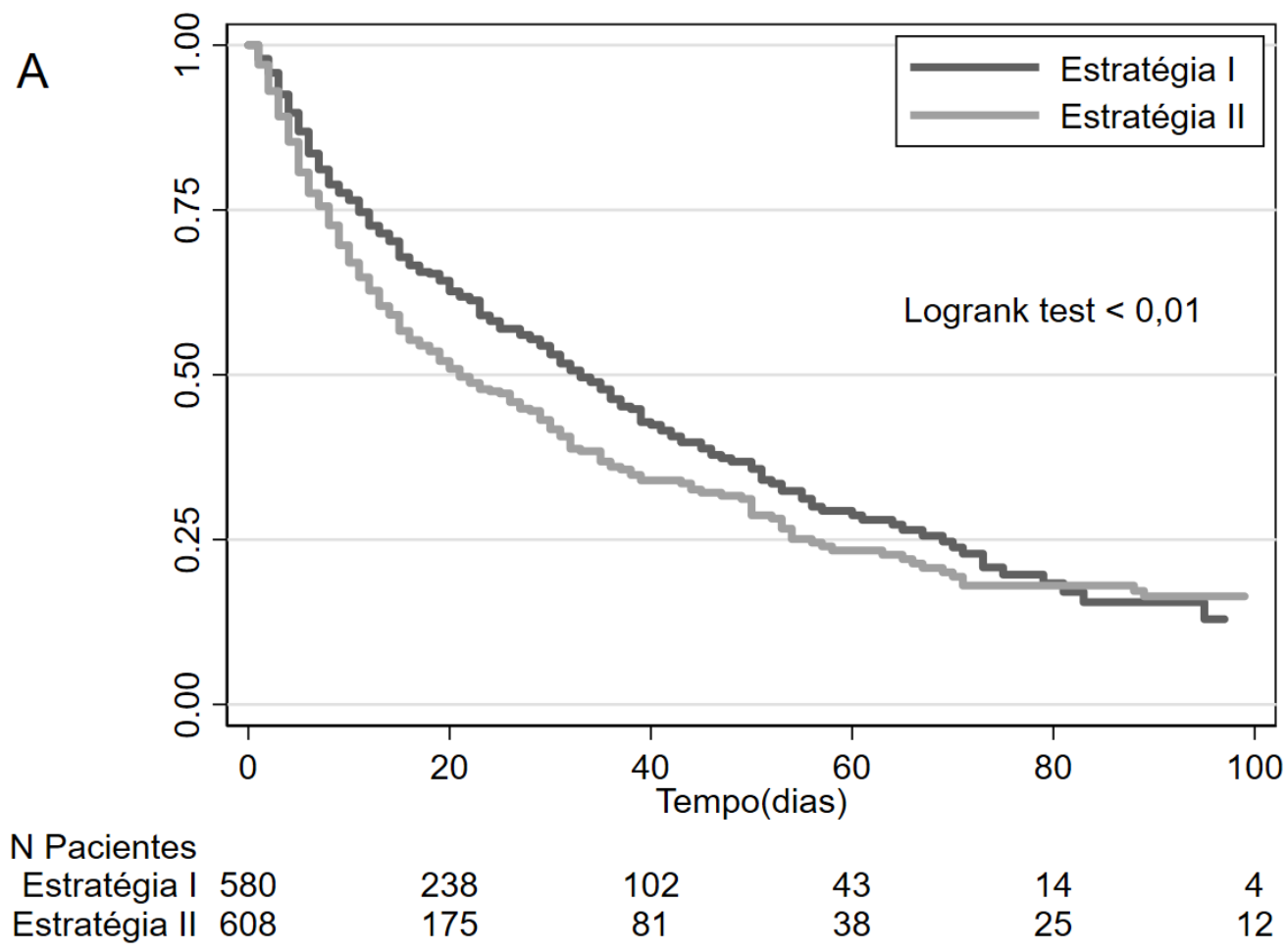

B

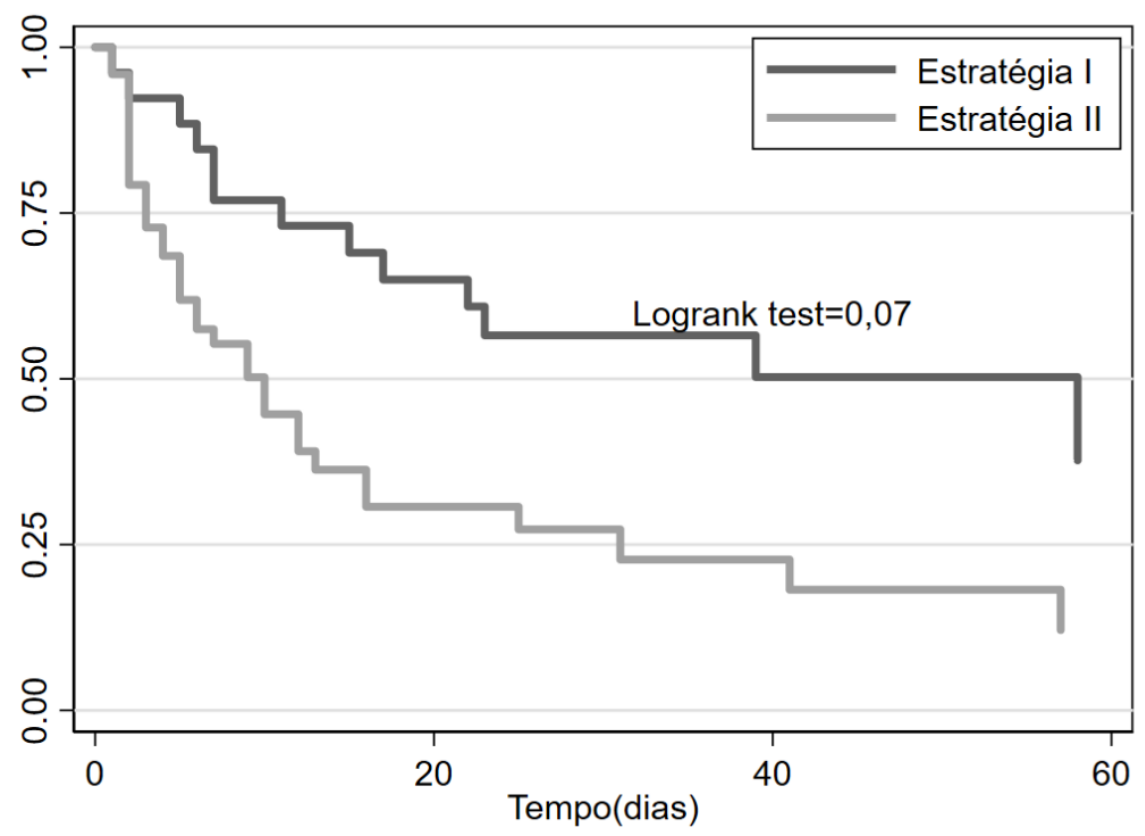

N Pacientes

$\begin{array}{ccccc}\text { Estratégia I } & 26 & 16 & 8 & 3 \\ \text { Estratégia II } & 49 & 11 & 5 & 2\end{array}$

Figura 6 - Curva de Sobrevida de Kaplan Meyer para os pacientes avaliados pela ECP da U.E.HCRMFP-USP de acordo com Estratégia de Identificação dos pacientes. A - Mortalidade intrahospitalar; B-Mortalidade após alta hospitalar.

Ao observarmos um modelo de regressão multivariada de Cox para ajustar o impacto da Estratégia de Identificação dos Pacientes, quando observamos o risco de óbito (Figura 7) e ajustamos 
para os fatores de confusão, vemos que a condição clínica oncológica têm a maior impacto para o risco de óbito, seguidos pelas clínicas gerais, no entanto, para a condição oncológica o risco é maior do que para as outras condições clínicas. Vemos ainda, que a Estratégia, idade e percepção também impactam significativamente para este risco. Por outro lado, vemos que o PPS tem efeito inverso, apresentando menor impacto.

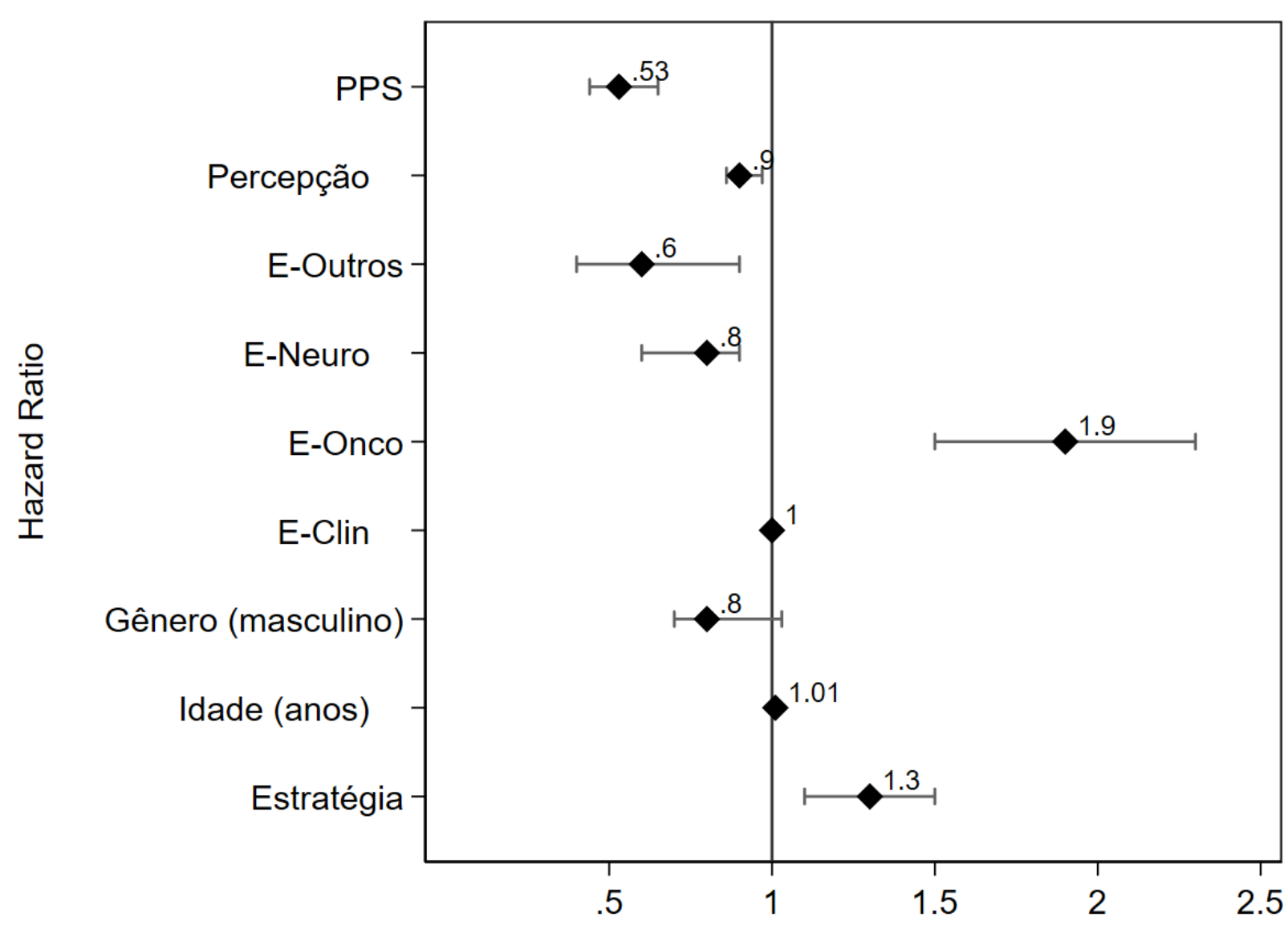

Figura 7 - Hazzard Ratios e intervalo de confiança 95\% para os fatores de confusão incluídos na versão final do modelo de regressão de Cox para ajustar o impacto da Estratégia de Identificação dos pacientes. 
Tabela 6 - Associação entre a Demanda e o Desfecho

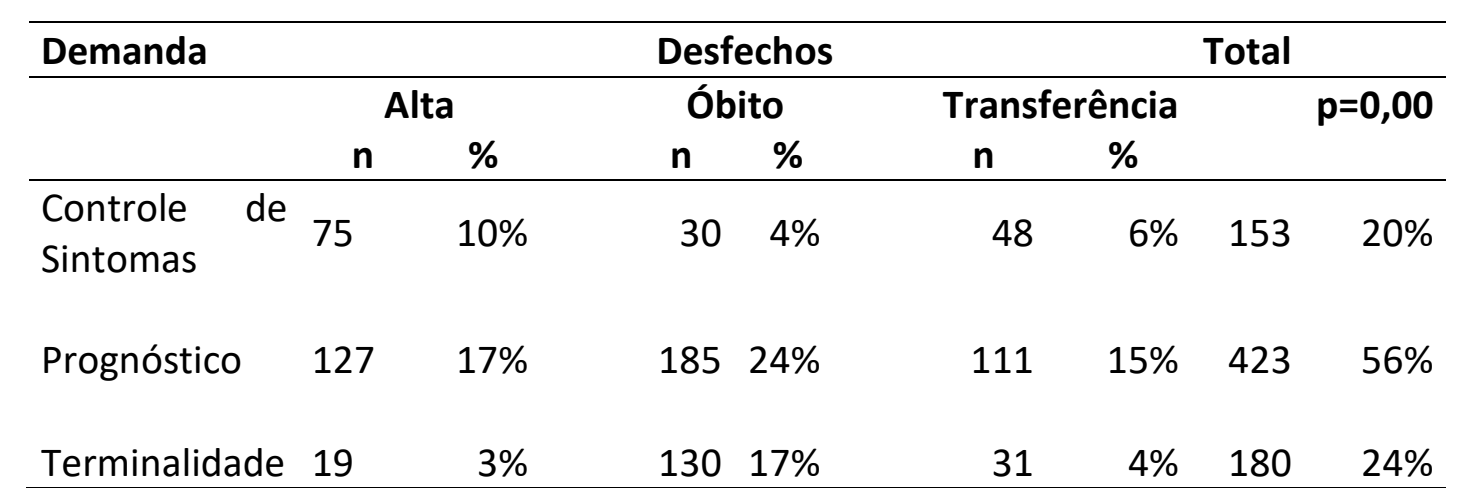

De acordo com os dados de demanda e desfecho da Estratégia II podemos observar que existe associação. Para o controle de sintomas (20\%) o desfecho prevalente foi a alta (10\%), para a definição de prognóstico (56\%) foi o óbito (24\%), e para o seguimento na terminalidade (24\%) também foi o óbito (17\%), demonstrando que para as de demanda de prognóstico e terminalidade a maioria dos pacientes tiveram como desfecho o óbito. 


\section{DISCUSSÃO}

O presente trabalho traz para discussão um assunto incipiente no Brasil. O reconhecimento de cuidados paliativos como especialidade médica no país ocorreu a partir de 2017(79) e a primeira regulamentação que normatiza o oferecimento de cuidados paliativos no SUS data do final de 2018(33), portanto bastante recentes.

As mudanças sociais ocorridas nas últimas décadas impactam significativamente no Cuidado à Saúde. As mudanças demográficas e epidemiológicas ocorridas, como o envelhecimento populacional(2) trouxeram o agravamento de algumas questões, que junto com as conquistas significativas da medicina refletiram no aumento de doenças crônico-degenerativas, modificando o perfil dos óbitos do país(13)e exigindo a reestruturação dos serviços de saúde, especialmente implicando na estruturação do SUS com aumento de demanda causando filas de espera nos serviços, especialmente nos SHE.

Neste contexto, tem se investido nos Cuidados Paliativos como uma nova forma de cuidado, especialmente para pacientes com doenças incuráveis, com o objetivo de melhoria da qualidade de vida(26,27) e otimização dos recursos de saúde(26,27), no entanto, esta deve estar em consonância com a estruturação do SUS, de acordo e integrado às linhas de cuidado(36).

Todas estas transformações têm refletido no aumento do uso do SHE causando aglomeração nestes serviços(42), o que pode ser reflexo da falta de identificação destes pacientes como beneficiários de cuidados paliativos e de local apropriado para atendimento, causando fragmentação da assistência(53).

Neste contexto, os serviços de saúde investiram em estratégias que pudessem otimizar o fluxo dos serviços internos, como por exemplo, utilização de sistemas informatizados e processos específicos para regulação da demanda e protocolos de alocação interna, com o objetivo de minimizar os efeitos deste problema(40).

Na U.E.-HCFMRP/USP(44) esta realidade não é diferente, e o impacto da aglomeração foi igualmente observado, no entanto, a administração do hospital, foi ao longo dos anos desenvolvendo e implantando estratégias para enfrentar a questão. Dentre elas estão: A implantação do Sistema e Regulação de Urgência e Emergência(22), os Leitos de Longa Permanência(46), a Sistematização da Solicitação de Leitos em Terapia Intensiva(47) e a criação do Núcleo Interno de Regulação(23). 
No entanto, devido à complexidade do problema, desafios ainda persistem, e a adoção da implantação de um serviço de cuidados paliativos foi mais uma tentativa para otimizar o fluxo de pacientes, agregando valor ao seu cuidado.

Abordar o tema de cuidados paliativos ainda implica em muitas dúvidas e questionamentos conceituais e culturais e discutir sua implantação em emergência é ainda mais complexo e desafiador. No entanto, é importante avaliar a necessidade de se discutir e implementar a filosofia dos cuidados paliativos ao longo das linhas de cuidado, além de adequar o atendimento oferecido a estes pacientes, melhorando a qualidade dos serviços.

O benefício da inserção dos cuidados paliativos no SHE tem sido discutido em outros países, havendo a reflexão sobre o papel da emergência não só como local de prolongamento da vida (curar, salvar), mas também, de atendimento de pacientes com perfil de cuidados paliativos (cuidar, acolher). No entanto, existem poucas evidências sobre como os serviços de emergência podem gerenciar melhor os pacientes que são clinicamente e socialmente complexos, promovendo a continuidade dos cuidados e evitando internações desnecessárias(80).

Ao considerar as características do SHE, não podemos deixar de lado assuntos como superlotação, sobrecarga de trabalho e ambiente estressante que podem ser uma barreira para implementação dos cuidados paliativos(57). No entanto, o SHE pode ofertar uma janela de oportunidade em que pela primeira vez seja apresentada a possibilidade de se rever o curso do tratamento do paciente, seus valores e desejos e incluir uma oportunidade de inserir os cuidados paliativos.

\section{A implantação do Serviço de Cuidados Paliativos na U.E.-HCFMRP/USP}

\section{Estruturação dos Processos}

A implantação da ECP na U.E.-HCFMRP/USP foi bastante complexa e salutar, pois desenhou e implantou processos e protocolos de atendimento específicos que puderam organizar o atendimento dos pacientes com necessidade de abordagem de cuidados paliativos no SHE (Figuras 1, 3 e 4) e os Protocolos de Sedação Paliativa e Infusão de Medicamentos e Soluções por Hipodermóclise, além do Folder de Orientação para equipes, pacientes familiares e o estabelecimento de metas através do Plano de Cuidados, o que possibilita a instrumentalização das equipes para o atendimento destes pacientes. 
A incorporação de tecnologias pode ser classificada em leve, leve-dura e dura. A incorporação de um aparelho de tomografia ou ressonância é um bom exemplo de tecnologia "dura", sendo de fácil identificação por parte dos membros da instituição e extremamente valorizado pela população. Já a incorporação de tecnologias "leves" como a estruturação de uma Equipe de Cuidados Paliativos no presente estudo, requer tanto preparo como a instalação de um novo aparelho de tomografia, como foi demonstrado.

Além disto, a incorporação de tecnologias leves apresenta um desafio maior, pois requer a adoção e manutenção de processos que geralmente têm caráter multidisciplinar, envolvendo diversos profissionais e dedicação da equipe. Uma estratégia que geralmente é favorável para se atingir este objetivo é a consolidação de pequenos marcos ou produtos que possam ser valorizados não só pela equipe envolvida, mas também para o restante da comunidade da instituição, como por exemplo a administração, além dos usuários. Neste sentido, a incorporação de processos de comunicação, novas vias de hidratação (hipodermóclise) e outros produtos apresentados nesta tese garantiram a incorporação paulatina e persistente da conscientização sobre a filosofia dos cuidados paliativos na U.E.-HCFMRP-USP, pois para que algo seja perene deve ser percebido como uma vantagem concreta para a vida laboral dos funcionários e da população envolvida.

\section{Processo de Comunicação}

Outro processo de fundamental importância que foi instituído pela ECP foram as conferências familiares, dando abertura no processo de comunicação entre a equipe, pacientes e familiares, possibilitando a participação de todos e principalmente das equipes de referência, dos pacientes e familiares no processo de tomada de decisão, definição de diretivas antecipadas de vida e do plano de cuidados de acordo com suas demandas, necessidades e possibilidades, garantindo a autonomia dos mesmos.

Neste sentido o acompanhamento pela ECP das equipes de referência para comunicação com pacientes e familiares foi de fundamental importância, visto que, em alguns casos a equipe era acionada somente para esta finalidade, tendo como objetivo a inclusão do paciente e família nas decisões sobre o planejamento de cuidados e considerando a comunicação como um dos pilares fundamentais do cuidado paliativo (74).

A tomada de decisão compartilhada a que se propõe a filosofia dos cuidados paliativos, garante o direito do paciente de decidir sobre seu tratamento de saúde, respeitando sua autonomia e escolha, 
garantindo informações relevantes sobre o prognóstico e o provável curso clínico de várias opções de tratamento(81).

Estudo recente ao abordar possíveis fatores que afetam a comunicação com familiares de pacientes idosos em Cuidados Paliativos mostrou que, na U.E.-HCFMRP/USP, a comunicação apresentou melhor avaliação positiva global em comparação ao ambiente do HCFMRP-USP, considerando a presença da equipe multiprofissional direcionada para o seguimento paliativo dos pacientes com número de profissionais proporcionalmente maior(82), o que pode reafirmar a efetividade e importância da implantação da ECP na U.E.-HCFMRP/USP.

\section{Educação Permanente dos Profissionais}

Nos EUA, os cuidados paliativos estão sendo cada vez mais incorporados ao treinamento dos emergencistas e considerado importante componente do atendimento de emergência(83), o que demonstra a pertinência do nosso estudo e necessidade de implantação do serviço como forma de melhoria da qualidade da assistência identificação dos pacientes e provocação do sistema de saúde para o atendimento desta demanda. Neste contexto, o aprendizado de habilidades essenciais de cuidados paliativos seria essencial para todos os médicos de emergência: avaliação da gravidade da doença e trajetórias de morte, formulação do prognóstico, comunicações difíceis, diretrizes avançadas e planejamento, presença da família durante a ressuscitação, gestão de sintomas, retirada de assistência não-benéfica, gestão da terminalidade, gestão de encaminhamentos para pacientes em cuidados paliativos, questões éticas e legais e competência para lidar com questões espirituais(84).

Sendo assim, um investimento fundamental neste processo foi a capacitação dos profissionais em temos relacionados em cuidados paliativos, tanto a capacitação dos membros da ECP de forma mais abrangente, como de todas as equipes da U.E.-HCFMRP/USP, através de fóruns de discussão, sensibilização dos funcionários e aulas semanais.

Vale ressaltar que a atuação em cuidados paliativos exige do profissional um aprofundamento das discussões bioéticas, tendo em vista as dúvidas que podem gerar na tomada de decisões importantes ao longo do trabalho. Sendo assim, foi de extremo valor a incorporação das reuniões Bioéticas com o objetivo das discussões entre os profissionais e de especialistas na questão, que colaboraram para fomentar um ambiente de trabalho seguro e tranquilo aos profissionais.

Em relação à metodologia de implantação nossos dados foram muito semelhantes a um estudo que elencamos para comparação. No estudo de Weng et al.(57) a estratégia utilizada também foi a contratação de profissional especialista para implementação do plano de intervenção na fase inicial e 
investido em formação da equipe o que também ocorreu na nossa realidade da mesma forma. Foi desenhado um fluxograma com as fases do atendimento para pacientes com perfil paliativo para facilitar a visualização e orientar as equipes, o que também ocorreu na nossa realidade.

\section{Trabalho com a Rede de Saúde}

Cuidados paliativos devem ser oferecidos considerando as linhas de cuidado estabelecidas dentro do ordenamento de saúde estabelecido nas Redes de Atenção à Saúde(84) e, portanto, perpassando todos os espaços de atendimento, sendo necessário o amadurecimento desta nova forma de cuidar para que de acordo com a demanda do paciente deva abranger a filosofia dos cuidados paliativos desde o serviço primário de saúde até o atendimento por equipe especializada e para isso deve haver um investimento dos sistemas, inclusive com locais adequados para o atendimento destas demandas. E ainda fazer parte dos sistemas de referência e contra-referência dentro dos princípios de alta segura, estabelecida pela Política Nacional de Humanização(65) como forma de melhoria da qualidade de comunicação entre os serviços de saúde para alcançar a garantia de continuidade do cuidado.

Seguindo este princípio, com o avanço do processo de implantação dos cuidados paliativos na urgência e o impacto desta atuação na rede de saúde, discutiu-se o papel do hospital de nível terciário e a adequação do sistema de saúde para acolhimento desta demanda, gerando frutos positivos, fomentando a capacitação da RUE - DRS XII em cuidados paliativos. Isto foi fundamental para o atendimento das demandas nos municípios que iriam receber os pacientes na pós-alta para se adequar às necessidades destes pacientes, visando a diminuição da necessidade de re-encaminhamentos para o SHE e para que os pacientes e familiares fossem atendidos adequadamente nestes espaços. Esta estratégia foi de fundamental importância, tanto pelo resultado dos trabalhos apresentados pelos participantes, com projetos de intervenção fomentando as discussões do tema nas suas unidades bem como pelo estímulo de uma rede de comunicação que pode oferecer suporte e discussão dos casos de pacientes que transitam entre os serviços, estabelecendo uma rede de trabalho em Cuidados Paliativos. Outro resultado importante que constou das falas dos participantes do curso foi o quanto a capacitação possibilitou a valorização dos profissionais de ponta, com relatos de melhoria nos acolhimentos e no processo de comunicação com familiares no domicílio, o que se apresenta com fundamental importância para a continuidade e qualidade dos atendimentos.

Tudo isso corrobora com o presente estudo, onde pudemos constatar que 56\% da demanda atendida pela ECP tiveram como objetivo a definição de prognóstico e destes a maioria, $24 \%$ tiveram como desfecho o óbito (Tabela 6), o que demonstra que, apesar de gravemente doentes, nunca tinham 
sido abordados sobre o planejamento do curso de sua doença, nem mesmo tinham um conhecimento do seu prognóstico, não tendo metas de cuidado definidas, um dos principais objetivos da atuação dos cuidados paliativos, ao garantir a proporcionalidade de medidas e alinhamento das expectativas. Esses achados confirmam que o SHE se tornou um centro de necessidades de cuidados paliativos não atendidos, sendo que os médicos de emergência identificam antes as necessidades de cuidados paliativos do que outros médicos. Isto mostra o desafio da identificação destes pacientes de forma precoce antes de sua admissão terminal(85) e, portanto, a necessidade de se trabalhar a rede de saúde.

A questão a ser discutida volta-se então, para o preparo desta rede de atendimento para identificação precoce deste perfil de pacientes e a criação de espaços que possam dar conta desta realidade. Estudo realizado no Reino Unido mostra que os pacientes que precisavam de atendimento de cuidados paliativos intermediários foram para o SHE, pois as necessidades surgiram fora do período de atendimento destes locais, pois não existem locais suficientes com atendimento $24 \mathrm{~h}(83)$, o que é muito semelhante à realidade brasileira. Hoje a rede de saúde compreendida pela abrangência de presente estudo não conta com serviço de cuidados paliativos que atenda esta demanda, restando apenas o SHE.

No início da implantação, a hipótese era de que a presença de pacientes com perfil de cuidados paliativos no SHE dava-se exclusivamente pelo fato da falta de preparo do sistema de saúde para atendimento destas demandas emergentes, sendo um dos motivos mais importantes a falta de organização e efetividade do mesmo, no qual o SHE continua sendo a porta de entrada do sistema de saúde para muitos pacientes (52). No entanto, alguns estudos demonstraram a adequação do uso do SHE por estes pacientes, devido à necessidade de investigações urgentes e intervenções não disponíveis em outros serviços, reconhecendo o papel do SHE na gestão de crises imprevisíveis para pacientes com necessidades de cuidados paliativos(83).

No entanto, acreditamos que a regulamentação dos cuidados paliativos no SUS, dentro das linhas de cuidado, pode ser uma oportunidade para os serviços implantarem os cuidados paliativos nos diversos espaços de atendimento e os pacientes poderiam ser encaminhados para seguimento nestes serviços após a alta hospitalar, evitando os inúmeros retornos ao SHE e que estes poderiam ser atendidos com melhor qualidade e mais próximo de seus familiares.

\section{Perfil dos Pacientes Atendidos pela ECP de acordo com a Estratégia de Identificação dos Pacientes}

Os locais de atendimento foram elencados de acordo com a divisão das áreas dentro da U.E.HCFMRP/USP e os dados do presente estudo foram categorizados de acordo com a Estratégia de 
Identificação de Pacientes, na Estratégia I a prioridade da identificação dos pacientes foi nas enfermarias de pacientes internados, bem como visitas e discussões programadas na neurologia e CTI, com o objetivo de também fomentar a capacitação das equipes. Na Estratégia II a prioridade definida pela equipe foi a identificação na Sala de Urgência, local que recebem os pacientes para definição dos tratamentos e /ou transferência para outros setores. Isto reflete nos dados que demonstram uma alteração significativa nos locais de atendimento havendo aumento de $30 \%$ na Sala de Urgência, queda na enfermaria de $18 \%$ e no CTI/UCO queda de 11,7\% (Tabela 3).

Ao longo do processo de implantação, a ECP adotou a Estratégia I como forma de suprir uma necessidade de trabalhar a demanda reprimida de pacientes crônicos com internação prolongada, sem possibilidade de alta por questões de organização do sistema de saúde e questões sociais e familiares e que necessitavam do atendimento para definição de metas e desenho de plano de cuidados, tendo em vista o início do Projeto de Desospitalização e encaminhamento de alguns destes para Leitos de Longa Permanência(46) e ainda a inserção de conceitos e entendimento dos cuidados paliativos no SHE.

Após esta primeira intervenção, através das discussões e avaliações dos processos de trabalho, a ECP verificou a necessidade de se investir no momento da internação dos pacientes, tendo em vista que este pode ser considerado o momento mais adequado para se discutir o plano de cuidados dos pacientes. No entanto, deve ser ressaltado que isto só foi possível após a capacitação das equipes e maior conhecimento em conceitos e protocolos em cuidados paliativos.

Para enriquecer e fomentar a discussão e comparação dos achados deste estudo escolhemos um trabalho muito semelhante realizado em um hospital público de emergência terciário no Taiwan(57). Trabalho este que apresentou um processo de implantação de cuidados paliativos utilizando a metodologia de avaliação em três fases: pré-intervenção, fase inicial de intervenção, fase tardia de intervenção e pós intervenção, o que muito se assemelha ao nosso estudo, uma vez que nossa análise se baseia em Estratégia I e Estratégia II. Quanto aos dados analisados, estes foram um pouco distintos, naquele estudo foram analisados o número de ordens de não ressuscitação, o número de consultas com equipe, os números de extubações, o número de conferências familiares e o uso da ala de cuidados paliativos, indicadores estes mais específicos da mudança em função da implantação dos cuidados paliativos, enquanto que no nosso estudo os dados coletados foram para definir o perfil dos pacientes e movimento dos atendimentos dentro da unidade. Em que pese a diferença de desfechos entre os estudos, ainda é possível observar a mudança de comportamento similar ao observado no presente estudo, com a mudança do fluxo de atendimento. À similaridade do observado naquele 
estudo, o presente estudo também mostrou modificação de comportamento, com diminuição das taxas de internação quando se passou da Estratégia I para a II.

Os pacientes atendidos pela ECP foram na maioria idosos e a condições clínicas mais prevalentes foram as clínicas gerais e oncologia que juntas representam em acima de $70 \%$ nas duas estratégias (Tabela 3), corroborando a hipótese de que o envelhecimento populacional e o aumento de doenças crônicas levaram os pacientes com este perfil aos SHE (13).

Considerando que o envelhecimento propicia o aumento da procura de idosos pelos SHE, devemos incluir na discussão a fragilidade destes pacientes, como vulnerabilidade fisiológica a estressores, o que é muitas vezes confundido como parte do envelhecimento normal. Diminuir estes estressores torna a mandatório diminuir quaisquer métodos diagnósticos e tratamentos desnecessários com ênfase ainda maior do que para a outras populações. No entanto, a dificuldade se apresenta pela falta de diretrizes clínicas que incluem gerenciamento da fragilidade no SHE, e seu estabelecimento pode auxiliar no reconhecimento rápido para melhoria do manejo destes pacientes, evitando quaisquer métodos diagnósticos e tratamentos desnecessários.

No estudo de Taiwan, foram analisados os dados dos pacientes com ordens de não ressuscitação e a maioria deles também foi entre idosos, 84\% maiores de 65 anos, quanto a enfermidade, $73,3 \%$ dos pacientes foram dentre os que não tinham câncer e a maioria deles 44,2\%, morreu no período menos que 7 dias.

Quanto à funcionalidade dos pacientes, pudemos verificar que a maioria, acima de $70 \%$ dos pacientes, tinha grave comprometimento funcional com PPS de 10, se caracterizando como totalmente dependentes com grave manifestação da doença e ECOG 4 acima de 85\%, comprovando que a maioria dos pacientes eram restritos ao leito ou cadeira.

Um desafio do início da implantação foi o equívoco de chamar a equipe principalmente para atendimento de pacientes em terminalidade, visto a falta de conhecimento sobre a abrangência do atendimento em cuidados paliativos e o despreparo das equipes para lidar com processos de morte. Através dos dados da funcionalidade dos pacientes pudemos observar um aumento no percentual de PPS >40 na Estratégia II obtendo ligeira melhora na inclusão de pacientes em estágios menos avançados da doença, o que mostra a efetividade da Estratégia II, nesta questão. Não obstante, muito ainda deve ser trabalhado para que se obtenha a mudança de cultura institucional tão necessária.

Quanto aos desfechos nas Estratégias I e II o óbito foi o mais prevalente (48,4\% e 50,6\%) e o óbito intra-hospitalar representou percentual acima de $65 \%$, que quando associado à baixa 
funcionalidade demonstram a gravidade dos pacientes atendidos. Isto demonstra que os pacientes que tem perfil para cuidados paliativos nos dois estudos são na sua maioria pacientes idosos, totalmente dependentes e gravemente doentes tendo como desfecho principal o óbito.

Quanto aos indicadores de processos analisados estes são os mais importantes para se verificar a efetividade da melhor Estratégia.

Quando observamos o índice de percepção vemos que na Estratégia II pudemos observar uma identificação mais rápida dos pacientes no SHE, tanto no total de pacientes quanto quando excluímos o óbito intra-hospitalar, com diminuição de 1,8 e 3,2 dias. Este dado pode sugerir que o investimento na capacitação das equipes pode ter sido efetivo ao melhorar a sensibilidade para reconhecer os pacientes com perfil de atendimento proporcional ou total em cuidados paliativos.

No concernente à duração da internação houve uma queda significativa de 3,6 e 2,4 dias, o que sugere que a Estratégia II se apresenta mais efetiva considerando a otimização do leito. Estes dados sugerem que em termos de fluxo, a Estratégia II seja mais vantajosa ao se implantar a ECP no SHE.

Em relação ao tempo de seguimento não houve alteração significativa. No entanto, associado com a duração menor da internação, podemos concluir que quanto mais cedo o reconhecimento deste perfil de pacientes, menor o tempo de internação, o que coincide com outros estudos que mostram que iniciar uma consulta de cuidados paliativos no SHE encurta o tempo da internação em média em 4 dias, além de melhorar a qualidade de vida e melhorar a satisfação do paciente. $(85,86)$. Outro estudo relata que a média de tempo de internação de pacientes que receberam cuidados paliativos no SHE foi reduzida em 3,6 dias se comparado com aqueles que só receberam cuidados paliativos após a internação(87).

Dados similares podem ser extrapolados para o estudo de Taiwan, uma vez que como indicador de processo podemos considerar o percentual de ordens de não ressuscitação do SHE em relação ao todo do hospital que foi de $10,8 \%$ na fase pré-intervenção para 22,8\% na pós-internação e a realização de 18 extubações no período de intervenção podendo ser reflexo da atuação da equipe com investimento na educação das equipes e definição de metas de cuidado e na discussão do benefício de limitação e retirada de medidas como conduta de conforto para os pacientes.

Quando analisamos a sobrevivência dos pacientes observamos uma maior mortalidade intrahospitalar nos 20 primeiros dias da intervenção para Estratégia II. Embora não tenha sido possível determinar os motivos de modo mais preciso, é razoável considerar que isto possa ter ocorrido por 
uma melhor definição do plano terapêutico individual dos pacientes, no qual a prevenção de intervenções fúteis e melhor preparo da equipe e da família para o óbito tenha ocorrido (Figura 6). O mesmo pode ser inferido para o comportamento da mortalidade extra-hospitalar, que foi mais rápida na Estratégia II, o que pode ser influência da definição do plano de cuidados e da definição das metas de forma precoce, de acordo com as preferências dos pacientes, limitando as medidas, com foco no conforto dos pacientes (Figura 6).

Através do modelo de regressão multivariada de Cox, observando o risco para o óbito, vemos que a condição clínica oncológica tem o maior impacto sobre o risco de óbito, seguido pelas clínicas gerais, no entanto, para a condição oncológica o risco é maior do que para as outras condições clínicas. O que se deve ao fato de que os pacientes com doenças oncológicas quando apresentam a diminuição da funcionalidade, já estão gravemente doentes e como demonstra a evolução da doença em função do tempo, existe a maior probabilidade de óbito de forma mais previsível do que nas doenças crônicas. Vemos também que a idade impacta significativamente para este risco, o que já é esperado, tendo em vista a fragilidade das pessoas idosas e doentes.

Como esperado, maiores valores de PPS estão associados a menor mortalidade intra-hospitalar mesmo quando a associação é corrigida para outros fatores de confusão (Figura 7). A utilização de escalas no cuidado tem a vantagem de agregar dados mais objetivos em termos prognósticos ou terapêuticos, na dependência de sua concepção. A PPS se mostrou de fácil aplicação e muito superior à ECOG para a população extremamente dependente que compôs o presente trabalho. Seu valor prognóstico é conhecido e futuros estudos podem auxiliar na sua utilização para outras dimensões, como por exemplo, no dimensionamento de tempo que os profissionais terão que dedicar ao cuidado de pacientes com maior dependência. Populações similares a este estudo requerem muito poucos exames de alta tecnologia e intervenções médicas, mas o tempo despendido com o cuidado de enfermagem, o treinamento de cuidadores e as intervenções das equipes multidisciplinares como a de ECP é muito maior. Além deste componente, a utilização de escalas pode estar associada ao planejamento terapêutico e à racionalização do cuidado, sendo poderia ser proposto, por exemplo, que aqueles pacientes com PPS menor deveriam já incluir em seu planejamento a preparação de familiares para o óbito, enquanto que valores maiores deverão incluir outras necessidades, como o treinamento para manejo domiciliar.

Não podemos ainda, deixar de ressaltar a importância do trabalho multiprofissional e a colaboração interdisciplinar que melhora a qualidade dos atendimentos e torna-se base importante para a implantação e desenvolvimento dos cuidados paliativos (57) enquanto cultura e forma de atendimento. Todo o processo de implantação teve a participação efetiva de todos os profissionais, 
tanto da ECP, como das equipes das unidades, de forma participativa, garantindo o tempo para entendimento, conhecimento e adaptação dos seus processos de trabalho.

Como assistente social da equipe foi muito importante o crescimento profissional, interligando o conceito da garantia da qualidade dos atendimentos adaptada à autonomia dos pacientes e familiares, considerando seus direitos, crenças e valores. Foi possível na prática aliado aos conceitos fundamentais de trabalho do serviço social, construir um panorama com as principais atribuições deste no contexto de atuação em cuidados paliativos, o que pode fomentar a prática de outros profissionais que atuam na área.

Através da prática diária observamos que os profissionais de saúde já saturados pelas condições de trabalho e emocionalmente frágeis pela gravidade dos pacientes, acabam por apresentar posturas de afastamento emocional, negação da morte, rigidez, falta de sensibilidade nos processos de trabalho, negando por vezes ou se mostrando insensíveis ao se depararem com situações que podem intensificar o seu sofrimento. No entanto, sabemos que negar uma situação ou tentar se afastar dela não a altera e no âmbito do trabalho em saúde isso acaba por levar ao desenvolvimento do esgotamento profissional (88).

Sendo assim, a interação extremamente importante e fundamental que facilitou a atuação de forma sistemática na humanização dos processos e relações intra-hospitalares foi o acolhimento e acompanhamento às equipes, especialmente o suporte e acompanhamento de familiares de pacientes em situação de terminalidade e o acolhimento dos profissionais para discussão dos impactos emocionais do atendimento, além do fomento de ferramentas de atuação para auxiliar no dia a dia.

Após o estabelecimento destes processos de acompanhamento de forma sistematizada foi possível observar uma melhor aceitação das equipes para se envolverem de forma mais humanizada nos atendimentos, tendo como reflexo positivo a diminuição dos conflitos entre equipes e com familiares.

Sendo assim, podemos talvez vislumbrar novos tempos para questões tão antigas, através de reorganização do sistema de saúde para melhoria das condições de atendimento desta população que merece ser tratada dignamente e com responsabilidade social e moral. Além da quebra de paradigma ao considerar o ganho que os profissionais de saúde expressam ao incorporar formas humanizadas de atendimento, voltando o olhar para a vida que ainda resta do paciente, não se contentando com o jargão mais proeminente e insensível: "não há mais nada a fazer" e alterando para sempre: "há muito que se pode fazer", diante de práticas que são realizadas através dos desejos e o acolhimento mais profundo dos anseios dos pacientes para o seu fim de vida, que colaboram para o bem estar das equipes que se sentiam fracassadas diante do processo de morrer, invertendo assim, a lógica da morte 
como processo reflexivo e como parte da vida de todos, e como um momento que pode ser pleno diante de um desejo realizado e a satisfação conseguida, transpondo os limites da medicina centrada na cura.

\section{Limitações do Estudo}

Algumas limitações devem ser ressaltadas neste estudo e, talvez, a mais importante seja que os dados foram coletados somente dos pacientes atendidos pela ECP. A U.E.-HCFMRP/USP passou por mudança significativa na incorporação dos conceitos de cuidados paliativos através dos processos de educação das equipes no decorrer do processo de implantação, mas não foi possível quantificar todos os pacientes que se beneficiariam desta abordagem. Neste aspecto identificamos como oportunidade de melhoria a necessidade de criação de um instrumento para triagem e documentação específica dos pacientes atendidos e com necessidade de abordagem paliativa.

Outra limitação importante foi que os dados dos atendimentos ficaram restritos à capacidade de atendimento da equipe, considerando que as estratégias de atuação foram elaboradas pela própria ECP, de acordo com as demandas de atendimento, elencando locais de atuação, visando conhecimento da demanda interna no primeiro momento, e depois adequação para atendimentos considerados prioritários. Um exemplo disto foi a atuação mais geral no início, com visitas específicas em alguns locais que julgávamos ser importantes, como CTI e neurologia e que após avaliação das prioridades se tornaram secundárias, devido à consideração da sala de urgência como um local de definição de condutas e do fluxo dos pacientes na unidade.

Com o início do serviço de cuidados paliativos, o primeiro desafio foi uma busca das equipes por atendimentos que não necessariamente precisariam ser atendidos pela ECP, devido a abrangência de atuação e visão holística do paciente. Através do processo de trabalho instituído, muitos pedidos de interconsulta foram solicitados para avaliações como controle de dor e outros sintomas, o que motivou a ECP a incluir a partir de 2016, a categorização dos atendimentos por tipo de demanda.

Além das demandas para atendimento de controle de sintomas $(17,3 \%)$ e avaliação para pacientes em terminalidade (26\%), a maioria dos atendimentos, 56,7\% foi categorizado como para definição de prognóstico (Tabela 5). Esta questão pode demonstrar a dificuldade dos médicos em validar uma condição de fragilidade dos pacientes que denotam um mau prognóstico em departamentos de emergência, se amparando na avaliação de profissionais para definição de condutas de retirada de medidas ou mudança no foco do atendimento para alívio de sintomas e conforto, 
considerando que este local foi idealizado como o serviço para atendimento de pacientes em situações agudas cujo objetivo é a manutenção da vida(51).

Uma limitação importante é que não foram mensurados desfechos mais objetivos da mudança cultural decorrente, como demonstrado no trabalho de Taiwan. Nossos desfechos foram restritos aos instrumentos e produtos gerados pelo processo de implantação e à mortalidade. Em relação à mortalidade, uma crítica possível seria que os pacientes em que se aplicou a Estratégia II estariam morrendo por se deixar de ofertar alguns cuidados ao invés da inferência de que se deixou de executar procedimentos fúteis. Embora não se possa excluir em definitivo esta alegação, o preparo das equipes de cuidado direto e a supervisão pela ECP, com protocolos bem estabelecidos nos permite pender para a assertiva de que a futilidade tenha diminuído e que o conforto oferecido aos pacientes foi garantido.

Quanto à diminuição do tempo para óbito pós-alta com a Estratégia II, os mesmos comentários podem ser realizados, haja vista que os protocolos utilizados garantiram o treinamento dos familiares e havia a garantia de acesso caso houvesse piora. $\mathrm{O}$ incremento do número de busca por novo atendimento na U.E.-HCFMRP-USP com a mudança para a Estratégia II nos garante por um lado que os pacientes não foram deixados desassistidos, mas por outro, que a rede básica de saúde não está preparada para cuidar deste tipo de paciente. Será necessário não somente a mudança cultural de inserção de cuidados paliativos intra-hospitalar, mas sobretudo, na rede de atenção primária, que deve ser melhor estruturada com incremento de métodos de trabalho como a visita domiciliar. Apesar de presente em Ribeirão Preto, sua capacidade ainda é muito limitada. Em suma, a inserção de cuidados paliativos no SHE como estratégia para reduzir a aglomeração pode ser limitada se não houver fortalecimento de todos os pontos da Linha de Cuidado, a exemplo do que se observou com outras estratégias implantadas pela U.E.-HCFMRP-USP nos últimos anos. 


\section{CONCLUSÃO}

A incorporação do serviço de cuidados paliativos no SHE demonstrou que Cuidados Paliativos são uma necessidade que deve ser parte de um atendimento integral, agregando suporte as equipes assistenciais e melhoria na qualidade do atendimento aos pacientes e seus familiares, modificando a cultura hospitalar sobre a morte e consolidando a prática paliativista em situações de urgência.

O estudo demonstrou ser mais efetiva a Estratégia II, que no contexto da melhoria dos fluxos internos diminuiu a duração da internação através dos processos de educação das equipes que propiciaram na melhoria do tempo de reconhecimento destes pacientes, garantindo adequação do atendimento as suas necessidades e efetividade do processo de comunicação, agregando a participação dos pacientes e familiares como corresponsáveis pelas decisões médicas, garantindo o princípio da autonomia e levando dignidade aos pacientes e familiares. 


\section{REFERENCIAS BIBLIOGRÁFICAS}

1. Miranda GMD, Mendes A da CG, Silva ALA da. Population aging in Brazil: current and future social challenges and consequences. Rev Bras Geriatr e Gerontol. 2016;19(3):507-19.

2. ONU UN. World Population Prospects 2019. [Internet]. United Nations. Department of Economic and Social Affairs. World Population Prospects 2019. 2019. 49-78 p. Available from: http://www.ncbi.nlm.nih.gov/pubmed/12283219

3. Conselho Nacional de Secretários de Saúde. Vigilância em Saúde Parte 1 - Coleção para Entender a Gestão do SUS. ${ }^{a}$. CONASS, editor. Brasília: Coleção para Entender a Getão do SUS; 2011.320 p.

4. De Almeida Da Costa P, Luana ; De Almeida Da Costa J, Patrícia D, Cavalcanti B. A VELHICE COMO EXPRESSÃO DA QUESTÃO SOCIAL NO BRASIL. 3322(83):3222. Available from: www.cieh.com.br

5. Federal U, Federal U. POLÍTICA SOCIAL DE PROTEÇÃO AO IDOSO: a reafirmação da cultura privacionista no trato das refrações da questão social. Rev Políticas Públicas. $2007 ; 11(1)$.

6. Mendes MRSSB, Gusmão JL de, Faro ACM e, Leite R de CB de O. A situação social do idoso no Brasil: uma breve consideração. Acta Paul Enferm. 2005 Dec;18(4):422-6.

7. Paiva S de OC. Envelhecimento, saúde e trabalho no tempo do capital. Cortez Editora; 2014. $304 \mathrm{p}$.

8. Queiroz Z. O impacto do cuidado na vida do cuidador de idosos: fator de risco de negligência doméstica em idosos dependentes. In: Berzins, MV MW (Org., editor). Rompendo o silêncio: faces da violência na velhice. São Paulo: Editora Martinari; 2010. p. 295-307.

9. Bieger J, Santos L, Claudia S, Wagner C, Manuela F, Caron R. O Envelhecimento (como) expressão da Questão Social e algumas considerações pertinentes ao Exercício Profissional.

10. Alencar TMD. A vida crônica é novidade na aids : as transformações da aids aguda para a aids crônica sob o ponto de vista dos pacientes [Internet]. Faculdade de Medicina da Universidade de São Paulo; 2006. Available from: file:///C:/Users/fsmontanari/Documents/Pessoal/Defesa/TatiannaMeirelesDantasAlencar.pdf

11. Crepaldi NY, Orfão NH, Yoshiura VT, Villa TCS, Ruffino-Netto A, Alves D. Desenvolvimento e implantação de um sistema para gestão de pacientes de tuberculose. Med (Ribeirão Preto). 2014;47(January):13-7.

12. Pazin-Filho A. Morte: Considerações Para a Prática Médica. Med (Ribeirao Preto Online). 2005;38(1):20.

13. Dos Santos CE, Peixoto Caldas JM, Serafim JA, Barros N, Pereira ADC, Capra MEZ, et al. Palliative Care in Brazil: With a View to Future Needs? Int Arch Med [Internet]. 2017;10:19. Available from: http://imedicalsociety.org/ojs/index.php/iam/article/view/2440

14. MINISTÉRIO DA SAÚDE Instituto Nacional de Câncer José Alencar Gomes da Silva 
(INCA). Incidência de Câncer no Brasil Estimativa 2018. INCA. Rio de Janeiro; 2017. 128 p.

15. Snyderman D, Haines C, Wender R. Cancer in the elderly. In: Reichel's Care of the Elderly: Clinical Aspects of Aging, Sixth Edition. Cambridge University Press; 2009. p. 392-411.

16. Smith BD, Smith GL, Hurria A, Hortobagyi GN, Buchholz TA. Future of Cancer Incidence in the United States: Burdens Upon an Aging, Changing Nation. J Clin Oncol [Internet]. 2009;27(17):2758-65. Available from: https://doi.org/10.1200/JCO.2008.20.8983

17. Linda T. Kohn, Janet M. Corrigan and MSD. To Err Is Human. Building a Safer Health System, Volume 6 [Internet]. Vol. 2, International Journal of Public Health. 1999. 93-95 p. Available from: https://books.google.com/books?hl=en\&lr=\&id=Jj25GlLKXSgC\&pgis=1

18. Kohn LT, Corrigan JM, Donaldson MS. To Err Is Human: Building a Safer Health System [Internet]. Kohn LT, Corrigan JM, Donaldson MS, editors. Washington, DC: The National Academies Press; 2000. Available from: https://www.nap.edu/catalog/9728/to-err-is-humanbuilding-a-safer-health-system

19. Wachter RM, Goldman L. Zero to 50,000-the 20th anniversary of the hospitalist. Vol. 375, New England Journal of Medicine. Massachussetts Medical Society; 2016. p. 1009-11.

20. Palabindala V, Abdul Salim S. Era of hospitalists. J Community Hosp Intern Med Perspect. 2018 Jan 2;8(1):16-20.

21. Pazin-Filho A, Scarpelini S. Medicina de Emergência na FMRP-USP - Você pode fugir, mas não há como se esconder! Medicina. 2010;43(4):432-43.

22. Adolfi Júnior MS, Pallini FM, Pessotti H, Wolf CM, Patelli HT, Capeli RD, et al. Regulação médica em emergência pela plataforma web: um estudo piloto. Rev Saude Publica [Internet]. 2010 Dec [cited 2019 Aug 15];44(6):1063-71. Available from: http://www.scielo.br/scielo.php?script=sci_arttext\&pid=S0034-

$89102010000600011 \& \operatorname{lng}=\mathrm{pt} \& \operatorname{lng}=\mathrm{pt}$

23. Ferreira AJ, Laurindo MC, Moraes A de A, Cerantola R, Barbosa LB, Pereira JG da C, et al. A implantação do Núcleo Interno de Regulação em Hospital Público Terciário. Med (Ribeirao Preto Online). 2019 Jul 2;52(1):16-23.

24. Hermes HR, Lamarca ICA. Cuidados paliativos: uma abordagem a partir das categorias profissionais de saúde. Cien Saude Colet [Internet]. 2013 Sep [cited 2019 May 18];18(9):2577-88. Available from: http://www.scielo.br/scielo.php?script=sci_arttext\&pid=S1413-

$81232013000900012 \& \operatorname{lng}=\mathrm{pt} \& \operatorname{tlng}=\mathrm{pt}$

25. Sudigursky D, Silva E da. Concepções sobre cuidados paliativos : revisão bibliográfica. Acta Paul Enferm. 2006;21(3):504-8.

26. Kelley AS, Morrison RHSS. Palliative Care for the Seriously Ill. N Engl J Med. 2015;20(747755).

27. Kavalieratos D, Corbelli J, Zhang D, Dionne-Odom JN, Ernecoff NC, Hanmer J, et al. Association between palliative care and patient and caregiver outcomes: A systematic review and meta-analysis. JAMA - J Am Med Assoc. 2016;316(20):2104-14.

28. Santos FS. Cuidados paliativos: diretrizes, humanização e alívio de sintomas. Atheneu, editor. 
São Paulo/SP/Brasil2011. Atheneu. 2011. 476 p.

29. Lefebvre EM, Platts-Mills TF. Resuscitating End-of-Life Care. Ann Emerg Med [Internet]. 2016;68(1):40-2. Available from: http://dx.doi.org/10.1016/j.annemergmed.2015.11.006

30. Machado M de A. Cuidados paliativos e a construção da identidade médica paliativista no Brasil. 2009;101. Available from: http://bvssp.icict.fiocruz.br/lildbi/docsonline/get.php?id=1935

31. World Palliative Care Alliance. Global atlas of palliative care at the end of life [Internet]. 2014. 111 p. Available from: http://www.who.int/cancer/publications/palliative-care-atlas/en/

32. Panorama dos Cuidados Paliativos no Brasil [Internet]. 2018. Available from: https://paliativo.org.br/wp-content/uploads/2018/10/Panorama-dos-Cuidados-Paliativos-noBrasil-2018.pdf

33. COMISSÃO INTERGESTORES TRIPARTITE. Resolução No 41, De 31 De Outubro De 2018. Diário Of da União [Internet]. 2018;seção 1:276. Available from: http://www.cofen.gov.br/wp-content/uploads/2018/11/Resoluçao-CP.pdf

34. Adolfi Júnior MS. Análise dos Fatores Associados ao Processo de Regulação Médica de Urgências e Emergências Através de um Sistema Informatizado Ribeirão. 2015.

35. BRASIL. Ministério da Saúde. Implantação das Redes de Atenção à Saúde e Outras Estratégias da SAS [Internet]. Ministério da Saúde. 2014. 160 p. Available from: http://bvsms.saude.gov.br/bvs/publicacoes/implantacao_redes_atencao_saude_sas.pdf

36. BRASIL. Ministério da Saúde. PORTARIA N 4.279, DE 30 DE DEZEMBRO DE 2010 [Internet]. 2010 p. 25. Available from: https://www.scopus.com/inward/record.uri?eid=2-s2.0$33645547325 \% 7 \mathrm{~B} \& \% 7 \mathrm{DpartnerID}=40 \% 7 \mathrm{~B} \& \% 7 \mathrm{Dmd} 5=5 \mathrm{c} 937 \mathrm{a} 0 \mathrm{c} 35 \mathrm{f} 8 \mathrm{be} 4 \mathrm{ce} 16 \mathrm{cb} 392381256$ da

37. Mayer, Thom; Jensen K. Hardwiring flow: systems and process for seamless patient care. 2009. $295 \mathrm{p}$.

38. BRASIL. Ministério da Saúde. Portaria n ${ }^{\circ}$ 1863, de 29 de setembro de 2003. 2003.

39. Hillier FS, Editor S, The N, Of P, Chain S, Where M. Patient Flow : Reducing Delay In Healthcare Recent Titles In The International Series In Operations Research \& Management Science. 2010. 466 P.

40. De Freitas L, Goodacre S, O'Hara R, Thokala P, Hariharan S. Interventions to improve patient flow in emergency departments: An umbrella review. Emerg Med J. 2018;35(10):626-37.

41. Garcia TC, Bernstein AB, Bush MA. Emergency department visitors and visits: who used the emergency room in 2007? NCHS Data Brief [Internet]. 2010;(38):1-8. Available from: http://www.ncbi.nlm.nih.gov/pubmed/20487622\%5Cnfile://C:/Users/ls/Desktop/وقالات 2 سرى اورز انس شلوغى/db38.pdf

42. Baker C. Accident and Emergency Statistics. House Commons Libr Brief Pap. 2015;(6964):134.

43. Lamba S, Nagurka R, Zielinski A, R Scott S, Scott SR. Palliative Care Provision in the Emergency Department: Barriers Reported by Emergency Physicians [Internet]. Vol. 16, 
Journal of palliative medicine. 2013. 143-147 p. Available from: http://online.liebertpub.com/doi/abs/10.1089/jpm.2012.0402

44. Uip D. Relatório de Atividades do Hospital das Clínicas da FMRP-USP. 2017.

45. BRASIL. Plano de Ação da RUE Ribeirão Preto -SP. Acessado em 21 set 2017. 2012. p. 11. BRASIL, Plano de Ação da RUE Ribeirão Preto -S.

46. Pazin-Filho A, de Almeida E, Cirilo LP, Lourençato FM, Baptista LM, Pintyá JP, et al. Impact of long-stay beds on the performance of a tertiary hospital in emergencies. Rev Saude Publica. $2015 ; 49$.

47. Neves FF, Pazin-Filho A. Gestão de recursos em terapia intensiva: aplicação de um sistema de informação para organização da fila. Rev Eletronica Gestão Saúde. 2016;7(2):730.

48. BRASIL. Ministério da Saúde. Manual de Implantação e Implementação - Núcleo Interno de Regulação para Hospitais Gerais e Especializados. 2017.

49. May P, Normand C, Brian Cassel J, Del Fabbro E, Fine RL, Menz R, et al. Economics of Palliative Care for Hospitalized Adults With Serious Illness A Meta-analysis. JAMA Intern Med. 2018;

50. Temel JS, Greer JA, Muzikansky A, Gallagher ER, Admane S, Jackson VA, et al. Early Palliative Care for Patients with Metastatic Non-Small-Cell Lung Cancer. N Engl J Med. 2010;8(19).

51. Basol N. The integration of palliative care into the emergency department. Turkiye Acil Tip Dergisi. 2015.

52. MacDonald N, Oneschuk D, Hagen N, Doyle D. Textbook Of Palliative Medicine. Palliative Medicine. 2016. 1322 p.

53. George N, Barrett N, McPeake L, Goett R, Anderson K, Baird J. Content Validation of a Novel Screening Tool to Identify Emergency Department Patients with Significant Palliative Care Needs. Acad Emerg Med. 2015;22(7):823-7.

54. Chan GK. End-of-Life and Palliative Care in the Emergency Department: A Call for Research, Education, Policy and Improved Practice in This Frontier Area. J Emerg Nurs [Internet]. 2006 Feb 1 [cited 2018 Jun 19];32(1):101-3. Available from: https://www.sciencedirect.com/science/article/pii/S0099176705006276?_rdoc=1\&_fmt=high \&_origin=gateway\&_docanchor=\&md5=b8429449ccfc9c30159a5f9aeaa92ffb\&ccp=y

55. Cooper E, Hutchinson A, Sheikh Z, Taylor P, Townend W, Johnson MJ. Palliative care in the emergency department: A systematic literature qualitative review and thematic synthesis. Palliat Med [Internet]. 2018 Jul 20;32(9):1443-54. Available from: https://doi.org/10.1177/0269216318783920

56. Shearer FM, Rogers IR, Monterosso L, Ross-Adjie G, Rogers JR. Understanding emergency department staff needs and perceptions in the provision of palliative care. EMA - Emerg Med Australas. 2014;26(3).

57. Weng TC, Yang YC, Chen PJ, Kuo WF, Wang WL, Ke YT, et al. Implementing a novel model for hospice and palliative care in the emergency department. Med (United States). 2017;96(19):1-5. 
58. Henson LA, Higginson IJ, Daveson BA, Ellis-Smith C, Koffman J, Morgan M, et al. 'I'll be in a safe place": A qualitative study of the decisions taken by people with advanced cancer to seek emergency department care. BMJ Open. 2016;6(11):1-11.

59. Cheung KY, Chan KC. Experiences of healthcare professionals in providing palliative end-oflife care to patients in emergency departments: a systematic review protocol. JBI database Syst Rev Implement reports. 2016;14(10):9-14.

60. Raichelis R. Intervenção profissional do assistente social e as condições de trabalho no Suas. Serviço Soc Soc. 2010;(104):750-72.

61. Lacerda LEP de. Exercício profissional do assistente social: Serv Soc Soc, São Paulo. 2014;117:22-44.

62. Silva M do R de F. Políticas Públicas na Área do Envelhecimento: possibilidades da autação do Serviço Social. Rev Políticas Públicas. 2012;(Número Especial):205-10.

63. Silva DC da, Krüger TR. Parâmetros Para a Atuação De Assistentes Sociais Na Política De Saúde: O Significado No Exercício Profissional. Temporalis. 2018;18(35):265-88.

64. Brasil. Ministério da Saúde. Secretaria de direitos humanos. Lei 8080/90 SUS. 2008;1-13.

65. BRASIL. Ministério da Saúde. Política Nacional de Humanização. Ministério da Saúde Secr Núcleo Técnico da Política Nac Humaniz Humaniz. 2004;2ed:51.

66. Urbano ED. Trabajo Social Y Cuidados Paliativos. 2013.

67. Carvalho, Ricardo T; Parsons HA (org. . Manual de Cuidados Paliativos ANCP. 2a ${ }^{\text {a }}$ Academia Nacional de Cuidados Paliativos; 2012. 592 p.

68. Frossard, Andrea, Rodrigues, Luciana, Oliveira, Bruno FC. Artigo de Revisão Serviço Social e Oncologia: os Cuidados Paliativos em foco Social Service and Oncology: palliative care in focus. Rev Facitec. 2018;02.

69. Alves J, Silva DA, Paulo S. Serviço Social e Cuidados Paliativos em Oncologia : Estratégias de Intervenção nos Cuidados. 2019;

70. Cavalcanti, Barreto Patrícia; Saturnino, Clara Isabel N.; Miranda APRS. Social Work and Palliative Care. Br J Soc Work. 2001;31(6):961-71.

71. Boyd K, Murray S. Supportive and Palliative Care Indicators Tool (SPICT). 2011;12. Available from: http://www.spict.org.uk/pluginfile.php/26/mod_page/content/48/SPICT_June2013 (watermarked).pdf\%5Cnhttp://scholar.google.com/scholar?hl=en\&btnG=Search\&q=intitle:S upportive+and+Palliative+Care+Indicators+Tool+(+SPICT+?+)\#0

72. Sales MG, Carvalho RT. Palliative Performance Scale [Internet]. 2009. p. 7. Available from: http://www.victoriahospice.org/sites/default/files/pps_portugese_0.pdf

73. Neto IG. A conferência familiar como instrumento de apoio à família em cuidados paliativos. Rev Port Med Geral e Fam [Internet]. 2003;19(1):68-74. Available from: http://www.rpmgf.pt/ojs/index.php/rpmgf/article/view/9906/9644

74. Stovall, RN, MSN, ANP-BC MC. Oncology Communication Skills Training: Bringing 
Science to the Art of Delivering Bad News. J Adv Pract Oncol [Internet]. 2015;6(2). Available from: http://www.advancedpractitioner.com/issues/volume-6,-number-2-(marapr2015)/oncology-communication-skills-training-bringing-science-to-the-art-of-delivering-badnews.aspx

75. Lourençato FM, Filipe A, Fortaleza AM, Ficher T, Carlos J, Zoppi D, et al. Criação do Grupo de Discussão Bioética para Avaliaçãa de Casos.pdf. 2015. p. 1.

76. Skaba MF. Humanização e cuidados paliativos. Cien Saude Colet [Internet]. 2005 Sep [cited 2018 Jun 19];10(3):782-4. Available from: http://www.scielo.br/scielo.php?script=sci_arttext\&pid=S1413$81232005000300035 \& \operatorname{lng}=\mathrm{pt} \& \operatorname{lng}=\mathrm{pt}$

77. Oken MM, Creech RH, Tormey DC, Horton J, Davis TE, McFadden ET, et al. Toxicity and response criteria of the Eastern Cooperative Oncology Group. Am J Clin Oncol [Internet]. 1982;5(6):649—655. Available from: http://europepmc.org/abstract/MED/7165009

78. Dos Santos AFJ. Projeto para o desenvolvimento de uma Equipe de Cuidados Paliativos na Unidade de Emergência do Hospital das Clínicas de Ribeirão Preto. 2014. p. 1-3.

79. Presente Edital A Associação P, Brasileira M. Edital de Convocação do Exame de Suficiência para obtenção do Certificado de Área de Atuação em Medicina Paliativa 2017.

80. Aminzadeh F, Dalziel WB. Older adults in the emergency department: A systematic review of patterns of use, adverse outcomes, and effectiveness of interventions. Ann Emerg Med. 2002;39(3):238-47.

81. George NR, Kryworuchko J, Hunold KM, Ouchi K, Berman A, Wright R, et al. Shared Decision Making to Support the Provision of Palliative and End-of-Life Care in the Emergency Department: A Consensus Statement and Research Agenda. Acad Emerg Med. 2016;23(12):1394-402.

82. Janssen TCM. Estudo Transversal Exploratório de Possíveis Fatores que Estudo Transversal Exploratório de Possíveis Fatores que Afetam a Comunicação com Familiares de Pacientes Idosos em Cuidados Paliativos. Faculdade de Medicina de Ribeirão Preto Universidade de São Pasulo; 2019.

83. Green E, Ward S, Brierley W, Riley B, Sattar H, Harris T. "They Shouldn't Be Coming to the ED, Should They?": A Descriptive Service Evaluation of Why Patients With Palliative Care Needs Present to the Emergency Department. Am J Hosp Palliat Med. 2017;34(10):984-90.

84. Quest TE, Marco CA, Derse AR. Hospice and Palliative Medicine: New Subspecialty, New Opportunities. Ann Emerg Med [Internet]. 2009;54(1):94-102. Available from: http://dx.doi.org/10.1016/j.annemergmed.2008.11.019

85. Wang DH. Beyond Code Status: Palliative Care Begins in the Emergency Department. Ann Emerg Med [Internet]. 2017;69(4):437-43. Available from: http://dx.doi.org/10.1016/j.annemergmed.2016.10.027

86. Siegel M, Bigelow S. Palliative Care Symptom Management in The Emergency Department: The ABC's of Symptom Management for The Emergency Physician. J Emerg Med [Internet]. 2018;54(1):25-32. Available from: https://doi.org/10.1016/j.jemermed.2017.08.004

87. Wu FM, Newman JM, Lasher A, Brody AA. Effects of Initiating Palliative Care Consultation 
in the Emergency Department on Inpatient Length of Stay. J Palliat Med. 2013;16(11):13627.

88. Medeiros-Costa ME, Lima LL De, Freitas JG. A síndrome do esgotamento profissional no contexto da enfermagem : uma revisão integrativa da literatura. Rev da Esc Enferm da USP. 2017;51:1-12. 


\section{APÊNDICES}

\section{APÊEDICE 1 - LEVANTAMENTO DE PACIENTES}

\section{POTENCIALMENTE PARA CUIDADOS PALIATIVOS}

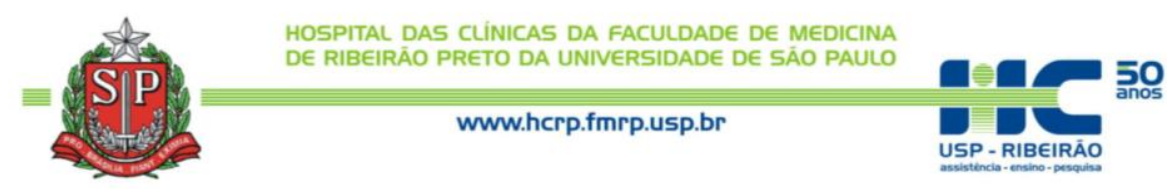

Levantamento de Pacientes Potencialmente para Cuidados Paliativos






\section{APÊNDICE 2 - PLANO DE CUIDADOS - UNIDADE DE EMERGÊNCIA (C. PALIATIVOS).}

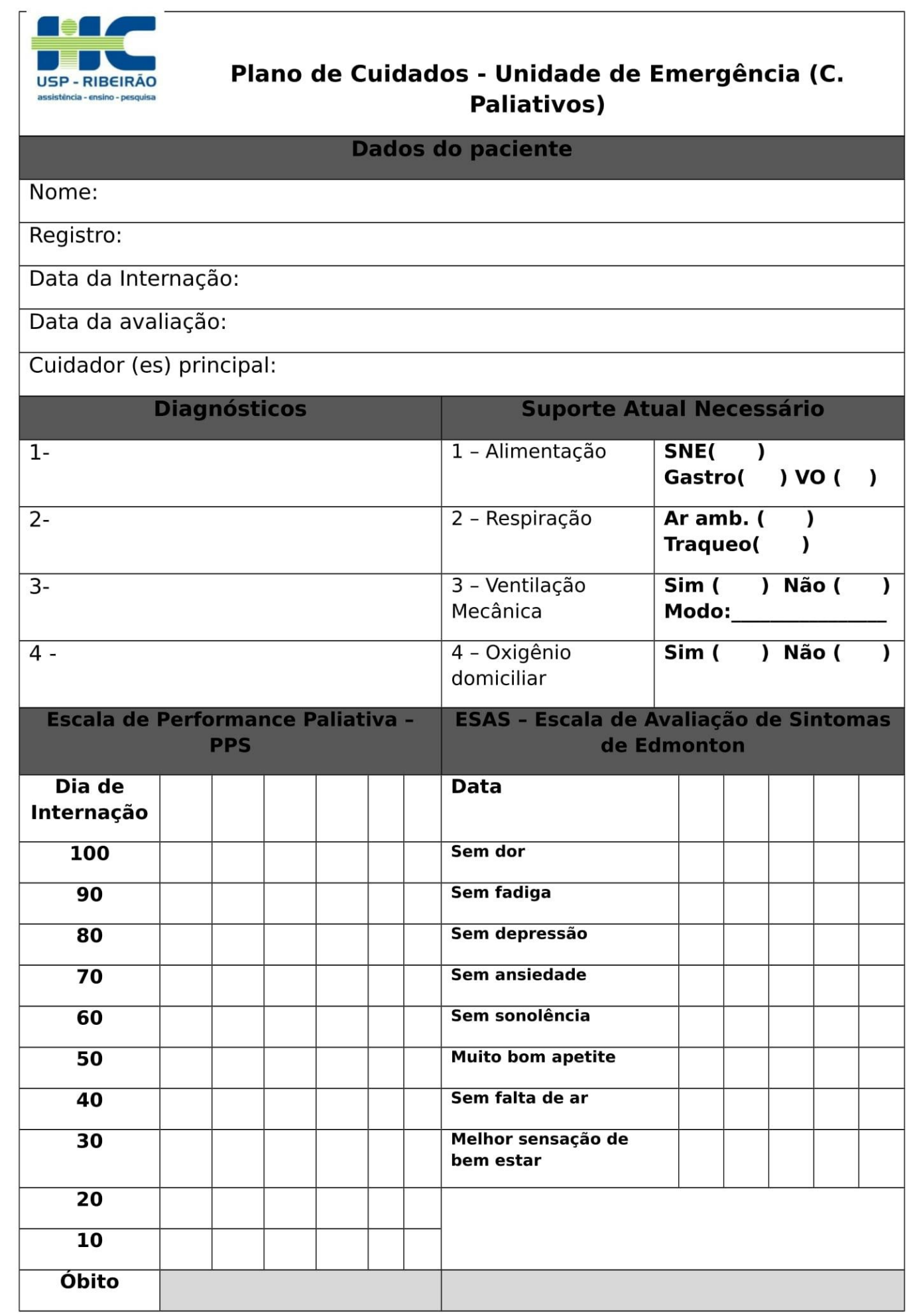


3. APÊNDICE 3 - PROPOSTA DE CAPACITAÇÃO PARA PROFISSIONAIS DA REDE DE URGÊNCIA E EMERGÊNCIA EM CUIDADOS PALIATIVOS.

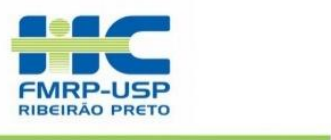

Proposta de capacitação para profissionais da Rede de Urgência e Emergência em

Cuidados Paliativos 


\section{INTRODUÇÃO}

\section{Contextualização do problema}

Cuidados Paliativos é a assistência integral oferecida para pacientes e familiares diante de uma doença grave que ameace a continuidade da vida. A sua inserção dentro do atendimento a paciente em situações de emergência e urgência é um desafio no atendimento, ao promover a discussão da possibilidade da terminalidade de vida nesse contexto. A criação do Serviço de Cuidados Paliativos na Unidade de Emergência ampliou o atendimento ao paciente ao acrescentar o foco no controle de sintomas, o aprimoramento na comunicação, a atenção ao binômio paciente-família e a condução do processo de terminalidade. A estratégia de criação desse tipo de serviço e formas de inserção no atendimento procura demonstrar a possibilidade de mudança na cultura hospitalar sobre o atendimento aos pacientes em situações terminais, ampliando o cuidado. Os atendimentos voltados aos conceitos de Cuidados Paliativos impactam tanto na maior qualidade do serviço prestado ao paciente e seus familiares, quanto na disseminação do conceito de cuidados paliativos no contexto de urgência e emergência, visando a construção de um serviço mais humanizado e que corresponda as demandas efetivas da população atendida.

Cerca de $1 \%$ da população morre a cada ano. Embora algumas mortes sejam inesperadas, a maioria pode ser prevista. Isso é uma tarefa difícil, mas se formos capazes de reconhecer indivíduos nos últimos anos de vida (1), independentemente do seu diagnóstico, e incluí-los em programa de cuidados paliativos, há fortes evidências de que eles são mais propensos a ter maior qualidade de vida, com aumento inclusive na sua sobrevida (2)

Segundo estimativa do Instituto Nacional de Câncer José Alencar Gomes da Silva, o Brasil deve registrar no biênio 2016- 2017, 596.070 novos casos de câncer, sendo esperados 295.200 entre homens e 300.870 entre mulheres (3). Já estimativas do Banco Mundial para o Brasil apontam que nos próximos 40 anos a população idosa brasileira crescerá a uma taxa de $3,2 \%$ ao ano e atingirá 64 milhões de habitantes em 2050, com previsão de que a população de 65 anos ou mais será $13 \%$ maior que a população até 19 anos (4). O envelhecimento associado com o aumento de doenças crônicas modificou o perfil dos óbitos no país nas últimas décadas - correspondendo a cerca de $70 \%$ de todas as mortes atualmente (5). Além disso, o alto custo das novas tecnologias médicas, as 
tecnologias duras*, trazem profundas consequências para o sistema de saúde, seus profissionais e seu orçamento, incluindo internações prolongadas e sofrimentos causados por tratamentos com benefícios incertos e com risco de malefícios, ocasionando o prolongamento artificial do tempo de vida, porém sem qualidade. Todos esses fatores impõem ao setor da saúde um cenário de grandes desafios econômicos e de gestão para adequação e aprimoramento do modelo de assistência na saúde (6).

De encontro a esta realidade, o tratamento sob o prisma paliativista vem sendo lentamente incorporado às terapêuticas e práticas assistenciais dos serviços de saúde, orientada sempre pelos princípios do Sistema Único de Saúde (SUS), fazendo uso de tecnologias leves e leves-duras*, muito mais acessiveis, corroborando com a humanização do cuidado.

Os cuidados paliativos são cuidados interdisciplinares (medicina, enfermagem, serviço social, capelania e outras especialidades quando apropriado) que se concentra em melhorar a qualidade de vida de pessoas, em qualquer idade, que apresentem alguma doença grave, com foco tanto na pessoa quanto em seus familiares (7). O objetivo é o tratamento da dor e outros sintomas físicos, além do sofrimento psíquico e espiritual, utilizando habilidades de comunicação para estabelecer metas de atendimento, fornecendo desta maneira apoio aos pacientes, seus entes queridos e equipes de assistência (8). Idealmente, os cuidados paliativos devem ser iniciados no momento do diagnóstico de uma doença grave e sem possibilidade de cura e intensificado proporcionalmente a evolução da doença (9). Os cuidados paliativos possuem bases cientificas e é fundamentado na Bioética, deve ser aplicado em conjunto com o tratamento curativo desde o diagnóstico inicial de uma doença grave e progressivamente tende a se tornar o único tratamento em sua fase avançada (10). Segundo a Organização Mundial da Saúde (11), os cuidados paliativos são uma forma de melhorar a qualidade de vida dos pacientes e seus familiares na prevenção e no alívio do sofrimento. (8)

\section{CONTEXTUALIZAÇÃO DA UNIDADE DE EMERGÊNCIA DO HCFMRP-USP}

As dependências da UE-HCFMRP-USP foram concebidas pela Fundação Sinhá Junqueira, para servir inicialmente de Maternidade, mas, mediante convênio assinado entre a Universidade de São Paulo e a Fundação, em abril de 1953, o 
prédio de quatro andares e capacidade para 170 leitos foi entregue, em regime de comodato, ao Estado de São Paulo, para que ali fosse instalado o Hospital das Clínicas da Faculdade de Medicina de Ribeirão Preto da Universidade de São Paulo (HCFMRP-USP).

Com a inauguração da Unidade Hospitalar do Campus, em fevereiro de 1979, a primeira sede do Hospital das Clínicas dá lugar à Unidade de Emergência do Hospital das Clínicas da Faculdade de Medicina de Ribeirão Preto (UEHCFMRP-USP) que foi oficialmente inaugurada no mês de abril de 1982.

A UE-HCFMRP-USP faz parte do Complexo HCFMRP-USP e é um hospital público que oferece toda sua capacidade instalada ao SUS. Pelo seu porte é um hospital estruturante e sempre teve papel central em diversos momentos na elaboração e construção de políticas públicas de Saúde referentes à Urgência e Emergência. A partir do ano 2.000 participou ativamente na configuração de uma rede assistencial regional de atenção às urgências, hierarquizada, regulada e humanizada. Neste cenário, no ano 2.000 foi iniciado o primeiro serviço de Regulação Médica na região que funcionou inicialmente dentro das dependências da própria Unidade de Emergência. Em 2011 e 2012 na Construção da Rede de Urgência e Emergência XIII (RUE XIII) e da Rede Regional de Atenção à Saúde XIII (RRAS XIII), a UE-HCFMRP-USP teve novamente papel estruturante desta rede.

A UE-HCFMRP-USP está inserida na RUE XIII do Departamento Regional de Saúde XIII (DRS XIII) que compreende 26 municípios (1.500.000 hab.) e na Rede Regional de Atenção à Saúde XIII (RRAS XIII), que engloba também os DRS de Franca, Araraquara e Barretos (4.000.000 hab.), sendo também referência para outros DRSs em alguns agravos mais complexos como, por exemplo, casos de queimaduras, politraumas e doenças cérebro vasculares complexas.

Na RUE XIII, a UE-HCFMRP-USP é classificada como hospital especializado tipo II, sendo credenciada em alta complexidade nas linhas de cuidado prioritárias do Trauma, do Acidente Vascular Cerebral (AVC) e do Infarto Agudo do Miocárdio (IAM).

Estão também vinculados à Unidade de Emergência um Centro de Intoxicações, um Banco de Tecidos e uma Unidade de Queimados.

Neste cenário a Unidade de Emergência trabalha com urgências e emergências referenciadas. Os Serviços de Regulação Médica do Estado 
(CROSS) e do Município de Ribeirão Preto fazem contato com a Unidade de Emergência, para solicitar vaga para pacientes que precisam ser regulados ou para simplesmente informar que estão encaminhando pacientes em Vaga Zero.

Além das linhas de cuidado prioritárias, Trauma, AVC e IAM, são atendidos na UE-HCFMRP-USP, casos de doenças infecto contagiosas emergentes, doenças infecto contagiosas de transmissão respiratória, doenças cardiorrespiratórias, quadros abdominais, pulmonares, violência sexual, sepses, acidentes por animais peçonhentos, cuidados paliativos, entre outras.

Para atender esta demanda, conta em sua porta de entrada com uma Sala de Estabilização Clínica (adulto e pediátrico) para pacientes clínicos em estado grave e uma Sala de Trauma para pacientes politraumatizados. Pacientes atendidos nestas áreas, após estabilização inicial podem ser transferidos para as diversas áreas de internação do hospital, de acordo com as suas necessidades. Em sua porta de entrada existem ainda consultórios para atendimento às Urgências não traumáticas de pacientes que não necessitam de cuidados intensivos imediato, tais como Clínica Médica, Neurologia, Cirurgia, Cirurgia de Cabeça e Pescoço, Otorrinolaringologia, Oftalmologia, Ginecologia, Ortopedia e Pediatria

A UE-HCFMRP-USP realiza uma média de 3.000 atendimentos mensais de urgência/emergência referenciada, que geram uma média de 1.000 internações. Em seu Centro Cirúrgico são realizadas uma média mensal de 500 cirurgias de alta complexidade. Conta com 167 leitos de internação. Um número significativo destes leitos é de Terapia Intensiva: 46 leitos.

Além do Corpo Clínico e do Serviço de Enfermagem, a UE-HCFMRP-USP conta com Equipe Multiprofissional composta por fisioterapeutas, assistentes sociais, terapeutas ocupacionais, psicólogos, fonoaudiólogos, nutricionistas e farmacêuticos.

Desde o ano 2.000 o Serviço Social está disponível nas 24 horas para realizar acolhimento e orientações aos usuários, principalmente aquelas vítimas de agravos agudos de grande gravidade como politraumatizados, acidente vascular cerebral e infarto agudo do miocárdo.

Neste contexto, muitos pacientes atendidos apresentam demandas de cuidados paliativos disputando espaços assistenciais destinados a pacientes com agravos agudos e com perspectivas terapêuticas. 
Este fato cria uma demanda a mais para o sistema de urgência e emergência, com pacientes atendidos em ambientes inapropriados, gerando uma série de inadequações:

- Longa permanência

- Risco elevado de procedimentos diagnósticos e intervenções terapêuticas inapropriadas/iatrogenias

- Controle de sintomas muitas vezes inadequado

- Assistência muitas vezes inadequada às demandas específicas

= Experiência negativa para pacientes, familiares e força de trabalho;

Sobrecarga de trabalho;

- Alta mortalidade;

- Custo financeiro elevado;

- Ocupação de leitos importantes dentro do sistema de urgência e emergência.

\section{OBJETIVOS}

1. Criar massa crítica de profissionais de saúde

2. Promover uma reestruturação do atendimento (emergência $X$ crise paliativa)

3. Adequar, da melhor forma possível, a alocação e recursos da rede, evitando latrogenia e Distanásia

4. Suscitar discussão sobre a possibilidade de criação futura de locais específicos para atendimento em cuidados paliativos

5. Ampliação da rede de suporte

\section{MATERIAIS E MÉTODOS}

A capacitação será para profissionais da Rede de Urgência e Emergência da DRS XIII englobando Ribeirão Preto e região, incluindo órgãos como: Serviço Móvel de Urgência, Regulação, Unidades de pronto atendimento, unidades básicas de saúde, hospitais, responsáveis por leitos de longa permanência, etc...

\section{PÚBLICO ALVO}


Unidades de pronto atendimento, unidades básicas de saúde, hospitais e longa permanência:

1. Médicos e Equipe multiprofissional

VAGAS

Aquífero Grarani:

- 03 vagas para cada município - 30 vagas;

- 02 vagas Hospital de Longa Permanência - São Simão.

- Total: 32 vagas

- Local de Realização a definir.

Horizonte Verde:

- 03 vagas para cada município(8) - 24 vagas;

- Sertãozinho - 05 vagas

- 02 vagas Hospital de Longa Permanência - Guariba.

- Total: 31 vagas

- Local de Realização a definir.

Vale das Cachoeiras:

- 03 vagas para cada município - 28 vagas;

- 02 vagas Hospital de Longa Permanência - Altinópolis e 02 vagas para Batatais.

- Total: 32 vagas

- Local de Realização a definir.

\section{ESTRUTURA FÍSICA}

Sala com cadeiras móveis

Equipamento de multimídia

Água e café

\section{CONTRAPARTIDA DOS MUNICÍPIOS}

Transporte e alimentação para os participantes. 


\section{CONTEÚDO PROGRAMÁTICO}

\section{ESTRUTURA}

- 03 turmas, totalizando 95 vagas

\section{CARGA HORÁRIA}

- $\quad$ 48h (24 h presenciais; $24 \mathrm{~h}$ atividade à distância):

- 5 módulos presenciais multiprofissionais (discussão de filme, rodas de conversa e oficinas) e 01 visita técnica acompanhamento discussão caso na UE. (4 grupos de +/-7 a 8 pessoas para cada turma) $-4 \mathrm{~h}$

- $\quad 05$ encontros (agosto a dezembro/2018)

- $\quad 01$ vez ao mês $\left(3^{a}, 4^{\mathrm{a}}\right.$ ou $5^{\mathrm{a}}$ feira -08 às $12 \mathrm{~h}$ ou 14 às $\left.18 \mathrm{~h}\right)$ - duração $4 \mathrm{~h}$

- $\quad 02$ tutores por módulo multiprofissional

- $\quad$ Avaliação Final - Projeto de Intervenção em Cuidados Paliativos no Município

- $\quad$ Certificado - presença mínima de $75 \%$

\section{MÓDULO I - INTRODUÇÃO}

- Nos conhecendo

- Empatia e Comunicação

- Cuidados Paliativos: Conceitos, Fundamentos e Modalidades de assistência

- Implantação de Equipe de Cuidados Paliativos

\section{MÓDULO II - AVALIAÇÃO GLOBAL DO PACIENTE}

- Controle de Sintomas (dor/dispnéia/delirium)

- Escalas de avaliação de sintomas e avaliação funcional;

- Controle de dor farmacológico e não farmacológico

MÓDULO III - PLANOS DE CUIDADOS 
- Elaboração de Plano de Cuidados baseados na demanda do paciente

- Nutrição em Cuidados Paliativos

- Tomada de Decisões em urgências

\section{MÓDULO IV - ABORDAGEM DO PACIENTE E DO FAMILIAR}

- Abordagem Psicológica e Social

- Reuniões Familiares

- Espiritualidade

- Luto

- Burnout

\section{MÓDULO V - ASSISTÊNCIA À FASE FINAL DE VIDA}

- Identificação da fase final de vida

- Cuidados nas últimas horas de vida

- Sedação Paliativa

- Cuidados com a Pele e Feridas

- Hipodermóclise

\section{MÓDULO VI - VISITA TÉCNICA}

- Acompanhamento da equipe de cuidados paliativos da UE.

- 4 turmas de 7 a 8 alunos

\section{RESULTADOS ESPERADOS}

Sensibilização dos gestores, capacitação da rede de urgência e emergência com a padronização de processos de trabalho espera-se que aconteça uma discussão sobre qualidade na assistência aos pacientes. Espera-se também que a partir desta formação seja discutido $\circ$ atendimento a este perfil de pacientes e 
adequação da rede de atendimento, considerando a otimização das densidades tecnológicas e melhoria do fluxo de atendimento.

\section{CONSIDERAÇÕES ÉTICAS}

O programa de capacitação será submetido para análise ao Departamento Regional de Saúde XIII, que será responsável pelo fomento e caberá à Unidade de Emergência do HCFMRP-USP receber os profissionais para a capacitação teórica e a elaboração do plano de aulas. Será garantida a confiabilidade das informações prestadas para todos os participantes e será fornecido certificado aos participantes que cumpriem acima de $75 \%$ das aulas teórica e práticas.

\section{CUSTO PROJETO}

Serão 40 horas aula (2 tutores) $X R \$ 90,00$ hora-aula presencial $=R \$ 3.600,00$

Serão 32 horas aula (2 tutores) $X R \$ 90,00$ hora-aula presencial $=R \$ 2.880,00$

Total $=\mathrm{R} \$ \mathbf{6 . 4 8 0 , 0 0}$

Encargos de $20 \%=R \$ 1.296,00$

Total Projeto por CIR - R \$7.776,00

Total Projeto - R\$23.328,00

O projeto será custeado pelo recurso da Educação Permanente pelas CIR's Aquífero Guarani, Horizonte Verde e Vale das Cachoeiras.

\section{Referências Bibliográficas}

1. Haga K, Murray S, Reid J, Ness A, O'Donnell M, Yellowlees D, et al. Identifying community based chronic heart failure patients in the last year of life: a comparison of the Gold Standards Framework Prognostic Indicator Guide and the Seattle Heart Failure Model. Heart. 2012;98(7):579-83. 
2. Temel JS, Greer JA, Muzikansky A, Gallagher ER, Admane S, Jackson VA, et al. Early palliative care for patients with metastatic non-small-cell lung cancer. $\mathrm{N}$ Engl J Med. 2010;363(8):733-42.

3. (INCA) INdCJAGdS. Estimativa 2016: incidência de câncer no Brasil. Instituto Nacional de Câncer José Alencar Gomes da Silva (INCA). Rio de Janeiro2016 [Available from: http://www.inca.gov.br/estimativa/2016/estimativa2016-v11.pdf. .

4. (CONASS) CNdSdS. Vigilância em saúde - Parte 1. Coleção para entender a Gestão do SUS 2011 [1:[Available from: http://www.conass.org.br/colecao2011/livro_5.pdf.

5. Schmidt MI, Duncan BB, Azevedo e Silva G, Menezes AM, Monteiro CA, Barreto SM, et al. Chronic non-communicable diseases in Brazil: burden and current challenges. Lancet. 2011;377(9781):1949-61.

6. Reville B, Foxwell AM. The global state of palliative care-progress and challenges in cancer care. Ann Palliat Med. 2014;3(3):129-38.

7. Care NCPfQP. Clinical practice guidelines for qual- ity palliative care. 2013 [Available from: http://www.nationalconsensusproject.org/guideline.pdf.

8. Santos FS. Cuidados paliativos: diretrizes, humanização e alívio de sintomas. Atheneu, editor. São Paulo/SP/Brasil2011.

9. Kelley AS, Morrison RS. Palliative Care for the Seriously III. N Engl J Med. 2015;373(8):747-55.

10. Cook D, Rocker $\mathrm{G}$. Dying with dignity in the intensive care unit. $\mathbf{N}$ Engl J Med. 2014;370(26):2506-14.

11. Sepulveda C, Marlin A, Yoshida T, Ullrich A. Palliative Care: the World Health Organization's global perspective. J Pain Symptom Manage. 2002;24(2):91-6.

12. SIMAO ABea. A atuação do Serviço Social junto a pacientes terminais: breves considerações. Serv Soc. 2010; 102:352-64.

13. I. N. A conferência familiar como instrumento de apoio à família em cuidados paliativos. Revista portuguesa Clinica Geral. 2003(19):68-74.

14. Stovall MC. Oncology Communication Skills Training: Bringing Science to the Art of Delivering Bad News. J Adv Pract Oncol. 2015;6(2):162-6.

15. Pessini L BL. Humanização e cuidados paliativos. 4 eds. São Paulo: Loyola; 2009. 
16. Pazin-Filho A, de Almeida E, Cirilo LP, Lourencato FM, Baptista LM, Pintya $\mathrm{JP}$, et al. Impact of long-stay beds on the performance of a tertiary hospital in emergencies. Rev Saude Publica. 2015;49.

\section{CURRICULO DA EQUIPE MULTIDISCIPLINAR}

Frederica Montanari Lourençato, Graduada em Serviço Social - Universidade Estadual Paulista - UNESP - ano conclusão- 2000; Curso de Administração Universidade Paulista - UNIP - ano conclusão- 2015; Curso Introdutório de Medicina Paliativa - Instituto Pallium Latino America de Buenos Aires - 2015; Atualmente trabalha de Assistente Social na Unidade de Emergência e Equipe de Cuidados Paliativos.

Jose Carlos dos Santos, Médico, formado na Universidade Federal do Paraná-1982; Residência Clínica Médica/Endocrinologia e Metabolismo, em 2006-2008; Médico Assistente da Clínica Médcia do HCRP; Professor Assistente do Curso de Medicino do Centro Universitário Barão de Mauá de Ribeirão Preto.

Fernanda Bernardes Ferreira, graduada em Fisioterapia pela Universidade de Ribeirão Preto - UNAERP (2001), Especialista em Fisioterapia Cardiopulmonar pela UNAERP (2004), MBA em Gestão Pública de Saúde pela Fundace/USP (2013), Membro da Associação Nacional de Cuidados Paliativos (2017). Atualmente trabalha como fisioterapeuta responsável pela Clínica Médica e Equipe de Cuidados Paliativos da na Unidade de Emergencia do HCRP e como Preceptora do Programa de Residência Multiprofissional da FMRP/USP.

Rita de Cássia Quaglio, Enfermeira com Graduação e Licenciatua em Enfermagem pela Escola de Enfermagem de Ribeirão Preto- USP (2010). Pós-graduação Stricto Sensu: "Mestrado Profissional em Tecnologia e Inovação em Enfermagem", pela Escola de Enfermagem de Ribeirão Preto da Universidade de São Paulo (2016); Curso Introductório de Orientación em Cuidados paliativos y Psico Social Oncología- Nível atualização- 60 horas (2012) e Curso Avançado de Orientacion em Cuidados Paliativos y Psico-Socio- Oncologia - Nível aperfeiçoamento 420 horas (2012-2013), ambos os 
cursos organizados pela Escola de Pós Graduação-Faculdade de Medicina da Cidade Autonoma de Buenos Aires/Instituto Pallium Latino America de Buenos Aires. Pósgraduação Latu Sensu em Gestão em enfermagem pela Universidade Federal de São Paulo (UNIFESP) e Universidade Aberta do Brasil - 416h (2014). Professora de formação de profissionais de nível técnico em enfermagem, pelo do Centro de Formação de Pessoal para a Saúde de Araraquara (CEFOR) da Secretaria do Estado da Saúde de São Paulo - Classe descentralizada de Ribeirão Preto. Enfermeira integrante das equipes: Equipe Gestora de Neurologia e da Equipe de Interconsulta em Cuidados Paliativos da Unidade de Emergência do Hospital das Clinicas da FMRPUSP.

Vanessa Maria de Castro Barros, graduada em Nutrição - Universidade de Guarulhos - UNG - ano de conclusão 2000 - Pós Graduação em Extensão em Gestão de Unidades de Urgência - FAAP - ano de conclusão 2011; Atualmente trabalha de Nutricionista de enfermaria da Unidade Coronariana da Unidade de Emergência e Equipe de Cuidados Paliativos.

Edgar lanhez Júnior, Médico, formado pela Faculdade de Medicina de Ribeirão PretoUniversidade de São Paulo- USP em 2006, Residência médica em Clínica Médica (2007-2009) e Residência Médica em Geriatria (2009-2011) pelo Hospital das Clínicas HCFMRP-USP; Curso de especialização em Cuidados Paliativos pelo Instituto Paliar (2013), Título de Especialista de Geriatria pela Sociedade Brasileira de Geriatria e Gerontologia- SBGG (2011) e suficiência em Medicina Paliativa pela AMB (2017), Médico assistente em Cuidados Paliativos na Unidade de Emergência- HCFMRP- USP (atual). 


\section{APÊNDICE 4-PROTOCOLO DE SEDAÇÃO PALIATIVA.}

PROTOCOLO DE SEDAÇÃO EM CUIDADOS PALIATIVOS

(elaborado pela equipe de Cuidados Paliativos UE e Campus)

1) Conceito

Define-se como sedação paliativa a redução intencional do nível de consciência, contínua ou intermitente, com o objetivo de controlar sintomas causadores de grave desconforto, refratários ao tratamento convencional, presentes na evolução de doenças incuráveis e progressivas em fase terminal, com consentimento do paciente ou seu familiar.Sedação paliativa se faz com medicamentos sedativos e não com drogas analgésicas ou coquetel de medicamentos aleatórios.

\section{2) Diferença entre Sedação Paliativa e Eutanásia}

\begin{tabular}{|c|c|c|}
\hline \multicolumn{3}{|c|}{ Distinção entre Sedação Paliativa e Eutanásia } \\
\hline & Sedação Paliativa & Eutanásia \\
\hline Princípio & Aliviar sintoma refratário/sofrimento & $\begin{array}{l}\begin{array}{l}\text { Provocar a morte para cessar o } \\
\text { sofrimento }\end{array} \\
\end{array}$ \\
\hline Meios & Diminuição do nível de consciência & Antecipação da morte \\
\hline Processo: drogas e doses & $\begin{array}{l}\text { Medicamentossedativos ajustados à } \\
\text { resposta do paciente }\end{array}$ & Medicamentos letais com aumento rápido \\
\hline Objetivo final & Alívio do sofrimento & Morte rápida \\
\hline Reversibilidade & Sim, a princípio. & Não \\
\hline Morte por causa natural & Sim & Não \\
\hline Somente no final de vida & Sim & Não \\
\hline
\end{tabular}

A sedação paliativa pode ser administrada durante alguns períodos ou continuamente, sendo que sua intensidade pode ser superficial (mantém nível de consciência em que paciente ainda pode se comunicar verbalmente ou não verbalmente) e profunda (mantém paciente em estado de inconsciência). Sendo a Sedação Paliativa uma opção terapêutica para o controle do sofrimento do paciente, sua temporalidade e intensidade devem ser proporcionais ao nível deste sofrimento que o paciente refere. Desta forma, normalmente, inicia-se a sedação de forma intermitente e superficial, titulando-se os medicamentos - logo o nível de consciência - de acordo com a resposta do paciente.

Há evidências de que a administração proporcionada de sedativos não encurta a vida e não antecipa a morte do paciente. Em paralelo ao uso da sedação, devem-se manter os cuidados para o conforto e a dignidade da vida até o seu final.

HOSPITAL DAS CLINICAS DA FACULDADE DE MEDICINA DE RIBEIRÃO PRETO DA UNIVERSIDADE DE SÃO PAULO Campus Universitário - Monte Alegre

Grupo de Interconsulta em Cuidados Paliativos 14048-900 Ribeirão Preto SP 


\section{3) O que é sintoma refratário?}

É todo sintoma que não pode ser controlado adequadamente, apesar de repetidas e intensas tentativas de tratamento tolerável, sem que se comprometa o nível de consciência. Devem existir os seguintes critérios:

I) Incapacidade de promover alívio adequado;

II) Associação com excessiva e intolerável morbidade aguda e crônica;

III) Improvável obtenção de alívio dentro de um prazo curto.

Os sintomas refratários que mais necessitam desde recursos são

- Dispneia quando refratária a oxigênio, broncodilatadores e opioides.

- Agitação e delirium ou inquietude refratária a neurolépticos.

Outros sintomas como dor, náuseas e vômitos, fadiga, dentre outros que causem grande sofrimento ao paciente e que não sejam passíveis de controle paliativo convencional, podem também ser submetidos à sedação paliativa, mas devem ser analisados cuidadosamente e preferencialmente discutidos com a equipe de Cuidados Paliativos.

Não confundir sintoma refratário com sintoma difícil. Sintoma difícil é aquele que para ser adequadamente controlado precisa de uma intervenção terapêutica intensiva, farmacológica e/ou nãofarmacológica. Considerar avaliação de especialista na área para determinar a refratariedade do sintoma.

\section{4) Indicação da sedação paliativa}

- Sintomas refratários do paciente (vide item 3)

- Quadro agudo ameaçador da vida em tempo curto -Ex.: Hemorragia maciça, TEP maciço.

- Morte iminente (horas a dias) com sofrimento intenso

Cabe sempre perguntar: "Quem está sofrendo?": É importante separar o sofrimento do paciente, dos sofrimentos da família e da equipe. Algumas atitudes por parte da família e/ou da equipe podem prejudicar, prolongar e aumentar osofrimento do paciente e até mesmo de todos. Na maioria das vezes, a morte ocorre sem a necessidade de sedar o paciente.

5) Orientações para indicação da sedação paliativa:

1. A doença é irreversível eos sintomas pelos quais se busca alívio são claramente definidos e intoleráveis ao paciente

2. Esta decisão deve estar de acordo com a vontade do paciente, família ou responsável legal e em consenso com a equipe multidisciplinar do setor.

3. Contraindicações, metas e expectativas com relação à sedação devem ser discutidas com a família, equipe assistencial e com o paciente, quando possível.

4. Os cuidados básicos devem ser mantidos e as medidas de conforto devem ser otimizadas.

5. Todas as etapas do processo de cuidado devem estar claramente descritas no prontuário do paciente.

HOSPITAL DAS CLÍNICAS DA FACULDADE DE MEDICINA DE RIBEIRÃO PRETO DA UNIVERSIDADE DE SÃO PAULO Campus Universitário - Monte Alegre 
7) Dos medicamentos sugeridos para sedação paliativa

\begin{tabular}{|c|c|c|c|}
\hline Drogas & Sintomas & Dose & Observações \\
\hline $\begin{array}{l}\text { - Midazolam (amp de } \\
5 \mathrm{mg} / 5 \mathrm{ml} ; 15 \mathrm{mg} / 3 \mathrm{ml} ; \\
50 \mathrm{mg} / 10 \mathrm{ml}) ; \\
\text { - Primeira escolha, mais usado, } \\
\text { facilmente titulável, rápido início } \\
\text { de ação ( } 2 \mathrm{~min} \text { EV) e curta } \\
\text { duração ( } 1,5 \text { a } 2,5 \mathrm{~h}) ; \\
\text { - Pode ser usado via EV ou } \\
\text { SC; } \\
\text { - Solúvel em SF0,9\%, SG5\% e } \\
\text { Ringer; } \\
\text { - Compatível com morfina na } \\
\text { mesma solução, mas desta } \\
\text { forma não é possivel titular as } \\
\text { drogas isoladamente; }\end{array}$ & $\begin{array}{l}\text { Qualquer sintoma } \\
\text { refratário, não usar } \\
\text { isoladamente em } \\
\text { delirium hiperativo }\end{array}$ & $\begin{array}{l}\text { Indução: iniciar com bolus de } 2,5 \mathrm{mg} \\
\text { ou } 5 \mathrm{mg} \text {, SC ou EV. Avaliar resposta } \\
\text { a cada } 15 \text { minutos e avaliar novo } \\
\text { bolus até paciente adequadamente } \\
\text { sedado (RASS } 0 \text { ou }-1 \text { ) } \\
\text { Manutenção: diluir } 1 \text { ampola de } \\
50 \mathrm{mg} / 10 \mathrm{ml} \text { de midazolam em } 500 \mathrm{ml} \\
\text { de SF0,9\% ou SG5\% e iniciar a } \\
5 \mathrm{ml} / \mathrm{h} \text { em BIC (12mg/dia). Avaliar a } \\
\text { cada } 30 \text { minutos e dobrar a } \\
\text { velocidade de infusão caso paciente } \\
\text { não apresenta sedação adequada } \\
\text { (dose usual } 20-120 \mathrm{mg} / \text { dia, mas } \\
\text { pode variar de } 3-1200 \mathrm{mg} / \text { dia) }\end{array}$ & $\begin{array}{l}\text { - Use doses menores (pode- } \\
\text { se omitir bolus de indução) em } \\
\text { pacientes sem uso prévio de } \\
\text { benzodiazepínico, caquexia, } \\
\text { idade> } 60 \text { anos, insuf. renal, } \\
\text { cardiaca ou hepática, uso } \\
\text { concomitante com opióides; } \\
\text { - Para agitação, por efeito } \\
\text { paradoxal ou não do } \\
\text { midazolam, deve-se associar } \\
\text { (ou trocar) neuroléptico } \\
\text { (haloperidol) à sedação. }\end{array}$ \\
\hline $\begin{array}{l}\text { - Haloperidol } \quad(a m p \quad 1 \mathrm{ml} \text {, } \\
5 \mathrm{mg} / \mathrm{ml}: 1 \mathrm{amp}=5 \mathrm{mg}) ;\end{array}$ & Delirium & $\begin{array}{l}\text { Dose habitual: Iniciar com } 2,5 \text { a } 5 \mathrm{mg} \\
\text { SC ou EV de } 12 / 12 \mathrm{hs} \text {, podendo } \\
\text { aumentar até } 6 / 6 \mathrm{hs} \text { caso } \\
\text { manutenção do delirium }\end{array}$ & $\begin{array}{l}\text { Não exceder } 20 \mathrm{mg} / \mathrm{dia} \text { por } \\
\text { risco de síndrome } \\
\text { neuroléptica maligna; } \\
\text { - Risco de reações } \\
\text { extrapiramidais, convulsões, } \\
\text { retenção urinária, diaforese; }\end{array}$ \\
\hline
\end{tabular}

Observação: Existem outros medicamentos para a sedação paliativa, porém estas são as mais utilizadas na prática médica.

\section{Observações importantes:}

1. Os opióides não devem ser utilizados isoladamente para obter sedação (ex: fentanila). Tentar atingir sedação paliativa somente com opióides provavelmente trará efeitos adversos neuroexcitatórios como mioclonias ou delirium hiperativo;

2. Os opióides prescritos devem ser mantidos com objetivo de alívio de dor e melhora dos sintomas respiratórios;

3. Meperidina é formalmente contraindicada em uso isolado ou associado. Não usar petidina, meperidina,

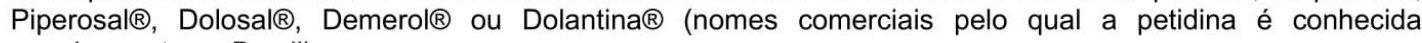
popularmente no Brasil);

4. Deve ser mantido o uso de neurolépticos quando a sedação paliativa é introduzida devido ao quadro de delirium / agitação refratários;

5. Outras drogas sedativas podem ser utilizadas, desde que sob a orientação de um profissional qualificado em Cuidados Paliativos;

\section{8) Referências}

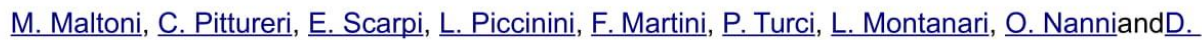

AmadoriPalliativesedationtherapy does nothastendeath: resultsfrom a

prospectivemulticenterstudyAnnalsofOncology 20: 1163-1169, 2009

Manual de Cuidados Paliativos / Academia Nacional de Cuidados Paliativos. - Rio de Janeiro: Diographic, 2012

Manual de Cuidados Paliativos do CREMESPCuidado Paliativo / Coordenação Institucional de Reinaldo Ayer de Oliveira. São Paulo: Conselho Regional de Medicina do Estado de São Paulo, 2008. 689 p. 


\section{APÊNDICE 5 - PROTOCOLO DE INFUSÃO DE MEDICAÇÕES E SOLUÇÕES POR HIPODERMÓCLISE.}

Introdução

$\mathrm{Na}$ pratica clinica inúmeras são as situações em que pacientes apresentam condições que impossibilitem a manutenção dos níveis adequados de hidratação e o controle efetivo de sintomas, devido à piora da condição clinica do paciente associada às comorbidade, potencializado muitas vezes pelo avanço do prognostico relacionando a finitude de vida ou pela idade avançada, sendo assim, geralmente a via endovenosa se apresenta de forma restrita, ou associada a contraindicações de procedimentos invasivos, como a caquexia, frequentes infecções e mesmo a limitações impostas pela sua adoção, concomitante com a limitação da autonomia (OLIVEIRA, 2008; CARVALHO, PARSONS, 2012)

A técnica da hipodermóclise, já bastante utilizada no passado, vem sendo utilizadana prática clínica, como alternativa segura e eficaz para administração de fluidos e medicamentos a pacientes em condições clínicas especiais.

As vantagens desta técnica são: ser uma via de administração segura, de baixo custo, que apresenta mínimo desconforto ao usuário, risco mínimo de complicação local e ínfimo de complicação sistêmica, de fácil manipulação e manutenção.

$\mathrm{Na}$ administração por hipodermóclise evita-se o metabolismo de primeira passagem, possibilitando uma concentração sérica estável do medicamento. Os níveis plasmáticos dos medicamentos são mantidos elevados por mais tempo em relação à infusão pela via endovenosa (EV),tornando-se assim, um sistema de liberação prolongada,o que evita picos plasmáticos que determinam o possível aparecimento de efeitos colaterais indesejáveis (OLIVEIRA, 2008; CARVALHO, PARSONS, 2012).

\section{Definição}

A infusão de fluidos e ou medicamentos por via subcutânea é denominada hipodermóclise ou terapia subcutânea (BRASIL, 2011).

\section{Indicações}

As principais indicações para o uso da hipodermóclise são ${ }^{1}$

1. Impossibilidade do uso da via oral ou da via enteral:

a. Grave intolerância à ingestão oral ou enteral (ex: náuseas e vômitos incoercíveis).

b. Processo obstrutivo do trato gastrointestinal.

c. Diminuição do nivel de consciência que permita uma ingestão oral com segurança, tais como demência, sonolência ou sedação.

2. Acesso venoso prejudicado ou impossibilitado, principalmente para pacientes repetidas vezes puncionados sem sucesso ou rede venosa empobrecida ou frágil

3. Desta forma, observa-se que não apenas os pacientes em cuidados paliativos seriam os únicos pacientes a se beneficiarem com a hipodermóclise.

\section{Contraindicações}

As contraindicações estão relacionadas aos distúrbios de coagulação, situações de emergência, desequilibrio hidroeletrolítico grave, sobrecarga de fluidos (ex: Insuficiência cardíaca congestiva e edema acentuado), desidratação grave, risco de congestão pulmonar (ex. Insuficiência cardíaca congestiva e síndrome da veia cava superior).

\section{1) Infusão de grandes volumes}

HOSPITAL DAS CLÍNICAS DA FACULDADE DE MEDICINA DE RIBEIRÃO PRETO DA UNIVERSIDADE DE SÃO PAULO Campus Universitário - Monte Alegre

14048-900 Ribeirão Preto SP

Grupo de Intercons 
A limitaçãode infusão de volume é de $3000 \mathrm{ml}$ em 24 horas, e o volume permitido para infusão por sítio de punção é de $1500 \mathrm{~mL} / 24 \mathrm{~h}$. Sendo assim,é preciso contar com um segundo sítio de punção,sempre em hemi corpo oposto a primeira punção, para a totalização dos $3000 \mathrm{~mL} / 24 \mathrm{~h}$, quando necessário.

\section{2) Desidratação grave}

A hipodermóclise não deve ser o procedimento de escolha para pacientes gravemente desidratados.

\section{3) Distúrbios de coagulação}

A hipodermóclise deve ser evitada nos pacientes que apresentem algum tipo de distúrbio de coagulação. Porém, cada caso deve ser avaliado criteriosamente,-pesando-sequantoaos riscos e benefícios.

\section{4) Anasarca}

Ahipodermóclise não é indicada na presença de edema importante ou anasarca.

\section{Material e procedimento - Conforme PO de Assistência de Enfermagem em Hipodermóclise}

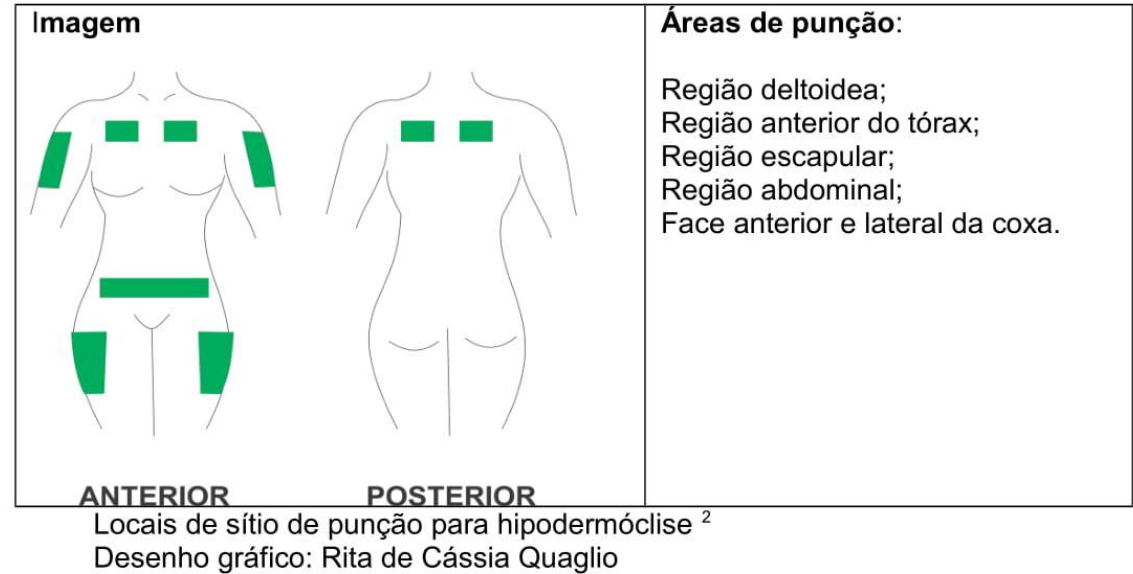

Não puncionar: Sobre proeminências ósseas, nas proximidades de articulações, em região delinfedema e ascite, em áreas de tumoração e de irradiação recente, na presença de erupções de pele, em regiões de lesões de pele esobre peleinfectada ou inflamada. A região torácica superior deve ser evitada nos pacientes com caquexia devido ao risco de pneumotórax. ${ }^{2}$

\section{Gotejamento}

Utilizar somente equipos microgotas para as infusão de volumes em hipodermóclise.

A infusão em bolus ou continua deve ser sempre lenta. (BRASIL, 2011; WALSH, 2005).

É possível a utilização de Bomba de Infusão Continua (BIC), para as infusões dos fluidos considerando as condições clinicas e as necessidades do paciente, neste caso é recomendado o fluxo de infusão entre 60 a 125 ml/h (CARVALHO, PARSONS, 2012; BRASIL, 2011; PALACIOS, 2009).

\section{Administração}

Os medicamentos padronizados neste protocolo deverão ser prescritos através da via descrita como "hipodermóclise", que constará no sistema eletrônico de prescrição, a fim de evitar conflitos de administração de medicamentos já padronizados pela via subcutânea (ex: heparina, insulina).

\section{Observações}

HOSPITAL DAS CLÍNICAS DA FACULDADE DE MEDICINA DE RIBEIRĀO PRETO DA UNIVERSIDADE DE SÃO PAULO Campus Universitário - Monte Alegre

Grupo de Interconsulta em Cuidados Paliativos 14048-900 Ribeirão Preto SP 
Referencias sobre o tema mostram troca de sitio de punção de 3 dias a 7 dias.No entanto neste protocolo adotaremos as recomendações da ANVISA e INFUSION NURSE SOCIETY, que orientaa troca do sítio de punção a cada 72 horas,ou antes, no caso de surgirem sinais de irritação local.Novo sítio de punção pode ser puncionadorespeitando a distância mínima de cinco (5) $\mathrm{cm}$ do local da punção anterior.

Na presença de sinais flogísticos o cateter deve ser retirado o mais precocemente possível e o sítio puncionado estará contra indicado para novas punções, por no mínimo 10 dias.

Se for observado edema local persistente, recomenda-se diminuir o gotejamento ou suspender temporariamente a infusão.

\section{Complicações}

As complicações da técnica podem ser classificadas em locais e sistêmicas:

\section{Locais}

São as mais comuns e devem ser pesquisadas ativamente durante todo o processo de hipodermóclise.

Nas primeiras 4 horas da infusão por hipodermóclise, é normal que haja sinais de irritação local sem que isso signifique infecção ou complicação. A persistência destes sinais após esse período de 4 horas deve levar a troca do sítio de punção.

Recomenda-se trocar o sítio da punção quando houver:

- Sinais flogísticos (edema, calor e eritema persistente);

- Sinais de infecção (febre, calafrio e/ou dor local);

- Endurecimento, necrose ou hematoma no local da punção.

\section{Sistêmicas}

Raramente ocorrem pelas características próprias da técnica. Entretanto, deve-se manter vigilância para os principais sinais de complicação sistêmica que são:

- Taquicardia

- Turgência jugular

- Hipertensão arterial

- Sintomas respiratórios, tais como tosse e dispneia (desde que não relacionados com a doença de base).

Referências

BRASIL. Agência Nacional de Vigilância Sanitária - Anvisa. Medidas de Prevenção de Infecção Relacionada à Assistência à Saúde. Série Segurança do Paciente e Qualidade em Serviços de Saúde, 2013. Acesso em: 28 de junho 2015.2 Disponível em: <http://portal.anvisa.gov.br/wps/content/Anvisa+Portal/Anvisa/Inicio/Servicos+de+Saude/Assunto+de+Interesse/ Aulas+Cursos+Cartazes+Publicacoes+e+Seminarios/Controle+de+Infeccao+em+Servicos+de+Saude/Manuais $>$.

CARVALHO, PARSONS (organizadores). Manual de Cuidados Paliativos ANCP/ 2.ed. ampl. e atual. Porto Alegre: Sulina, 2012.

PALACIOS, RH. Utilidad de la via subcutânea em la estratégia de atención al paciente com demência em fase avanzada. Revista Española de Geriatira y Gerontologia, v4, nS2, p 37-42. 2009.

WALSH, G. Hypodermoclysis - an alternative method for rehydration in long-term care. Journal of Infusion Nursing, v.28, n.2, p.123-129, 2005. 


\section{APÊNDICE 6 - FOLDER DE ORIENTAÇÃO - EQUIPE DE CUIDADOS PALIATIVOS}

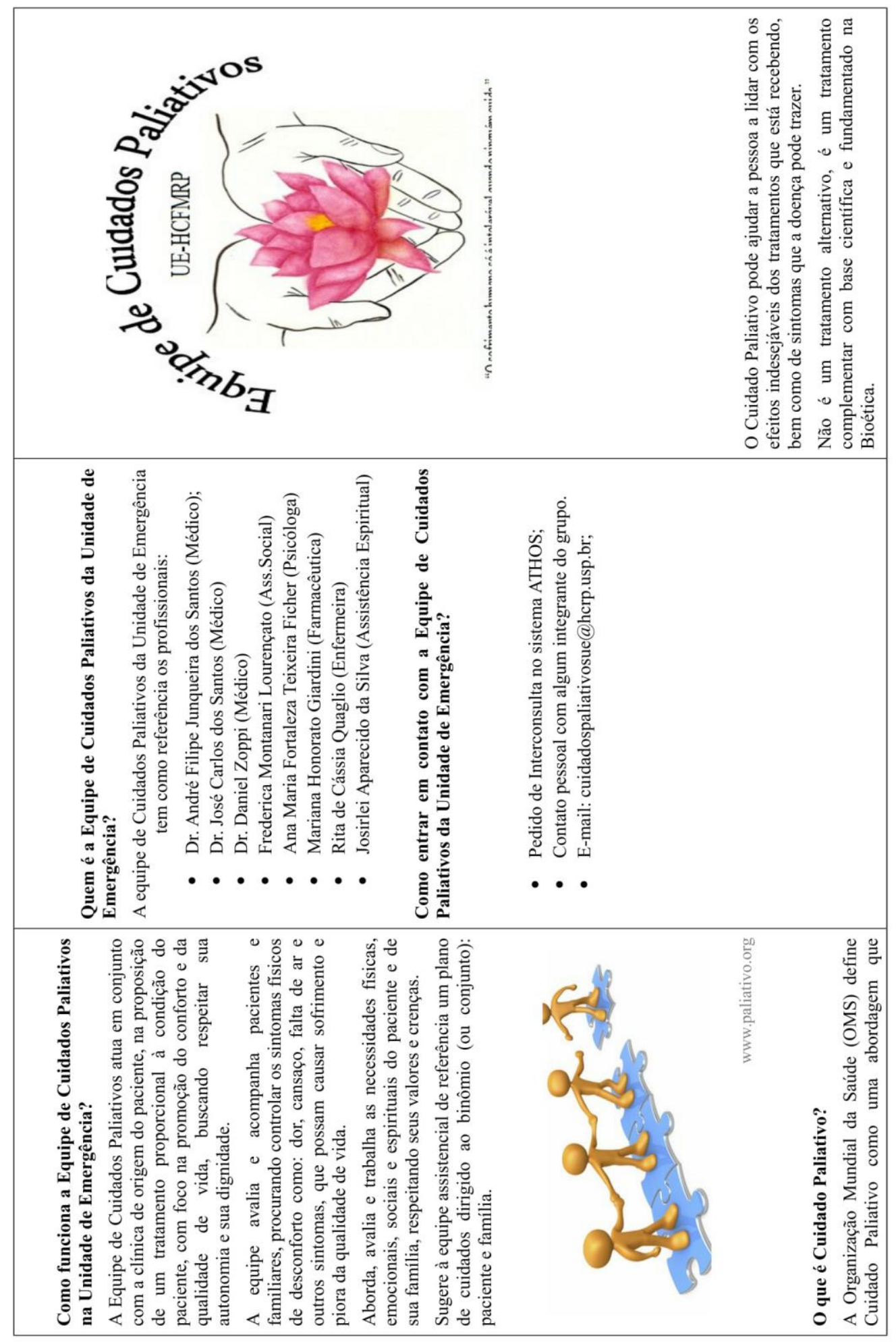




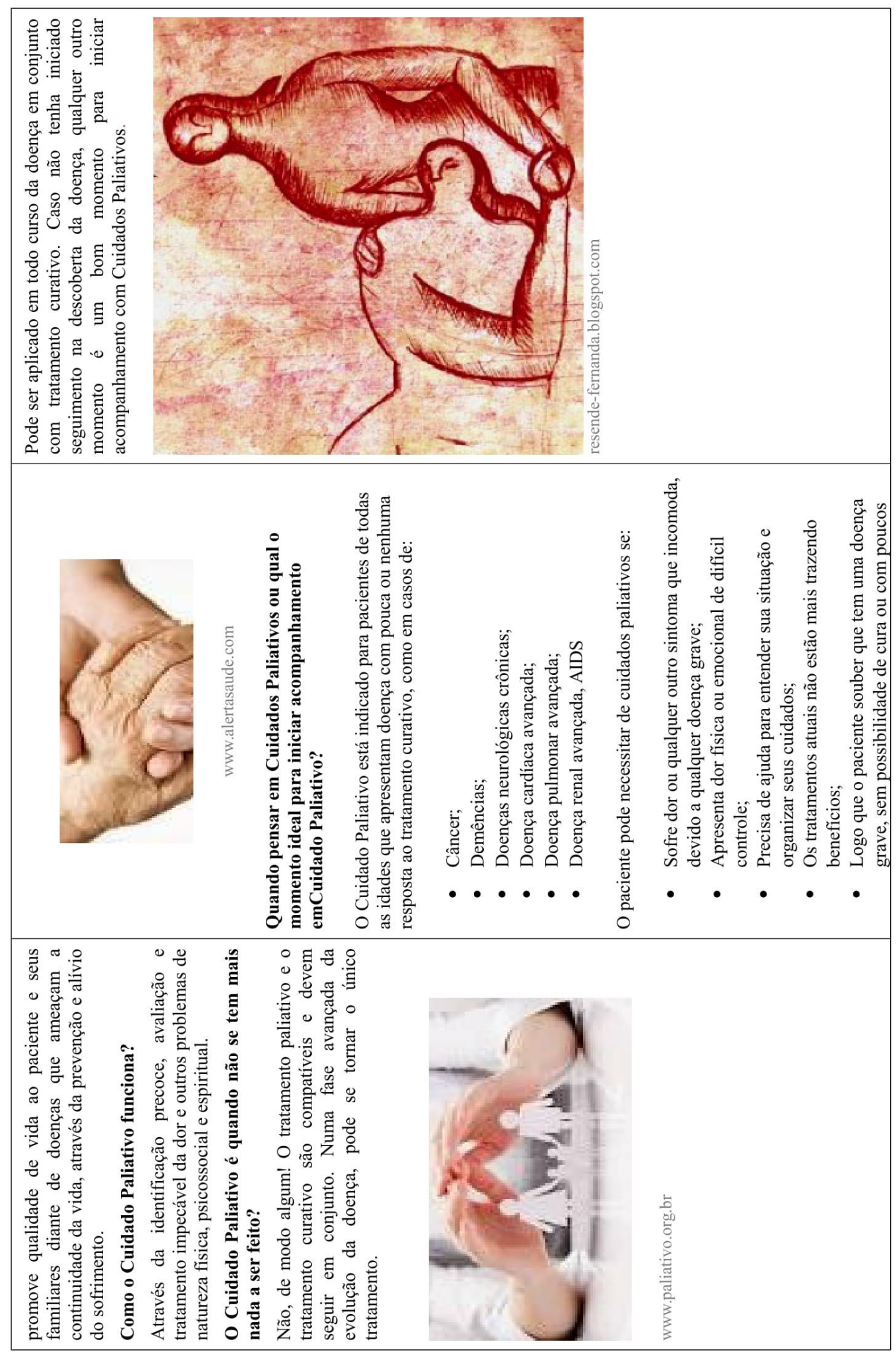




\section{APÊNDICE 7 - OFÍCIO CIRCULAR 02/2014 - IMPLANTAÇÃO DE INTERCONSULTA DA EQUIPE DE CUIDADOS PALIATIVOS}

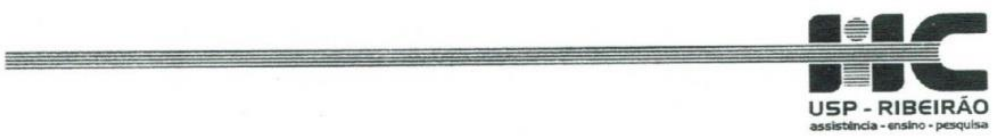

Ribeirão Preto, 07 de agosto de 2014

\section{Circular $\mathrm{N}^{\circ}$ 02/2014}

DIR-U.E/ APF/ sb

Referente: Implantacão de Interconsulta de Equipe de Cuidados Paliativos - UE

Prezados(as) Senhores(as),

Desde janeiro de 2014, a equipe multidisciplinar da Unidade de Emergência está organizando o processo de trabalho relativo à "cuidados paliativos e terminalidade da vida", inicialmente com a formação de um grupo para realização semanal de reuniōes de estudos sobre o assunto e a criaçăo de um protocolo de atendimento para atendimento desta demanda.

Como fruto deste processo, estamos formando um grupo multidisciplinar para atendimento de interconsultas aos pacientes, formado por profissionais das diferentes áreas de atuação. Sendo assim, encaminhamos para conhecimento o protocolo inicial do projeto para conhecimento dos critérios de elegibilidade e conseqüente encaminhamento de casos para acompanhamento do grupo.

GRUPO DE CUIDADOS PALIATIVOS E CUIDADOS ESPECIAIS - UE

OBJETIVO: fornecer consultoria e acompanhamento conjunto, quando necessário, às diversas equipes que assistem aos pacientes internados na Unidade de Emergência (UE) que possam se beneficiar de abordagem baseada em cuidados paliativos e com necessidades especiais nas diversas áreas de atuação multidisciplinar disponivel.

> EQUIPE MULTIDISCIPLINAR: enfermagem, equipe médica, fisioterapia, psicologia, nutrição, farmácia, serviço social, fonoaudiologia, apoio espiritual.

> DINÂMICA DE ATUAÇÃO: na fase piloto de implementaçăo do grupo o atendimento se dará através de solicitação por pedido de interconsulta (PI) por parte da equipe original responsável pelo paciente. Todo PI direcionado ao grupo de cuidados paliativos deverá ter ciência e concordância por parte das equipes médica e de enfermagem do local de internaçăo original, sendo tais equipes representadas por pelo menos 1 médico e 1 enfermeiro que assistem o paciente durante a internação corrente.

> o PI deverá ser entregue no Centro de Estudos da UE, $2^{\circ}$ andar, para recebimento pelo grupo de cuidados paliativos. Em tempo hábil, disponibilizaremos local na enfermaria do $2^{\circ}$ andar para depósito dos novos Pls, tendo em vista que durante o fim de semana e à noite 0 Centro de Estudos não funciona.

> A equipe de cuidados paliativos realizará a discussão dos casos em grupo sempre que possivel e fará sugestōes em relação ao cuidado dispensado ao paciente. $\mathrm{O}$ acatamento das sugestōes fica a critério da equipe assistente original, assim como as medidas técnicas e burocráticas que se façam necessárias para fornecer o cuidado proposto. 
CRITÉRIOS PRINCIPAIS DE ELEGIBILIDADE PARA AVALIACÃO PELIs -ensino-pesquisa CUIDADOS PALIATIVOS (OMS 2002):

$>$ portador de enfermidade avançada e progressiva

poucas possibilidades de resposta à terapêtica curativa

- evolução clínica oscilante, caracterizada pelo surgimento de várias crises de necessidade

grande impacto emocional para o doente e sua família

$>$ impacto social para o doente e sua familia

prognóstico de vida limitado

$>$ necessidade de adequação terapêutica

$>$ pacientes que comumente se encontram nesse perfil incluem doentes em fase avançada de: AIDS, câncer, síndromes demenciais, doenças neurológicas progressivas, insuficiência cardiaca congestiva, doença pulmonar obstrutiva crônica, insuficiência renal, sequelas neurológicas, outras situações incuráveis e em progressão.

- Qualquer caso pode ser passivel de avaliação nesse momento inicial, cabendo ao grupo a definição dos casos com real necessidade de avaliação pela equipe de cuidados paliativos.

\section{> GRUPO DE INTERCONSULTA}

- Dr. Rômulo R. Lôbo-Médico

- Dr. José Carlos dos Santos - Médico;

- Dr. Alexandre Baldini de Figueredo - Médico;

- Frederica Montanari Lourençato - Assistente Social

- Leni Peres Cirillo - Assistente Social;

- Gabriela Cristina S. Ferreira - Psicóloga;

- Ana Maria F. Teixeira Ficher - Psicóloga;

- Rodrigo Magri Bernardes - Enfermeiro

- Maurício da Silva de Assis - Enfermeiro;

- Paula Issa Okubo - Fonoaudióloga;

- Mariana Honorato Giardini - Farmacêutica

- Roseli dos Santos Alves - Auxiliar de enfermagem;

- Talita Moreira da Costa - Fisioterapeuta

- Josirlei Aparecido da Silva - Apoio Espiritual.

Atenciosamente,

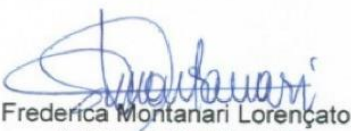

Asistente Social - UE

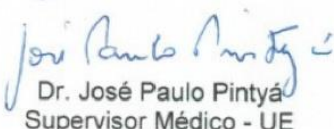

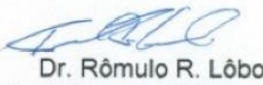

Médico Assistente da Clínica Médica- UE

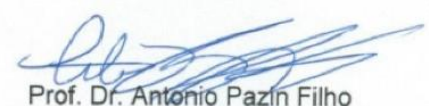

Coordenador da Unidade de Emergência 
ANEXOS

\section{ANEXO 1 - APROVAÇÃO NO COMITÊ DE ÉTICA}

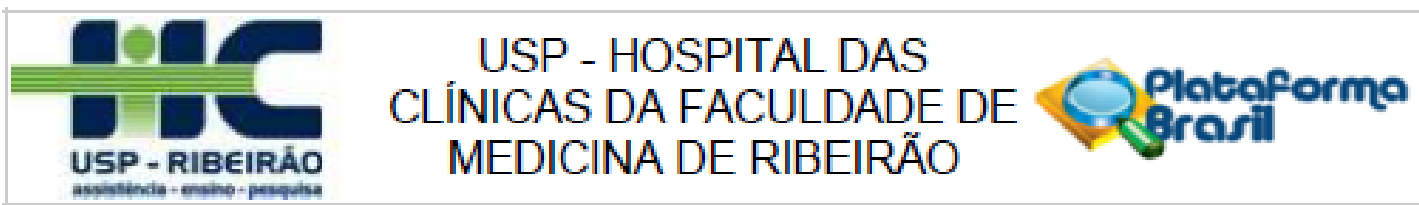

\section{PARECER CONSUBSTANCIADO DO CEP}

DADOS DO PROJETO DE PESQUISA

Título da Pesquisa: Implantação UM de serviço de cuidados paliativos no setor de emergência de um hospital público universitário

Pesquisador: FREDERICA MONTANARI LOURENCATO

Área Temática:

Versäo: 1

CAAE: 90562418.5 .0000 .5440

Instituiçäo Proponente: Hospital das Clínicas da Faculdade de Medicina de Ribeirão Preto da USP -

Patrocinador Principal: Financiamento Próprio

\section{DADOS DO PARECER}

Número do Parecer: 2.889 .685

Apresentaçäo do Projeto:

Cuidados Paliativos é a assistência integral oferecida a pacientes e familiares diante de uma doença grave que ameace a continuidade da vida. A sua inserção no atendimento a pacientes em situações de urgência e emergência é um desafio ao promover a discussão sobre os limites de tratamentos exclusivamente curativos, considerando a proporcionalidade das condutas médicas frente à abordagem da qualidade de vida. A criaçäo de um Serviço de Cuidados Paliativos pode melhorar o atendimento ao acrescentar o foco no controle de sintomas, na comunicação, e na abordagem da terminalidade, evitando a distanásia e ampliando as formas do cuidado.

Objetivo da Pesquisa:

Objetivo Primário: Avaliar a implantação do serviço de cuidados paliativos na Unidade de Emergência do HCFMRP-USP: Avaliar o impacto da atuação de uma equipe de interconsulta nos três primeiros anos de atendimento.

Objetivo Secundário: Analisar os dados coletados sobre o processo de implantação do serviço; Analisar a necessidade de aprimoramento do conhecimento dos profissionais do serviço de urgência;Analisar os dados referentes à atuação da equipe de interconsulta.

Avaliação dos Riscos e Benefícios:

Riscos: Dados retrospectivos que poderão não responder a algum questionamento adicional Benefícios: Acompanhamento integral do processo de implantação como um todo.

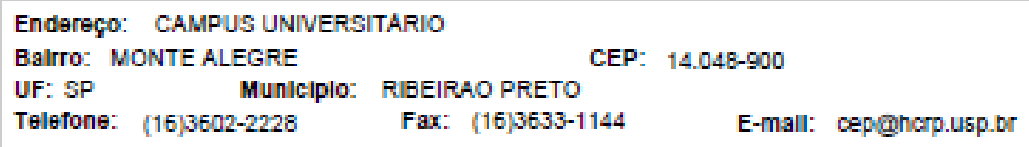




USP - HOSPITAL DAS
CLINICAS DA FACULDADE DE Q
MEDICINA DE RIBEIRÃO

Continusçbo do Parecer: 2.689 .685

\section{Comentários e Consideraçöes sobre a Pesquisa:}

Trata-se de levantamento e análise da série histórica do processo de implantaçäo do serviço de cuidados paliativos e avaliação do processo de capacitação da equipe e sensibilização dos colaboradores. Os dados referem-se à: preparação para implantação, metodologia aplicada, formação da equipe de interconsulta, $e$ levantamento do perfil dos pacientes. A amostra será de conveniência, com 1435 pacientes atendidos entre os anos de 2013 e 2017. por se tratar de um banco de dados retrospectivo.

Considerações sobre os Termos de apresentação obrigatória:

Documentos devidamente apresentados. Solicita a dispensa de aplicação do Termo de Consentimento Livre e Esclarecido (conforme item 8 do capítulo III, inciso IV da Resolução CNS 466/12), por se tratar de dados retrospectivos e administrativos.

Recomendaçōes:

näo se aplica

Conclusões ou Pendências e Lista de Inadequaçōes:

Diante do exposto e à luz da Resolução CNS 466/2012, o projeto de pesquisa, assim como a solicitação de dispensa de aplicação do Termo de Consentimento Livre e Esclarecido, podem ser enquadrados na categoria APROVADO.

Consideraçōes Finais a critério do CEP:

Projeto Aprovado: Tendo em vista a legislação vigente, devem ser encaminhados ao CEP, relatórios parciais anuais referentes ao andamento da pesquisa e relatório final ao término do trabalho. Qualquer modificação do projeto original deve ser apresentada a este CEP em nova versão, de forma objetiva e com justificativas, para nova apreciação.

Este parecer foi elaborado baseado nos documentos abaixo relacionados:

\begin{tabular}{|c|c|c|c|c|}
\hline Tipo Documento & Arquivo & Postagem & Autor & Situaçäం \\
\hline $\begin{array}{l}\text { Informaçöes Básicas } \\
\text { do Projeto }\end{array}$ & $\begin{array}{l}\text { PB_INFORMAÇŐES_BÁSICAS_DO_P } \\
\text { ROJETO 1118577.pdf }\end{array}$ & $\begin{array}{c}29 / 05 / 2018 \\
15: 38: 33\end{array}$ & & Aceito \\
\hline $\begin{array}{l}\text { Projeto Detalhado / } \\
\text { Brochura } \\
\text { Investigador }\end{array}$ & ProjetoMestradoFrederica 23052018 .doc & $\begin{array}{c}23 / 05 / 2018 \\
14: 13: 21\end{array}$ & $\begin{array}{l}\text { FREDERICA } \\
\text { MONTANARI } \\
\text { LOURENCATO } \\
\end{array}$ & Aceito \\
\hline $\begin{array}{l}\text { Declaração de } \\
\text { Pesquisadores }\end{array}$ & $\begin{array}{l}\text { ParecerdoCentrodeEstudosUnidadedeE } \\
\text { mergencia.pdf }\end{array}$ & $\begin{array}{c}23 / 05 / 2018 \\
14: 11: 49\end{array}$ & $\begin{array}{l}\text { FREDERICA } \\
\text { MONTANARI } \\
\text { LOURENCATO }\end{array}$ & Aceito \\
\hline
\end{tabular}

Endereģo: CAMPUS UNIVERSITARIO

Bairro: MONTE ALEGRE CEP: $14.048-900$

UF: SP MUnICIPIO: RIBEIRAO PRETO

Telefone: $(16) 3602-2228 \quad$ Fax: $(16) 3633-1144 \quad$ E-mall: cep@horp.usp.br 


\section{USP - HOSPITAL DAS \\ CLÍNICAS DA FACULDADE DE MEDICINA DE RIBEIRÃO}

Continusçlo do Parecer: 2.689 .685

\begin{tabular}{|c|c|c|c|c|}
\hline $\begin{array}{l}\text { Declaração de } \\
\text { Pesquisadores }\end{array}$ & AprovacaoOrcamentoUPC.pdf & $\begin{array}{c}23 / 05 / 2018 \\
14: 11: 27\end{array}$ & $\begin{array}{l}\text { FREDERICA } \\
\text { MONTANARI } \\
\text { LQURENCATO }\end{array}$ & Aceito \\
\hline Orçamento & Orcamento.pdf & $\begin{array}{c}23 / 05 / 2018 \\
14: 08: 16\end{array}$ & $\begin{array}{l}\text { FREDERICA } \\
\text { MONTANARI } \\
\text { LOURENCATO }\end{array}$ & Aceito \\
\hline $\begin{array}{l}\text { TCLE / Termos de } \\
\text { Assentimento / } \\
\text { Justificativa de } \\
\text { Ausência } \\
\end{array}$ & $\begin{array}{l}\text { DispensadoTermodeConsentimentoLivre } \\
\text { eEsclarecido.pdf }\end{array}$ & $\begin{array}{c}23 / 05 / 2018 \\
14: 07: 39\end{array}$ & $\begin{array}{l}\text { FREDERICA } \\
\text { MONTANARI } \\
\text { LOURENCATO }\end{array}$ & Aceito \\
\hline Cronograma & Cronograma.pdf & $\begin{array}{c}23 / 05 / 2018 \\
14: 06: 45\end{array}$ & $\begin{array}{l}\text { FREDERICA } \\
\text { MONTANARI } \\
\text { LOURENCATO }\end{array}$ & Aceito \\
\hline Folha de Rosto & FolhadeRostoPlataformaBrasil.pdf & $\begin{array}{c}23 / 05 / 2018 \\
14: 05: 40\end{array}$ & $\begin{array}{l}\text { FREDERICA } \\
\text { MONTANARI } \\
\text { LOURENCATO }\end{array}$ & Aceito \\
\hline
\end{tabular}

\section{Situação do Parecer:}

Aprovado

Necessita Apreciação da CONEP:

Nảo

RIBEIRAO PRETO, 04 de Junho de 2018

Assinado por:

MARCIA GUIMARÄES VILLANOVA

(Coordenador)

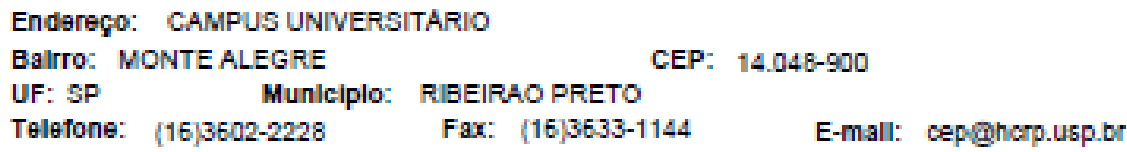

